San Jose State University

SJSU ScholarWorks

Master's Theses

Master's Theses and Graduate Research

1994

\title{
How voice operates in popular culture through the performance persona of Muhammad Ali
}

Andrew J. Hale

San Jose State University

Follow this and additional works at: https://scholarworks.sjsu.edu/etd_theses

\section{Recommended Citation}

Hale, Andrew J., "How voice operates in popular culture through the performance persona of Muhammad Ali" (1994). Master's Theses. 760.

DOI: https://doi.org/10.31979/etd.znt2-56vc

https://scholarworks.sjsu.edu/etd_theses/760

This Thesis is brought to you for free and open access by the Master's Theses and Graduate Research at SJSU ScholarWorks. It has been accepted for inclusion in Master's Theses by an authorized administrator of SJSU ScholarWorks. For more information, please contact scholarworks@sjsu.edu. 


\section{INFORMATION TO USERS}

This manuscript has been reproduced from the microfilm master. UMI films the text directly from the original or copy submitted. Thus, some thesis and dissertation copies are in typewriter face, while others may be from any type of computer printer.

The quality of this reproduction is dependent upon the quality of the copy submitted. Broken or indistinct print, colored or poor quality illustrations and photographs, print bleedthrough, substandard margins, and improper alignment can adversely affect reproduction.

In the unlikely event that the author did not send UMI a complete manuscript and there are missing pages, these will be noted. Also, if unauthorized copyright material had to be removed, a note will indicate the deletion.

Oversize materials (e.g., maps, drawings, charts) are reproduced by sectioning the original, beginning at the upper left-hand corner and continuing from left to right in equal sections with small overlaps. Each original is also photographed in one exposure and is included in reduced form at the back of the book.

Photographs included in the original manuscript have been reproduced xerographically in this copy. Higher quality $6^{\prime \prime} \times 9^{\prime \prime}$ black and white photographic prints are available for any photographs or illustrations appearing in this copy for an additional charge. Contact UMI directly to order.

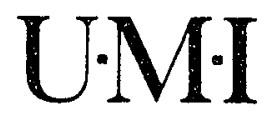

University Microfilms International

A Bell \& Howell Information Company

300 North Zeeb Road. Ann Arbor. MI 48106-1346 USA

313/761-4700 800/521-0600 
Order Number 1358184

How voice operates in popular culture through the performance persona of Muhammad Ali

Hale, Andrew Joseph, M.A.

San Jose State University, 1994

Copyright (C)1994 by Hale, Andrew Joseph. All rights reserved.

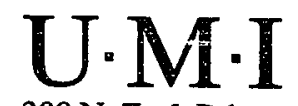

300 N. Zeeb Rd.

Ann Arbor, MI 48106 


\title{
HOW VOICE OPERATES IN POPULAR CULTURE THROUGH THE PERFORMANCE PERSONA OF MUHAMMAD ALI
}

\author{
A Thesis \\ Presented to \\ the Faculty of the Department of Theatre Arts \\ San Jose State University \\ In Partial Fulfillment \\ of the Requirements for the Degree \\ Master of Arts
}

by

Andrew J. Hale

May, 1994 
(C) 1994

Andrew J. Hale

ALL RIGHTS RESERVED 
APPROVED FOR THE DEPARTMENT OF THEATRE ARTS

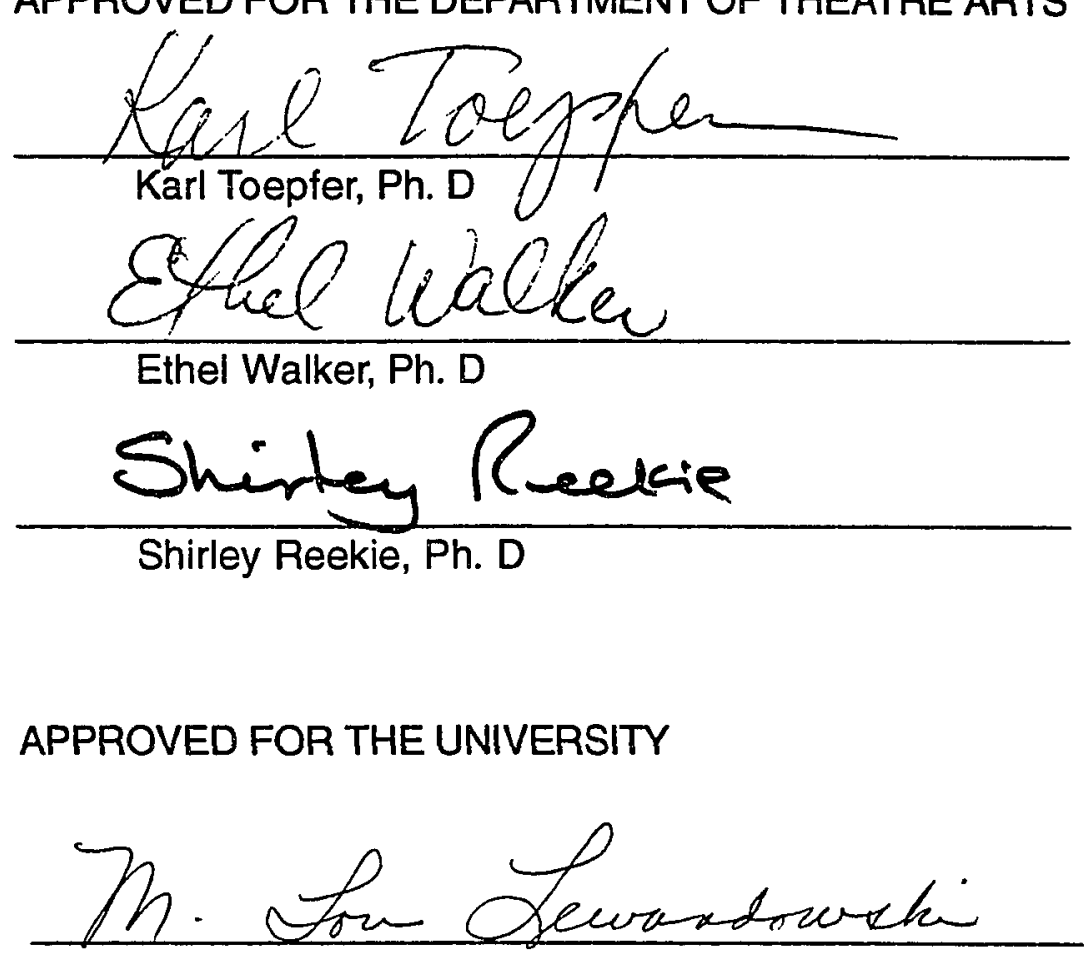




\title{
ABSTRACT
}

\section{HOW VOICE OPERATES IN POPULAR CULTURE THROUGH THE PERFORMANCE PERSONA OF MUHAMMAD ALI}

\author{
by Andrew J. Hale
}

This thesis addresses the issue of Muhammad Ali and his use of voice in the performance arena. It discusses both his mercurial rise to "star" performer status, which in turn helped elevate the very sluggish and static sport of professional boxing in the early 1960's, as well as his particular manner and practice of vocal skills in and out of the boxing ring and their subsequent effect on his success and power in the actual physical encounter.

Research into this subject exposes Ali's manipulative and profitable use of television and pre-fight promotion. In fact, his most effective and dramatic performances were not in the "squared circle," but rather in off-ring encounters, such as press conferences and interviews. In addition, his complete estrangement from the normal mold of the boxer and the public's reaction is also examined, as well as his "signifying" affirmation of his blackness in a white-controlled institution. 


\section{ACKNOWLEDGEMENTS}

I would like to extend my appreciation to the members of my committee, Karl Toepfer, Ethel Walker and especially, Shirley Reekie. And to Gina Maria

Giambra, for the use of her computer and printer. And for her love and encouragement. 


\section{TABLE OF CONTENTS}

CHAPTER

PAGE

1. THE PROBLEM AND ITS SCOPE . . . . . . . . . . . . . . 1

Introduction ................. . . 1

The Problem . . . . . . . . . . . . . . 2

Previous Discussion and Present Status of Problem . . . 4

Previous Discussion . . . . . . . . . . . . . . 4

Present Status of Problem . . . . . . . . . . . . 10

Purpose of the Study . . . . . . . . . . . . . . . . . 10

Parameters and Definitions . . . . . . . . . . . . . 11

Parameters . . . . . . . . . . . . 11

Definition of Terms . . . . . . . . . . . . . 15

Methodology . . . . . . . . . . . . . 20

Method of Procedure and Sources . . . . . . . . . 20

Method of Interpretation . . . . . . . . . . . . . 21

Organization of Thesis . . . . . . . . . . . . . . . . . 22

2. HISTORICAL CONTEXT FOR THE PERFORMANCE CODE OF

BOXING .................... 24

Introduction . . . . . . . . . . . . . . 24

Historical Background . . . . . . . . . . . . . . . . . 25

Jack Johnson . . . . . . . . . . . . . . . . . . . 27

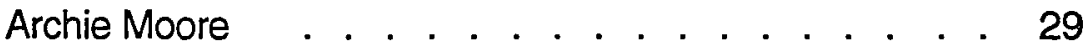

Floyd Patterson . . . . . . . . . . . . . . . . . 32

Television: The Perfect Medium . . . . . . . . . . . . . . 34 
3. VOICE AS AN ELEMENT OF PERFORMANCE CODE . . . . 38 Introduction . . . . . . . . . . . . . 38

Language and the Destruction of Opponents . . . . . . 38

Rhetoric and Strategy . . . . . . . . . . . . . 41

Ali as Debater . . . . . . . . . . . . . . . . . 47

Ali as Hypnotist . . . . . . . . . . . . . . . . 49

Illiteracy and Liston . . . . . . . . . . . . 51

Death, Madness and Escapism ～. . . . . . . . 54

Control and "the Crazy Nigger" . . . . . . . . . . 56

The Weigh-in . . . . . . . . . . . . . . 58

Success in Madness . . . . . . . . . . . . . . . 60

4. VOICE AND SPECTACLE . . . . . . . . . . . . . 66

Introduction .............. . 66

Ali's New Mode of Weaponry . . . . . . . . . . . . . . . 67

Parody and Stepin Fetchit . . . . . . . . . . . . . . . . 72

Ideology and Spectacle . . . . . . . . . . . . . . 77

Ali as Prophet . . . . . . . . . . . . . . . . . . 80

Ali's Invasions and Knightings . . . . . . . . . . . . . 84

Gimmickry and Gorgeous George . . . . . . 86

The Musicality and Practice of the Voice . . . . . . . . . 90

Ali and Presley . . . . . . . . . . . . . . . . . . 94

5. VOICE AND SEXUALIDENTITY . . . . . . . . . . . . . 98

Introduction . . . . . . . . . . . . . . . . 98

Sexuality and Complexity . . . . . . . . . . . . . . 99 
Sexuality and Symbolism in the Ring . . . . . . . 100 Ali's Complex Sexual Nature . . . . . . . . . . . 102

The Feminine in Ali . . . . . . . . . . . . 104

Liston: Fear in the Feminine . . . . . . . . . 106

George Foreman and N'golo . . . . . . . . 110

6. CONCLUSION . . . . . . . . . . . . . 117

Summary . . . . . . . . . . . . . . 117

Implications . . . . . . . . . . . . . . . . 118

Recommendations . . . . . . . . . . . . 121

NOTES . . . . . . . . . . . . . . . . . . . . . . . . . 126

REFERENCES . . . . . . . . . . . . . . . . . . 130

APPENDIX ......................... 138 


\section{Chapter 1}

The Problem and its Scope

\section{Introduction}

Preconceived notions of the performance code for professional boxing have led, for the longest time, to the acknowledged perception that a pattern of volatile, brutal and senseless acts define this institution. This has been governed and enhanced by the ever-pervasive norm of the stoic, silent, and intellectually inept male combatant. The performance code of professional boxing had been dominated prior to 1960 by an "ugly" and "voiceless" quality that affected the consciousness of popular culture. The dynamic of the boxer was simple and clearly defined: the fighter's "fight" in the ring was his sole function; his role was a fighter whose moral dilemmas have been reduced to physical superiority within the ring. Sonny Liston, George Foreman and Mike Tyson represent the best examples of this structured pattern, that the boxer/fighter is absent from any moralistic complexity; he is in the ring for the destruction and brutalization of any adversary willing to step against him. The performance is simple and significant in its purpose: superior strength in ring combat is the result of pure physical superiority.

However, since the arrival of Muhammad Ali, popular culture has been forced to reconsider and reevaluate those familiar myths that the boxer is an illiterate brute and boxing a barbaric and senseless pastime. Perhaps Ali's single-greatest contribution to the elevated estrangement of the boxer from the norm was to give, both literally and figuratively, a voice to the performing artist in physical performance. The identity of the boxer was no longer inconsequential nor insignificant once the fight (previously, regarded as his sole societal 
function) had ended. With the introduction of voice and language into such a male-oriented domain, the boxer (and his perceived performing code) attained a more well-rounded human identity, albeit not without controversy and disbelief. The communicativeness and demonstrativeness of voice and language gave to the performer an identity and function both in and out of the ring; he was able to successfully articulate a new-found intellectual mechanism that brought about victory and power.

\section{The Problem}

There has been no serious investigation into understanding Muhammad Ali's "voice" and whether or not there was a link between his voice and the phenomenal success that he generated in and out of the ring. Previous researchers obviously labeled him a loud-mouth, and sport journalists referred to him as a great athlete, but neither had analyzed or approached systematically his vocal skills. What has become apparent is the weakness of previous research; there has been a lack of attention and a lack of questions concerning how it worked, and how well Ali understood the limits of its use; certainly it is a fact that Ali was a great fighter, that he was tremendously successful, and that he talked in and out of the ring. What is interesting is that there has been no scholarly or systematic study conducted on the potentiality of a link between any of these factors. Why?

Primarily, boxing has always been a blue-collar sport, and writers of the sport have always been aware that their public has been of the archetypal, macho perspective. This blue-collar audience worked on a base-obvious level in which what they read and what they vicariously viewed should be one and 
the same. Intellectual and psychological analyses have never had a strong readership, at least for the followers of the sport. Most boxing fans have enjoyed the beer, blood, screams and suspense of the game. In fact, it was this kind of ambience that Brecht had hope to emulate in his Epic Theatre design; a healthy participatory audience intensely engaged in the performance. Study of the psychological and intellectual stimuli of an individual boxer has never been an element of the boxing fan's code of performance. Instead, sport journalists have been the translators of the boxer's actions and reactions; how he performed, how good his condition was; what strategy worked against his foe; which punch hit the mark. These writers have been the primary source of boxing's accessibility to the social classes. They have described for the boxing fan the sport at its most physical and elemental. Interest has never been strong on motivational factors involved in a boxer's victory or defeat.

In competition, the voice of the boxer becomes secondary to our fascination with the physical. It is not difficult to understand this point if one has ever been to a live boxing event. Here, in the throes of a near-visceral experience, those subtleties of motivation, that would be essential in serious and semiotic investigations, get overlooked. At ringside, analytical perceptions and psychological motivations of the boxer are perhaps the last thing in mind. It is the sweat, blood, skill and masculinity of the fighters that fascinate. Therefore, interest in stimulating research, for example, the relation between Ali's use of speech as a means of weaponry and his success in performance, has been lacking, simply because interest and accessibility of boxing's fans and readers have been lacking.

However, there have been several scholarly investigations by social 
historians such as Sammons's Beyond the Ring. Gorn's The Manly Art, and Robert's Papa Jack. With these, as with others, emphasis was placed on cultural, social and historical aspects, not on relations between boxer and success, or boxer and performance, or even boxer and social identity.

Furthermore, what has not been confronted by previous discussion and is at the forefront of this semiotic investigation, is: to what extent does the identity of boxing and the identification of the professional boxer, controlled by a dramatic code, depend on this normative perception of the relation between the vocal (words deployed) and the physical (punishment employed) experience? And lastly, if power is ultimately in the voice (which this thesis sets out to examine), then the performing code of Ali not only obscured the rationale behind the basic concept for battle within the ring, it also changed societal and cultural perceptions. As Angelo Dundee exclaimed in a filmed interview, "His mouth created everything" (The Championship).

\section{Previous Discussion and Present State of Problem}

\section{Previous Discussion.}

There has been quite an extensive amount of past study and discussion pertaining to professional boxing and the success of Muhammad Ali over the last thirty years. These previous studies include the works of John Contrell, George Sullivan, Jack Olsen, Robert Lipsyte, George Plimpton, Thomas Hauser, Henry Korn, Peter Wilson, Randy Roberts, Elliot J. Gorn, Jeffrey Sammons, and Gerald Early. All have given fairly descriptive analyses and anecdotes in the various areas of Ali's career and life. However, a major limitation in all these sources is the lack of information concerning Ali's 
boyhood and his African-American culture. Early, the only black writer in the above list, wrote extensively on the black boxer in professional boxing, but little on the African influences and African-American codes of "signifying" that Ali exploited.

It is important to note that during the time of Ali's arrival, there were few, if any, black sports journalists of wide release in the media. The dominate perspective on Ali's formidable years (1960-65) was from a white perspective.

Contrell's and Sullivan's contributions are significant in that both represent early and accurate portraits of a young Cassius Clay as he rose from Olympic stardom to World Heavyweight Champion. Their work has especially contributed to this thesis in the areas concerning Ali's emergence as a popular performer and superior athlete. Specifically, their ideas give a working narrative and clear backdrop to Ali's formative years.

It is from Sullivan that the initial theoretical foundation for this thesis was developed; he was the first source to actually acknowledge the significance of Ali's mouth in and out of the ring. Also beneficial was Contrell's discussion of the significance television and the age of mass media proved to have upon the success of Ali's emerging career. He specified how well the timing of Ali's arrival fitted with the enormous boom of television. In his discussion, Contrell made key references to Ali's big mouth turning the heads of those who normally had no interest in the sport. But his and Sullivan's major limitation was in not examining or explaining how Ali's mouth was turning heads. Neither explore the aciual language spoken by Ali; what he was saying, and most importantly, how he was saying it. Neither question or comment on the fact that Ali had horrible diction and syntax, nor that he had a tendency to shout-out double 
negatives, as well as "cain'ts" and "ain't's." One is left with only the impression that Sullivan and Contrell were merely acknowledging the fact that in a sport that normally was vacant of such behavior, here was a young, black boxer acting crazy and talking loudly.

Sport journalists Olsen, Lipsyte, and Plimpton, primary and investigative sources, significant perceptions to this thesis. Olsen was one of the first to realize, as denoted by the title of his book The Riddle of Cassius Clay, that Ali was indeed a complex and elusive figure. His perception of Ali was all attitude; he discussed Ali's feelings and moods pertaining to race issues, family life, future goals and ambitions. He found more interest in examining the inner workings of the young boxer than in analyzing the "act" of Ali. This perception is valid in so far as it represents the reporting of a white journalist being allowed into a black man's social and psychological environment. However, it does not explore Ali's motivation for his peculiar behavior in and out of the ring; specifically, his loud use of poor grammar, and his equally loud use of body movement. Olsen recognized that Ali was elusive, but he does not specify how this elusiveness enhanced his performance or his celebrity.

Like Olsen, Lipsyte was another writer allowed to carry on a one-on-one correspondence with the boxer. Much of his writing pertains to Ali as controversial black sports icon who continually questioned and challenged the boxing authorities and their set determination to shut him up, hence, control him. Lipsyte's account of Ali's battles against Liston and Patterson in the mid 1960 's, proved very impoitant. He made note that Ali's complex nature was stimulating a rise in popular culture's consciousness. Lipsyte's perceptions are of a social conscious nature. They explore Ali's importance to the black and 
youth movements in relation to the very liberal agenda of the 1960's. All are valid in so far as they represent Ali's image as a black sports icon. However, they do not focus on the rhetoric of Ali, both as a political speaker or as an actor in the ring. From my reading, one very strong impression set itself firmly: Lipsyte followed Ali, wrote down everything he said, then put it in the context of social significance. There were no structural or systematic analyses conducted on how Ali performed. It seems like other writers of the times who noted Ali's "unique" gift of gab, Lipsyte, too, stopped short of providing a serious critique on the make-up of this unique gift.

Plimpton, however, went further in his discussion; specifically, in relation to Ali's "psychological pressures" as contributing factors to the defeat of Liston. He acknowledged Ali's uncanny thought processes that were involuntarily absorbed not only by Liston but by most of his opponents. Plimpton's work provided a detailed description of a most significant event: Ali's conversation with Jim Jacobs, Angelo Dundee, and Bundini Brown while viewing early fight footage of Jack Johnson.

Although Plimpton recognized and discussed Ali's psychological prowess in performance, he did not explore the significance Ali's voice had in relation to these "psychological pressures." Plimpton's perception of Ali, much like Lipsyte's, is a very subjective one. Hence, most of his writings deal with Ali in a clearly favorable light. In fact, it was difficult to find any writer who criticized or critiqued Ali's "performances." Most merely reported that they occurred and were very provocative.

Where other writers discussed isolated and specific episodes into the study of Ali, Hauser gave a wide scope generalizing Ali's entire adult life and 
career. He made no attempt to examine Ali in a semiotic or scientific approach. And no research of Ali's childhood was presented. His book only attempted to discuss Ali as a biography enhanced by the opinions of others, and how they felt toward him.

The recent work of Henry Korn enhanced the theoretical debate that developed as this project proceeded into unchartered areas. Although Korn recognized and discussed Ali's vocal powers and their relation to a type of sociological "madness," his perception concluded that Ali's success was dependent on something other than his voice.

The scholarly writings of Roberts, Gorn, Sammons, and Early provided clear and concise research into the areas of racial, societal, cultural and ideological identification for which professional boxing and the boxer, in particular Jack Johnson, Joe Louis and Ali, have contributed and elicited. Roberts' work on Johnson provided a tremendous deflation to the ever-growing bias and myth that Ali was not only the first black voice in boxing, but also the first controversial figure as well. His Papa Jack gave to this study a firm basis on which Ali's performer code could be made comparable. However, he made no serious investigation into Ali or his image. In his last chapter, Roberts briefly equated the social antics of Johnson and Ali. But not much was made of this.

Sammon's and Gorn's work provided essential historical and socioeconomical perspectives into the world of professional boxing. It was quite interesting that Sammons's conclusion to his study of boxing called for its abolishment. And yet, in the same vein, he acknowledged the importance of Ali's act and influence on diverting society's attention from several boxingrelated tragedies during the early 1960 's. But the problem with both these 
scholars is the fact that they were social historians. They write of boxing and Ali in terms of historical and cultural significance, which is fine. However, neither explores the operation of the voice or the social identity of the boxer in relation to popular culture. Their primary question, which is the common thread of most all the previous sources, is: what he did.

Furthermore, the articles of Gerald Early generated a new perspective on the black athlete and the black consciousness. His work included crossreferences to Eldridge Cleaver, Amiri Baraka, Jervis Anderson, Al-Tony Gilmore, Floyd Patterson, and even Gorgeous George and the Congressional Record. Specifically, Early's opinions on the "Black Intellectualism" helped assess Ali's sense of escapism and spectacle, since Early was one of the few black writers on boxing and Ali published.

However, a major limitation of Early's achievernents was the fact that he made no reference to Ali's "black" dialect. Nor did he examine Ali's harsh parody of the black stereotype, which was very prevalent in his "act." Moreover, he did not develop any qualifying relation between Ali's success as a militant social icon and his success as a black sports hero who fostered the use of language in performance.

Furthermore, I came across no source that included an informative description of Ali's boyhood (beiore his twelfth year), what he was like, how did his mouth play a part in his early years, and whether there were any influences in his life based on African or African-American traditions.

In closing this section on previous discussions, it is important to note that the context for which this thesis is based is "Ali, the boxer-actor." However, it has been within the context of "Boxing and Ali," that most other 
writers have made their judgments and perspectives. Primarily, what has been written is based on a white perception of a black boxer in a White-dominated sport. Significantly, what has been absent, and indeed a major limitation, is examining and interpreting Ali in a larger sphere of signification. He is bigger than boxing. Hence, in order to fully grasp Ali's performer code, it is necessary to go outside the context of boxing which previous writers have failed to do, and examine other contexts, such as his African-American roots.

\section{Present Status of Problem.}

This study probes into a very under-theorized area of performance. Although the many writers mentioned before have contributed significant portions in regards to Ali's boxing and personal success (social, political, economical, and religious), there has been no scholarly or serious investigation that gives attention to the plausible link of Ali's voice and his success in performance. This has been the major weakness of previous research and the problem at hand, the lack of attention, analysis, and questioning on the signifying effects of this vocal mechanism in relation to physical performance had in changing society's perception of the boxer's performance code.

Further, this semiotic investigation will persuade through argument that there is validity to the hypothesis that the mechanism of language was largely responsible for the success of Muhammad Ali.

\section{Purpose of the Study.}

The purpose of the study is twofold: Firstly, to analyze and attempt to answer these theoretical questions in relation to Muhammad Ali: How 
significant was his "voice" in (male) physical performance? What was the relation between his "voice" and his success in physical performance? To what extent did the power of Ali's voice affect the success in changing the social identity of popular culture? And finally, what is the relation between success and "voice" as a device of "power" in athletic performances? Secondly, this thesis wages a theoretical battle to extend the understanding of two opposing theories, one made by Henry Korn, the other made by George Sullivan. Both assert that Ali was a great athlete and possessed the "gift of language." However, in Muhammad Ali: Retrospective, Korn contended that, "There is no doubt that Ali would have become champion without a voice." (96). In The Cassius Clay Story, Sullivan wrote:

Clay wagged a finger under Liston's shiny nose and announced to him, "I want you, Liston!"---This was typical of the tactics that Clay would use over the next 18 months to bewilder and anger Liston. Eventually, (that voice) would help him win the championship [italics mine]. (46)

The above italicization should draw attention to and consequently reinforce several relevant terms and actions that will be shown to have been part of Ali's "performance persona," which in turn will also be shown to have had an effect on this phenomenon of "voice" and its link to his power and success in the ring.

\section{Parameters and Definitions}

\section{Parameters.}

Appropriate parameters must be set so as to keep the basic focal direction of this thesis, Muhammad Ali, voice, and success in performance, from 
straying into other no less significant aspects for which the historical frame of this study extends (1956-74). The use of Ali's voice was not culturally bound; interest and focus was not bound by culture, so aspects, controversial or otherwise, such as Ali's religious and political influences, will not be included or addressed extensively. No doubt these aspects which were indeed significant to the dynamic make-up of the 1960's would present a thoroughly intriguing topic for future research. But as for the problem at hand, only Ali's artistic, athletic, and social endeavors and accomplishments, both in and out of the boxing ring, will be the primary concerns.

The historical period covered in this study will extend from 1956, the year Rocky Marciano resigned his championship belt to Floyd Patterson, to 1974, the year Ali battled George Foreman. There will be occasional references to past champions from recent and not so recent periods of boxing history, such as Jack Johnson, Joe Louis, Sugar Ray Robinson, and Archie Moore. Also, there will be corresponding references made to Ali's own amateur and Olympic years. However, the bulk of this study will focus on the years from 1962 to 1964 , so as to thoroughly examine the historic ring encounter between Ali and Liston (2/24/64) and those years and fights prior and leading up to this bout, such as the contests with Archie Moore and Henry Cooper. This will give the reader a better understanding of not only Ali's activities as he campaigned for a title match, but also of Liston's and his years as heavyweight champion.

In between the Liston and Foreman confrontations, there were some twenty-six bouts; of these Ali was defeated twice, once by Frazier and once by Norton. None of these twenty-six shall be discussed. The reason will be given in the following paragraph. Furthermore, there was a span of three years of 
inactivity (1967-70) for Ali due to his refusal to be inducted into the armed forces. This issue will not be discussed. These three years and the work Ali did for race relations and social causes would indeed present a fascinating study for future research. It is a fact that Ali did not leave the sport until 1981 after his losing decision to Trevor Berbick. In the interim from 1974 to 1981, Ali did partake in numerous fights that attracted huge interest and attention. But his bout against Foreman, for the purposes of this study, was the last overwhelmingly dramatic obstacle that he was able to overcome.

On this same subject, it is quite evident that the ring wars between Ali and Frazier, which numbered three, are considered legendary and heroic, especially Ali-Frazier III, historically known as the "thrilla' in Manilla." The same can be said of Ali's encounters with Ken Norton, which also numbered three. However, aside from brief references to Ali-Frazier I, these classic heavyweight bouts will be conspicuously absent since they do not critically or structurally adhere to the line of reasoning and the purposes of this thesis. It goes without saying that both Frazier and Norton were great ring warriors and competitors, and indeed brought out some of the best from Ali. Yet they did not possess the magnitude nor physical significance in their opposition as did Ali's confrontations with Liston and Foreman.

Basically, what Liston and Foreman possessed and presented not only to Ali, but also to popular culture, was an aura of invincibility and invulnerability; they were signifiers of pure aggression and masculinity, and the kind of opposition that Ali needed to face and overcome in order to challenge popular culture's normative perception of the boxer.

The various aspects of professional boxing, press and camera 
interviews, literary articles and books, as well as film and stage presentations will be dealt with only to the extent which they contribute to the areas of Ali's methodology, ideology, psychology, physiology, weaponry, voice, and success in performance.

Concerning the two names the subject has used, it is significant to note that Cassius Clay did not officially change his name to Muhammad Ali until after his upset victory over Liston, at which time Clay announced his conversion to the Nation of Islam. To avoid any confusion for the reader, the name "Muhammad Ali" will be used entirely unless warranted by the date or time or quote from a reference that may necessarily be made.

Concerning advantages and limitations found in this undertaking, there was actually only one prominent limitation, and that involved a personal bias. However, my only limitation proved to be to my only advantage. It was most beneficial to investigate a particular boxer and performer for whom no previous support or admiration was felt. There has never been any bias for the outspoken Ali. Rather, when I had begun this thesis, I identified with the normal performing ethics embodied by Joe Frazier and Ken Norton. Obviously, with an advantage such as this, it was difficult to heighten or promote any special treatment in the direction of Ali. Since there was no schtick nor subjectivity towards Ali, an objective perspective would be realized.

Lastly, there will not be any references made to the present physical condition of Ali. It is proíoundly ironic that the man responsible for elevating the identity of the boxer/performer by the use of his voice is now made virtually speechless by the nervous disorder, Parkinson Syndrome, and, some will say, by the sport he so changed. Moreover, this thesis is not intended to examine 
the reasons for this debilitating condition, nor is it meant to excuse or ignore its very serious potentiality for injury. Certainly, debate and research could be procured on the basis of whether or not Ali did in fact take too many blows to the head for far too long, and indeed this type of venture would make very fascinating research. But this investigation has set its parameters around the years in which Ali's voice and reflexes were fast and effectively responsible for his success.

\section{Definition of Terms.}

The definitions of terms that appear here are for the purposes of this particular thesis only. With this knowledge, it is possible to find these same terms or phrases in other writings with slightly different meanings.

Bum: an opponent who lacks the skills, talents, speed and grace to go the entire distance of a fight much less be in the same ring with the champion.

Capping: a Black Semantic term that is somewhat synonymous with "signifying," and characterized by exploitation of the unexpected and quick verbal surprises (Smitherman, 1978: 119).

Code: a set of signals for sending messages; one code operates in tension with another (Webster-Merriam, 216).

Context: refers to the condition in which a specific code operates; it is out of this condition that the readability of signs emerge.

De-contextualizing: taking the signs out of their narrative context.

Dramatic Code for Boxing: Professional boxing connects us to a dramatic code which dominates our perception of boxing in the other codes or "contexts." The dramatic code here refers to images of physical combat with 
fists. Almost any image of such combat is incongruous to the deployment of speech and is associated with the resolution of a conflict which is "beyond" the power of voice or langauge to resolve.

Boxing is always fighting against perceptions established by a dramatic code which a narrative code, a media code, a genre code, a performance code cannot dominate, subvert, transform, or expand. The dramatic code is the key to decontextualizing those "signs of power" constructed by boxing and to disentangling the codes from each other.

Estrangement: that which is alienated from the median; to divert from its original use or possessor; to apply to a purpose foreign to its original or customary one (Webster, 1973: 626).

Ham and Egger: close relation to bum, if not his literary brother; an unskilled boxer.

Griot: in African tribal culture, a revered person, always an elder, who was responsible for maintaining tribal history (Smitherman, 1978: 148).

Language: a system of signs that expresses ideas, and is therefore comparable to a system of writing, the alphabet of deaf-mutes, symbolic rites, polite formulas, military signals, etc (Saussure, 1959: 16).

Narrative Code for Boxing (or more properly, the "master narrative"): the rules and conventions of boxing as they are prescribed by boxing organizations, or "boxing history" (tradition), or the conditions of presentation established by the mass media. The rules and conventions of boxing which tell us that $a$ performance is professional boxing are the result of narrative signifying practices, a text, written by ideology (social reality), which enables us to identify boxing as a sport (media code), within which boxing is a genre (Toepfer). 
N'golo: from the Zairois and refers to a person's lifeforce or libido; Mailer refers to Ali's " $n$ 'golo" in The Fight, an account of the Ali-Foreman prizefight, popularly known as the "Rumble in the Jungle" (139).

Norm: articulations of conventions, patterns of signification defining classes of identities (Toepfer). Also, the standard, model, or pattern for a group; especially such a standard or achievement as represented by the median or adverse achievement of a large group (Webster, 1973: 1221).

Normative Perception: the model or standard for which the general populace adheres to or recognizes as being ideologically normal.

Parrying: the fending off of an opponent's straight right by simply catching it and pushing it aside and downward, out of the way. The parry actually redirects the oncoming blow, while the block can at best only neutralize it.

Performance Code: the exposing and expressing of possibilities or choices for reading and understanding a text; this code refers to the tension between an idealized or constant mode of signification and an "actual" mode of signification (Toepfer).

Performer Code: a structuralist term referring to the production and transmission of signs which are peculiar, even exclusive to a performer, rather than to an historical era, a genre, a medium, a performance style, a narrative form, or an archetypal structuring of performance (Toepfer).

Psyched-out: in the case of sport and physical encounter, the disrupting or destroying of one's concentration so as to cause defeat in one's physical performance.

Rubber match: refers to the third time around between a rivalry that has 
split the first two matches.

Semiology: a science that studies the life of signs within society; it would be part of social psychology and consequently of general psychology (Saussure, 1959: 16).

Semiotics: a general philosophical theory of signs and symbols that deals especially with their function in both artificially constructed and natural language, and comprises syntactics, semantics and pragmatics (WebsterMerriam, 1973: 1053).

Sign: that by which anything is shown, made known, or represented; something that indicates, expresses, or signifies that a fact, quality, action, gesture, attitude, feeling, voice, or perception by which information is communicated (Webster-Merriam,1973: 1688, and Harland, 1988: 180).

Signification: meanings, indication; the holding of different things together in mind on a non-perceptual basis; the act of signifying the thing which the sign refers to; the referent (Webster, 1688, and Harland, 29).

Signifying: a black mode of discourse, that refers to the verbal art of insult in which a speaker humorously puts down, talks about, needles the listener. Sometimes "signifyin" is done to make a point, sometimes it's just for fun (Smitherman, 1978: 118).

Signifying Practices: patterns of signification; a set of indicators or signs that constructs meaning and communciates a text.

Slipping: the bending at the waist and knees so that a boxer can just avoid the oncoming blow and is in perfect position to counterpunch.

Sticking: refers to a boxer's connecting with either a lead jab or staight right. 
Structuralism: a theory/science that is concerned to know the (human) world---to uncover it through detailed observational analysis and to map it out logically. The structuralist's stance is still the traditional scientific stance of Objectivity, the goal the traditional scientific goal of Truth (Harland, 1988: 12). Also, the structuralist distrusts reliance in the senses; it is a reductive mode of thought in which nothing has identity unless it is in tension with something (Toepfer).

Text: In Semiotic Theory, systematic configuration of signs for which a meaning can be constructed; a performance insofar as it is reproducible or readable; it pertains to conditions of characterization: modes of conflict, structures of contrast, dimensions, intensities, color, texture, ornamentation, number of signifiers, range of devices; a text refers to signs in movement (Toepfer, 1991).

Voice: the use of words or sounds uncharacteristic of or to the stereotypical boxer of the times.

Voiced-out: vocal weaponry used in the psyching-out of one's opponent.

Throughout this thesis I have made several references to the various weight-divisions of Muhammad Ali and other boxers, specifically heavyweight, light heavyweight, middleweight, and welterweight. The definitions of these specific weight classifications are taken from On Boxing (Oates, 1987: 5).

Heavyweight---no weight limit (above 196 pounds)

Light Heavyweight---from 169 to 175 pounds

Middleweight---from 155 to 160 pounds

Welterweight----from 141 to 147 pounds

Lightweight --- from 131 to 135 pound 
Methodology

Method of Procedure and Sources.

This thesis is a semiotic investigation involving four major phases: (1) comprehensive reading entailing primary and secondary published material pertaining to professional boxing, its history and origins, its organizations, rules, trainers, promoters, managers, fighters, fans, motion pictures, stage presentations and criminal elements; its sociological, cultural, political, economical, scientific (medical), artistic and literal factors and debates; (2) in depth reading of primary and secondary published material pertaining to the life and careers of Muhammad Ali; included in this process were essays, reports, articles, books, monographs, film and stage reviews; (3) comprehensive viewing of actual film fights or excerpts from the actual fight films involving heavyweight champions Jack Johnson, Jess Willard, Jack Dempsey, Gene Tunney, Max Schmeling, Jack Sharkey, Primo Carnera, Max Baer, Jim Braddock, Joe Louis, Ezzard Charles, Jersey Joe Walcot, Rocky Marciano, Ingemar Johansson, Joe Frazier, Ken Norton, George Foreman, Michael and Leon Spinks, Mike Tyson, Evander Holyfield, and specifically Floyd Patterson, Sonny Liston, and Muhammad Ali; those specific fights involving Ali that were viewed can best be realized by consulting the Appendix for his entire professional fight record; and (4) comprehensive viewing of fight interviews, commercials, rehearsals for stage plays, motion pictures, documentaries, press footage of pre-fight weigh-ins and post-fight interviews, non-participatory fight commentaries, television and news programs, and award ceremonies involving Muhammad Ali. 


\section{Method of Interpretation.}

The next level of the methodology involved this writer's interpretation of the signifying practices, ascertained and compiled, from the above-mentioned four phases of procedures and sources.

With an approach based on codes and signs, this semiotic investigation focused on the decoding of the theoretical question: What was the relationship between voice and success as demonstrated by the performance of Muhammad Ali? In the process of decoding this theoretical dilemma, it became evident that there were different codes at work, and that a defining and determining of each respective code would be essential to the success of the methodology.

Moreover, in professional boxing the notion of performance entails signifying practices which are not prescribed by the various media, genre, and narrative codes. The performance code for boxing is complex because it operates in the ring and out of it and therefore has to be understood from an historical perspective. It can not be determined only from the rule books, from the performance of any one boxer, from the fight documentation of any particular era, or even from personal experience as a boxer; it has to be looked at in the following de-contextual manner: how a certain number of boxers in different "contexts" performed in an out of the ring---Jack Dempsey, Gene Tunney, James Corbett, Joe Louis, Max Schmelling, Rocky Marciano, Ingmar Johannson, Floyd Patterson, Sonny Liston, etc.---in relation to the variable which makes Ali so distinctive, the phenomenon of voice.

This investigation of an interdisciplinary problem sought to analyze and define professional boxing and performance into semiotic terms; hence, the 
prevalent references to codes and signs.

\section{Organization of Thesis}

The following thesis has been organized into six chapters and one appendix. The introductory chapter, "The Problem and Its Scope," contains the introduction of the problem, the purpose of the study, the parameters and definition of terms, the previous discussion and present status of the problem, as well as the method of investigation.

Chapter Two, "Historical Context for the Performance Code of Boxing," discusses the recent history of professional boxing prior to the rise of Muhammad Ali, as well as the significance his performer code had in relation to television and mass media.

Chapter Three, "Voice as an Element of Performance Code," examines the newly created performer and performance codes of Ali, especially how his voice and the power generated from it came to reflect a new rhetoric and new identity for the boxer in professional boxing. An analysis of the signifying practices of Ali, specifically, his voice and how he used it in and out of the ring is also included.

Chapter Four, "Voice and Spectacle," discusses Ali's ability to situate and integrate the voice in other aspects of performance, specifically, in relation to (1) the successfully marketable ability to make predictions of upcoming bouts; and (2) the highly publicized roles as poet and musician and actor.

Chapter Five, "Voice and Sexual Identity," focuses on the issue of sexuality and gender, specifically, on Ali's complex nature of sexuality in and out of the ring, and its emasculating effect on Liston and Foreman. 
Chapter Six, "Summary and Conclusions," contains the summation of the structure and problem of this investigation, as well as the results and conclusions, specifically, how Ali's voice enhanced his success in physical performance. This chapter will also include recommendations, references, and sources that may elicit further interest and research in this interdisciplinary subject. 
Chapter 2

Historical Context For the Performance Code Of Boxing

\section{Introduction}

This chapter will introduce the historical background portion of this thesis and give the reader a general outlook to what the scope and landscape of professional boxing resembled at the mid-century mark. This period focuses specifically on the heavyweight divison, with such names as Rocky Marciano, Archie Moore and Floyd Patterson, a time just prior to the arrival of Ali. Also beneficial to this chapter will be the inclusion of Jack Johnson, who obviously did not fight at mid-century but rather at the turn of this century. Nonetheless, his history and confrontations strongely parallel those of Ali, and, therefore, shall be addressed. Furthermore, the reference to Johnson will logically serve to chronicle the emergence of Joe Louis, Sugar Ray Robinson, and Archie Moore and lead into the era of the 1960's and Ali. What will then be discussed is Ali's connection to the visual phenomenon of televison and his understanding of the limits of the mass media.

As noted in the "Method of Interpretation" section, the performance code for professional boxing is arrived at and understood from an historical perspective, in which a group of boxers are examined and figuratively taken out of their performing "contexts" and structurally put in relation to a specific variable of another boxer. It is through this form of de-contextualization that a researcher can better interpret a particular genre, such as boxing, wrestling, and football, and a specific performer such as Ali. 


\section{Historical Background}

The heavyweight champion of the world has nearly always been a silent, "voiceless" performer, allowing and commanding his fists to speak for him. $\mathrm{He}$ let others, such as promoters, managers, trainers, speak to the cameras, the microphones, the assembled masses. Men such as Tex Rickard, Doc Kearns, Mike Jacobs, James Norris, Al Weill and Cus D'Amato were responsible for developing the ring performance's popular and commercial value. ${ }^{1} \mathrm{~A}$ large audience for performance has always been more anxious to see two men fight for a king's crown than to see two fighters talk and debate for some invisible glory. Fight fans want and have always entertained this odd desire to see blood drawn and flesh damaged for whatever atavistic and vicarious purpose.

Further, the idea that there exists an ugly antagonism between the combatants seems to escalate and magnify the hungry public's need to see the ring battle (Sammors, 67). To generate and add more interest and excitement for a match, there have been occasions when a popular champion of the day has strayed from his acknowledged and silent domain and has made a verbal challenge or two. In his article from the Saturday Evening Post, "The Biggest Fight Build-Up in History," Stanley Frank cites several vocal instances by prevailing fighters of their respective days. John L. Sullivan "abused every obscene no good in the bar." Bob Fitzsimmons promised to "spit in Jim Corbett's eye" (21).

But on the whole, with the exception of Jack Johnson, normally the boxer, fighter or plodder, black or white, has sat silent, smiling perhaps, at press conferences, in front of microphones or cameras, while the mechanism of selling the fight was left to others. Endless film footage shows managers and 
promoters, such as the ones already mentioned, smiling while their proteges, sit alongside, pencil or pen in one hand for the signing of contracts, as the other hand rises against the image of his future adversary. The "voiceless" boxer does his "talking" in the ring.

Traditionally, as Robert Lipsyte observes, fighters such as "Jack Dempsey, Joe Louis and Rocky Marciano, sweet-natured killers, have been considered the model heavyweight champions" (Italics mine, 74). It has been this positioning of the heavyweight champion as role model that has helped embed into the consciousness of popular culture the troubling perception that a boxer or fighter can be nothing but a "sweet-natured killer," silent and simple. Boxing has always enjoyed the fact that its players have generally been uncomplicated and unsophisticated. However, with the arrival of Muhammad Ali this myth would be radically challenged by expanding the role of voice and language in performance.

Interestingly enough, in 1970, when Ali was about to fight Jerry Quarry, his first match since expulsion in 1967, there was another not so simple and silent black boxer having a strong influence upon Ali. Within in his Atlanta apartment, along with Angelo Dundee, Ali's trainer, Jim Jacobs, boxing's premier student, and Drew Bundini Brown, Ali's alter-ego, Ali sat and studied a fight film involving Jack Johnson. Ali was in awe of the old fighter's antics and boxing style. He was interested in the way Johnson always insisted on being the first fighter to climb into the ring, and the way he signaled his next move. As Plimpton observed:

At one point in the film, the deep, simulated voice of Jack Johnson announced just prior to the Jim Jeffries fight, "If I felt any better, I'd be scared of myself." Ali laughed, and one felt that he might have 
stored the line away for future use... When Johnson grinned and appeared to taunt Tommy Burns in the early rounds of the fight that won him the heavyweight chmpionship, Ali commented, "He's something else." He watched Johnson make a derisive gesture with his glove, waving good-bye to Burns as he turned for his corner at the end of the round. "Look at that," Ali said. "He's signifying, 'See ya later, partner.' (153-4)

\section{Jack Johnson.}

It is crucial to mention that Ali was not the first fighter to vocalize his opinion and persona in and out of the ring. Before him there were a number of boxers, not all heavyweights, who possessed the wit and intelligence sharp enough to attract some attention. Perennial and legendary champions such as Sugar Ray Robinson and Archie Moore are among this elite and significant group. However, it is Jack Johnson who must be considered the first, and up until Ali, the premier boxer-talker-rabble-rouser. In fact, there is a very close symbiosis that exists between Johnson and Ali: both were great defensive fighters; both possessed great hand and leg speed; both loved to "taunt" their opponents; both played with or kept up a continuing dialog with the audience during the fight, both did their best to defy present rules, laws and norms during their respective societal agenda (it must be understood that Johnson's era of civil rights were a far cry from those of Ali's); both were severely criticized because of the "abusive" use of their mouth; and of course both were arrogant and black in a white-dominated sport.

Art Evans, writing on the topic of black boxers at the turn of the century, explains that, "It must be understood that in order to be successful, entertainment must be socially acceptable to the audience" (109). Jack Johnson, perhaps the equal to Ali, as boxing skills go, was far more eloquent, 
articulate, outrageous, arrogant and intelligent. However, one thing denotes a significant difference between the two: in the 1960's Ali was socially accepted; in the 1900's Johnson was ostracized.2

Johnson held the heavyweight crown from 1908 to 1915 . After Johnson won the crown, as Evans indicated:

Whites became disillusioned with boxing as a professional sport because the then popular theory of Social Darwinism (which supported the belief of white superiority) was shattered. A central concern of white fans was that a black would permanently reign as champion; this situation they would not tolerate. (100)

There are several credible sources that identify and highlight the major contributions and influences of Johnson: Al-Tony Gilmore's Bad Nigger! The National Impact of Jack Johnson (1975, New York); and Randy Roberts's Papa Jack: Jack Johnson and the Era of White Hopes (1983, New York). Roberts, in one paragraph, describes the magnitude and omnipotence of this larger-thanlife pop-iconoclast. He wrote:

(Johnson) was an uncompromising man, even when confronted by the overwhelming power of white authority. He touched his leg and spoke his mind and was not content to allow twelve white jurors to think what they wanted. In his mind he was Papa Jack, a name he signed on the pictures of himself that he gave to close 'lady friends.' Papa Jack, the best lover and talker and boxer in the world [italics mine]. (prologue)

Incidentally, it is quite compelling that Roberts, for his preface to Papa Jack. chose to quote from Mailer's "King of the Hill," which depicts and attributes "the great word" to another black boxer of Johnsonian status, Muhammad Ali:

Ego! It is the great word of the Twentieth Century. If there is a single word in our century that has added to the potentiality of language, it is ego. 
It is perhaps most accurate to admit that one ego helped begat another. Through the struggles of Johnson and other black athletes, especially boxers, the America of the 1960's could be and was able to be "socially accepting" to the likes of Ali.

\section{Archie Moore.}

Besides Johnson, Sugar Ray Robinson and Archie Moore also rampaged through their respective weight divisions with wit and controversy, will and arrogance. ${ }^{3}$ All could display a virtuosity of fanciful dialog and wellchronicled, as well as well-articulated, outspokenness. Jack Johnson was eventually forced to escape out of the country after being convicted of violating the Mann Act. Robinson refused to make his entrance onto a press conference and weigh-in ceremony through the back door. And Archie Moore, in fact, possessed more wit, was more of a conversationalist, was far more articulate and displayed a much higher vocabulary than the energetic and bombastic Ali (Contrell, 82). But what defines the difference between these remarkably gifted athletes and Muhammad Ali is simply timing; the timing of their place in history and in what was conspiring in their time within the nation, especiaily in regards to the non-burgeoning efforts of the civil rights movement. ${ }^{4}$ With television as a focal point for pop culture, Ali would be able to accomplish what Johnson could not: to be accepted for who and what he was.

Much like Patterson, Moore had some success in deconstructing the norm of the silent boxer. In fact, Moore was known for his eloquence in speech and his liveliness of mind. He had been nicknamed "the Mongoose," for his sly 
craftsmanship within the ring. In the Marciano fight (1956) he had suckered the champion into the wrong moves, but did not have the power to capitalize on them (Plimpton, 17). However, most of his career as a performer occurred before the great emergence of television, and therefore, mostly journalists were familiar with his face and voice. By the time television and Ali arrived, Moore's best days as a fighter were gone. In Man of Destiny, Contrell described the significance the age of television proved to have upon the success of Ali's career in relation to Moore's. He wrote:

In contrasting the careers of Clay and Moore (Moore had been fighting since Clay's birth in 1942), one cannot help reflecting how very fortunate Clay was to be fighting at such a time, when high financial rewards were available, and the mass medium of television enabled a dynamic personality to project himself into millions of homes and become a nationally known figure overnight. In times so favourable for the showman, Cassius would be able to talk and fight his way to a world title in less than four years and after only 19 professional bouts. In the case of Archie Moore, it took 17 years and 160 bouts to get a world title bout. (84)

It is important to note, that because of the sacrifices of past athletes, like Archie Moore and Joe Louis, athletes like Ali, with all of his "blackness" and voice intact, and with television as a backdrop, could eventually receive their just rewards. Contrell made a point that Ali:

Would later pursue that big, 'ugly bear,' Sonny Liston, with a honey-pot and rope, and he would be called the shrewdest and slickest showman in boxing history. But, in truth, his publicity stunts were no more inspired than Moore's old tactics (he campaigned quite effectively for a fight with Marciano) and certainly he (Clay) never equaled the witticism of Archie in his heyday. (84)

Moore demonstrated his liveliness of mind and famous wit by accepting a challenge from George Plimpton to a three round exhibition boxing match. As 
Plimpton noted:

He wrote back promptly on a letterhead which included a head portrait of himself, a montage reproduction of a few representative newspaper clippings extolling his virtues, and an embossed announcement down one side of the stationary that the letter was from the "Offices of the Light-Heavyweight Champion" (17).

Moore had become Ali's first trainer after the 1960 Olympics. After Ali was unable to conform to the working ethics of Moore (Moore ran his camp like a drill instructor, having Ali clean latrines, etc.), Ali left for Miami to fight under Angelo Dundee. In 1962, Ali entered the ring against his former mentor. However, before the actual fight, both participated in a very unprecedented event. Both were invited to appear in a thirty-minute televised program entitled,

"The Great Debate." Contrell described this verbal match-up:

The two most loquacious fighters of our time were locked in oral combat. Moore was unrivaled as boxing's Methuselah. Modestly adorned about the neck with a medal inscribed "I'm the Greatest," $\mathrm{Mr}$. Clay led off the discussion by explaining in his free-and-easy iambic pentameter why the great indestructible Moore must fall in four. Moore retaliated, "The only way I'll fall, Cassius, is by tripping over your prostrate form." (82-3)

It continued:

CLAY: If I lose, I'm going to crawl across the ring and kiss your feet. Then I'll leave the country. (This rhetoric would be a staple of Ali's normative mode of performance, especially during promotion in the seventies against Frazier, Foreman and Norton.)

MOORE: Don't humble yourself. Our country's depending on its youth. Really, I don't see how you can stand yourself. I am a speaker, not a rabble-rouser. I'm a conversationalist, you're a shouter.

Moore's clarification between what he was and what Ali was demonstrated that the norm of the boxer could be deconstructed. He and Ali could estrange themselves from the role of the prizefighter by using the voice in 
performance. Yet, this did not necessarily undermind the performing code of the boxer. Voice had to be used primarily in the fashion that would provoke the loudest response. In other words, being a speaker, as in Moore's case did not seriously foster any change in the public's perception. What did was Ali's big mouth; he was a rabble-rouser, a shouter, as Moore indicated. People became aware of Ali precisely because he was loud. Moore spoke, but softly, and not enough to generate a response.

Tom Wolfe, in his article, "The Marvelous Mouth," examined Moore's and Robinson's marginal success as "showmen" in relation to Ali's. He wrote:

It may not seem like much to cynics on the outside that a fighter should size up the fight business as show business, but damned few before Cassius Clay ever did it. Sugar Ray Robinson and Archie Moore, the two fighters whom Cassius admires most, became showmen and bosses of the sort Cassius aspires to be, but they had no master plan, even though they were both bright, like Cassius. (193)

\section{Floyd Patterson.}

A good example of the "voiceless" boxer is Floyd Patterson, heavyweight champion from 1956 to 1962. Patterson, a quiet man of undiscernible strength out of the ring, had his set image and never really wavered from it. His was not the "brute" or "menace" identity, say of a Liston, but rather one of complicated silence and stoic acquiescence, who like his predecessors (Marciano, Louis, and Dempsey), let the charismatic manager/trainer play the role of "selling" the champ and the fight to the sport media and general public. In one memorable film sequence from The Stylists: The Heavyweights (HBO, 1990), concerning the upcoming rubber match with Ingmar Johansson, Patterson can be seen sitting at a press table with his manager, Cus D'Amato, standing directly 
adjacent to his prodigy. Patterson is answering questions from the media. He is courteous, soft-spoken, smiling, and unobtrusive. There is nothing really remarkable about this press gathering. It differs from nothing that the public has witnessed thus far. It possessed nothing out of the ordinary; it was simple, complete and "normal." Patterson was effectivley playing a role when he conformed to the norm of the fighter; an image of manly silence, perhaps a nod here or there, a shake of the fist now and then. To illustrate this type of conformity to the role of the boxer, Patterson, while training for his upcoming fight with Ali, was invaded by Ali. When asked by Ali, "How are you going to beat me, you're smaller, slower and older?" Patterson's response for the cameras was a shake of his fist (The Championship). This was the norm of the prizefighter.

Furthermore, as Floyd Patterson confirmed, the professional boxer has always been subjugated and identified as a secondary citizen, the dumb brute who dared not open his mouth for fear of weakening his silent masculine image. Patterson wrote:

The prizefighter in America is not supposed to shout off his mouth about politics, particularly when his views oppose the Government's and might influence many among the working classes who follow boxing. The prizefighter is considered by most people to be merely a tough, insensitive man, a dumb, half-naked entertainer wearing a muzzled mouthpiece. He is supposed to stick to his trade---fighting and keeping his mouth shut and pretending that he hates his opponent. ("In Defense of Cassius Clay," 55)

Ironically, when he wrote this, Patterson was not conforming to the norm; instead, he was deconstructing that norm. Interestingly enough, it was he who from 1956 through 1962 virtually set 
the normative standard of the silent and historically media-shy pugilist who let his manager, Cus D'Amato, set the tone for the boxing establishment. Morrison, in his "Boxing's Most Misunderstood Champion," wrote:

That Patterson has failed to fully exploit the immense potentialities for profit and publicity residing in ownership of the heavyweight title is an established fact which has mystified large uninstructed regions of the boxing world and brought heavy, though generally unjustified, censure by boxing writers and laymen alike down on the heads of the champion and his manager, Cus D'Amato. (77)

To give the reader some indication how the public perceived Patterson and boxing in the in 1959, Morrison indicates that Patterson, "as of this date continues to be the least known and understood heavyweight titleholder in history. In the U.S. and abroad, (he) has been sneeringly and patronizingly referred to as a 'phantom champion,' a 'reluctant champion,' and 'the forgotten man of boxing'" (77). This reference helped develop the general mood and stoic ambiance that professional boxing and the populace seemed forced to endure. ${ }^{5}$ His shy and quiet persona enhanced and defined a clear and normative performer code for the professional boxer. Charles "Sonny" Liston would extend this prevalent mode of the image of the fighting man much further.

\section{Television: The Perfect Medium}

In youthful America at the turn of the century, and even into the midcentury mark (inclusive to Moore and Robinson), bigotry and racism overwhelmed and subverted the black athlete's rise to success and greatness (recall Johnson's forced exit on a bogus conviction charge). During Johnson's reign the civil rights movement was in its infancy, quite the contrary when Ali's 
reign took hold, as Sammons explained:

By the mid- to late 1950's, Blacks had assumed a more militant position, combining legal tactics with boycotts and Ghandiinspired civil disobediences.... Blacks proudly marched down the road of activism, joined by a number of athletes, especially boxers.... By the early sixties the country was certainly in turmoil, if not on the verge of revolution. (190-1)

In the midst of this monumental movement and culturally significant time stood Ali; it was fifty years since a black heavyweight voiced his opinion and extolled his own loquacious and outrageous virtues.

In 1956, the popular yet "rugged, aggressive, and unstylistic" heavyweight champion, Rocky Marciano, retired undefeated after forty-nine bouts (Sammons, 151). Over the next seven years the title would change hands five times. From the time he became heavyweight champion when he defeated forty-two year old Moore (who had previously challenged Marciano the previous year) in five rounds for the vacant title (Sugar, 64), Patterson began to be stigmatized from the liberal black community as an "accomandationist" [sic]. As Sammons explains, when, at a time of upheaval and potentiality for change in the black community and general popularity, Patterson chose "to follow in the tradition of Joe Louis, becoming a relatively popular champion despite the dreadful quality of his opponents" (192).

Patterson's passive and obliging manner out of the ring generated a strong negative reaction from the militant black community, who were proudly marching down the road of activism. Many black Americans were tired of "black athletes being used to cover up the transgressions of a repressive system" (191). He was not progressive enough to be representative as a role model for the more astute and militant blacks. Liston was no better. He was 
black and he spoke for no one but himself. His public image of menace was directed at blacks and white. Likewise, his alleged link to organized crime did not enhance the strong, positive stand black America was trying to sustain. When Patterson and Liston met in 1962, the new breed of blacks struggling for social equality and economic progress believed that the real fight was being waged in the streets, not in the ring (Sammons, 192).

Alongside the burgeoning civil rights movement toward social and cultural acceptance in America, the mass medium of television was in full blossom and affecting almost everything, from commercial enterprises to presidential candidates. The timing was perfect for an athlete to take advantage of the now ever-present camera and enter every household to extol his reasons why he should be the next heavyweight champion of the world. Ali was ideal for this emerging social, cultural and political phenomenon now at its zenith in America. The early 1960's was the era of being seen, whereas during the eras of Louis, Robinson, Moore and even Marciano being heard, via radio, was the only venue available.

Television became an instrument of persuasion, not only for the civil rights movement and their consciousness-raising efforts, but also for Ali and his loud declaration and image of the boxer: "I don't have to be what you want me to be, I'm free to be who I want" (Lipsyte, 84). And Ali wanted to be heavyweight champion of the world, and in order to achieve that he realized it had to be as a showrinan with an attitude and plan. The key was voice.

Interestingly enough, Ali, in front of microphone and camera at the ListonClay post-fight press review, proclaimed he was through talking, that his mouth had done its job: getting the mass media to promote and publicize his 
estrangement onto the paying public. Ali understood the limits of mass media, and the significance of television. He played his cards well; the public bought his act because his act was fresh, exciting, attractive and, most importantly, entertaining. Moreover, the media machine was helping shape his image.

In a 1963 Newsweek article, a short yet revealing passage described the celebrity television had created for Ali and his underlying motive. The article read:

What almost everyone ignores in discussing contender Cassius Clay is that he is a figment of his own imagination. When he turned professional after winning the 1960 Olympic lightheavyweigint championship, he frankly decided that he was going to be a big-mouthed braggart. "I'm gonna talk and talk and talk," he said, "and all the people are going to know my name." Cassius Clay has kept the faith. Clay has set world records for marathon talking, running feuds, pumping egotism, and bad poetry. (93)

The salient point here is that Ali's image, however constructed, had been seen in many households. People became aware of him through his well-publicized mouth. Aspects of American culture previously uninterested in boxing had become conscious of it to an extent that was unprecedented. Ali was creating a new audience. He not only challenged but he broke the norm of the boxer.

Although the public recognized their faces, Marciano, Liston and Patterson were really only seen speaking when asked questions about upcoming fights; their voices were hardly indicative of their fighting and public image. But with Ali, the connection with the mass media was immediate and successful. 


\section{Chapter 3}

\section{Voice as an Element of Performance Code}

Introduction

This chapter will introduce the notion of voice in performance and how it developed into a major element of Ali's performance code and, subsequently, challenged the average perception of the professional boxer. Instrumental in this was Ali's particular use of voice as a source of power, both physically and psychologically. Also included in this chapter will be a structural analysis made of Ali's signifying practices in relation to language and the submission of his opponents. A key to this elaboration will be the inclusion of Ali's film Aka: Cassius Clay, in which he and Cus D'Amato confront one another on stage in a debate.

Lastly, this chapter will introduce Sonny Liston and his role as recipient to Ali's "madness" and psychological tactics prior to and during their historic confrontation.

\section{Language and the Destruction of Opponents}

Ego, subject, and language are all important aspects in the study of signs, also referred to as semiology. Semiotics as a theory is much like what Ali's performance persona exemplified: both are self-conscious and both have, at the core of their respective texts, the involvement and implementation of language. In Ali's case, the voice unleashed "an unsettling ego," and as Sammons pointed out "polarized the boxing community and the public at large" (181). His blinding faith in himself and his need to express this greatness inspired either adoration or contempt. His ego was one that could not be 
ignored or denied, especially with professional boxing in such a static and sluggish state in the early 1960's. Significantly, Ali's claim that he was "the Greatest," even though he was not champion, did result in increased ticket sales (181). In London, before his battle with Liston, Ali fought Henry Cooper. As was customary, each fighter entered the ring one after the other, with Ali entering last. He made his entrance with a wave of hisses and boos from the spectators, after they realized Ali was wearing, both a robe with the words "the Greatest" emblazoned on the back, and a crown on his head.

These antics, as well as his vocal harangues, were signifying practices that formed a language that is different from other heavyweight boxers. One of these other heavyweight boxers was Charles "Sonny" Liston. It will be Liston (and George Foreman) who will be extensively linked to Ali and Ali's successful use of language in performance. Not even Patterson was more indicative of the silent and stoic "image" of the brute boxer than Liston. Liston, after his two quick destructions over Patterson in 1962, represented in the ring such a perception of mean masculinity and powerful aggression, that a victory over him would surely have signified an amazing accomplishment. To challenge or change popular culture's normative perception, Liston was the kind of opposition that Ali needed to confront and overcome.

Liston's "language" contained no voice or silly antics; his performer code is that of the average boxer's code: stoicism and intimidation. Liston's ego was based on excessive intimidation generally instilled by a cold long stare at his opponent. Ali's ego was constructed on the basis of voice and psychological prowess. Norman Mailer discussed the relation that ego has in terms of the psyche of Ali. He wrote: 
Ego! It is the great word of the Twentieth Century. If there is a single word our century has added to the potentiality of language, it is ego. Everything we have done in this century, from monumental feats to nightmares of human destruction, has been a function of that extraordinary state of the psyche which gives us authority to declare we are sure of ourselves when we are not. Muhammad Ali begins with the most unsettling ego of all. Having command of the stage, he never pretends to step back and relinquish his place to other actors---like a six foot parrot, he keeps screaming at you that he is the center of the stage. "Come here and get me, fool," he says. "You can't, because you don't know who I am. You don't know where I am. I'm human intelligence and you don't even know if I'm good or evil." This has been his essential message to America all these years. He is America's Greatest Ego. He is also the swiftest embodiment of human intelligence. Yet, he is the very spirit of the Twentieth Century---he is the prince of mass man and the media. (Italics mine, 3-4)

In his effort to isolate and discuss Ali's psyche and ego, Mailer has inadvertently described the power of language. He infers that language assumes intelligence, and since Ali does not merely speak but rather screams profoundly and loudly at his opponent, he creates an unsettling yet highly intelligent image of power. It is Ali's ability to do more than just converse with his opponent that makes his language so unusual. He employs a distinct rhetoric, for which Mailer has identified: he screams at you. Even worse, he screams at you while he hits you and then he dances away so you are unable to hit him. This is a specific strategy that Ali employs to unsettle his listener. "Is that all you got, chump? or "that's a sissy punch!" take on a new effect, especially when you are being hit and yelled at at the same time. The following section will describe Ali's peculiar ways of speaking and what strategies he used for speaking. 


\section{Rhetoric and Strategy.}

Insults, boasts and claims, as Mailer's passage exemplified, were all aspects of Ali's rhetoric and strategy. However, what Mailer and other previous sources have overlooked in their study and approach to Ali were his peculiar ways of speaking in performance. For instance, Ali had horrible diction. He was constantly using contractions and double negatives. In the film Aka: Cassius Clay, Ali is asked, in a staged debate with boxing trainer and manager, Cus D'Amato, "How would you be able to defend yourself against the great hitting power of Joe Louis"? Ali, looking into the camera, insists that "Louis may be able to hit hard, but it don't mean nothin' if he cain't find nothin' to hit!"

A better example of Ali's use of the English language, especially his constant tendency in not closing or finishing an active participle with its final letter or consonant sound, can be seen in the following passage. Words such as "gonna," and "slow-movin'," are his most often coined colloquialisms, along with his usual contractions, "I'm," you're" and "let'em."

Look, you're tellin' me that Joe Louis would have knocked me out? How would Joe Louis knock me out when this is Joe Louis: (Ali mimics the flat-footed, one dimensional boxing style of Louis) What's he gonna do while I'm jumping and flipping and moving, pop-pop? I'm sticking and doing my little shuffle, pop. Andhow would Joe Louis---Now don't say that I can do this for a minute, because I can keep this up fifteen rounds, ten rounds, three minutes a round. Now, how is Joe Louis gonna get to me? I just can't see slow-movin' Joe Louis who was shorter than I am, fought (at a) lighter weight than I do, and not half as fast with his feet or hands. How could Joe Louis knock me out? Would I just quit dancing that night and stand there and let'em hit me? If he hits me once, he won't hit me the second time. (Aka: Cassius Clay)

In spite of this shaky syntax, Ali's monologue is an effective moving narration. It 
pops and jumps quickly and breathlessly, always in the active present. He is consistently boasting that he is "doing," that there is nothing passive about him or his performance. In fact, throughout the passage, Ali is moving, circling, dancing, or shuffling. In relation to this non-stop movement, his rhetoric is virtually identical. It is a rat-ta-tat verbal ambush filled with active present participles, such as jumping, flipping, moving, sticking, popping, and dancing. His performance is an "ing"-filled act; it is never passive. This may be the reason Ali uses "I'm" and other "incorrect" contractions in his speech; his thought processes are in such an active and vibrant state, he does not have the time to peel the words apart for fear of losing his next thought.

Furthermore, Ali asks questions of his audience, rhetorical questions, questions that appear to be almost insulting for him even to begin to answer. His disbelief and incredulousness are very evident, especially when he begins a question with, "Look, you're tellin' me....?"; "And, what's he gonna do...?"; or "Now, how is he...?" Towards the end of his speech, Ali even expresses some harsh sarcasm at the thought of Louis knocking him out: "Would I just quit dancing that night and stand there and let'em hit me?"

It is fascinating, when watching this film footage, how Ali effectively explains his fighting strategy. Although he was not well educated, Ali expressed his intelligence through his street-smarts. His dialect and style of talking were hip and fashionable with how the young-on-the-street were inter-relating. It was definitely in the present tense as can be seen in his use of "Now," "I'm," "I do," or "I can." His was not a stale, stiff or stoic quality. It was happening; it was now, fast, haphazardly so. His rhetoric was laced, as he himself described, with a "pop-pop" nature. 
Another element of peculiarity in Ali's manner of speech concerns his abrupt shifts of his thought processes, specifically, during the pre-fight gatherings. He would begin a thought and then not carry it through; he would skip rather to another thought. This jump would be fast and loud, as exemplified in the press conference announcing his upcoming fight with Liston. Ali, in a span of maybe fifteen seconds, from the time he enters the room to the time he finally sits down alongside Liston, spews off some ten or eleven different ideas. He begins:

The annihilation is on! Let's get it on! I'll whoop you now! Floyd Patterson was so scared he couldn't even walk. Man, I ain't scared, I'll come to your house at two o'clock in the morning lookin' for you. I ain't scared of nobody. It's gonna take a good man to whup me! You can look at me l'm loaded with confidence! I can't be beat. I had a hundred eighty amateur fights, twenty-two professional fights and I'm pretty as a girl. (The Championship)

It is these abrupt shifts in statements that are significant. He starts talking about one thing, then goes to another. It seems he has two distinct audiences that he is trying to reach: Liston, his fighting opponent, and this media machine. Ali wants somebody else to hear him speak besides his fighting opponent. So, he adopts a rhetoric that allows him to be heard by more than just his opponent. Part of that rhetoric is his invention of words such as "flustration," "bum," "ghettowhopper," and "onliest." He invents words, he makes the language his own. But he also has these shifts, these jumps from one idea to the next, which would indicate, if you are listening to him, an unpredictable avenue of strategy. You do not know where he is going with his idea or thought process. He engages the audience, not just his opponent, in an unsettling yet provocative rhetoric. He makes it seem easy, that he goes from one thing to the next; thoughts and 
words are just tossed away. Moreover, he is not focused on a theme to which we have access or understanding. It is like a punch, rat-ta-tat, "pop-pop," coming from the right or left, above or below. It is difficult to guard against or even see approaching, as Wolfe effectively noted:

He has a whole act about it, beginning with a pantomime of him shoving open the swinging doors and standing there bowlegged, like a beer delivery man. The he plays the part of the crowd falling back and whispering, "It's Cassius Clay, Cassius Clay, Cassius Clay." Then he plays the part of an effete Las Vegas hipster at the bar with his back turned, suddenly freezing in middrink, as the hush falls over the joint, and sliding his eyes around to see the duel. Then he plays the part of Cassius Clay stalking across the floor with his finger pointed at Sonny Liston and saying, "You big ugly bear, you big ugly bear." ("Marvelous Mouth," 146)

This aspect of Ali's rhetoric is made more unsettling when it is put in relation with his non-speaking action. In other words, what his body is doing while he is speaking.

As he enters the room for the press conference, Ali is nearly running as he "slaps skin" with everyone in front of him. As he shouts, "The annihilation is on!" he gives the impression that he is at play, excitable, child-like; there is a rapidity, a swiftness to all his gestures. But they are not long, smooth movements. Rather, they are clipped, sharp, and tense. Much like his rhetoric, Ali's bodily action is disturbing. He jumps from one body position to another. He begins to sit down but then he changes his mind. He starts pointing his index finger in tune with the swaying up and down of his right arm as he screams at Liston, "Man, I ain't scared!. I'll come to your house at two o'clock in the mornin' lookin' for you." Then he shuffles about facing the cameras with his chin raised high, "I ain't scared of nobody." His non-speaking part of his 
performance is consistent with his style of discourse: move, move, pop, pop, keep it moving, never sit still, confuse and energize. When he finally sits down in repose, his body and voice have strategically unsettled many in the room; specifically, his fighting opponent, Liston. (Liston's reaction will be discussed much more fully in Chapter Five, "Voice and Sexual Identity.")

Henry Korn made the comment that Ali "built a career on his gift of language. (And) there is no doubt that Ali would have become champion without a voice" (96). However, George Sullivan believed that the above assertion is not accurate. He noted:

Clay wagged a finger under Liston's shiny nose and announced to him, "I want you, Liston!"---This was typical of the tactics that Clay would use over the next eighteen months to bewilder and anger Liston. Eventually, they would help him win the championship. (Italics mine, 46)

Furthermore, it is my contention that it was because of, and not in spite of, Ali's "gift of language" within and outside of the ring that his dominance and success were assured. What played an important role in the success achieved by Ali was his ability "to bewilder and anger" his adversary. Although riddled with poor syntax and loud double negatives, the following short monologue describes Ali's own sense of effectiveness in bewildering and frustrating an opponent, particularly how dominant a role voice becomes:

There is no way in the world for a man that don't have no footwork [sic] to catch me, even a welterweight. (To the cameraman) Keep your camera moving because I'm kinda fast....A lightweight's not this fast. Plus, I'm talking to him, I'm making him flustrated [sic]: "C'mon chump, you're not no champ. Look at you, you're losing, you've lost three rounds already. C'mon now, l've hit you four times." This worries a man. (Aka: Cassius Clay)

Again, one can see the abrupt shifts in ideas expressed and the hurried 
intensity in his rhetoric. Similar to most of his taped interviews, Ali performs a kind of narrative dance. He is perpetual movement and noise.

As far as boxing strategy is concerned, Ali is simply a master at defensive boxing, knowing hitting power means nothing if one can not find anything to hit. Never known for his one-punch knockout ability, Ali relied on speed rather than power. Tiring out his opponent physically and psychologically was his operative means of destruction. Julius Menendez (U. S. Olympic boxing coach in 1960), from a personal interview, said the thing that was good about Ali, "was that he had a pace that most boxers could not follow; they could not stick with it. He'd set a pace for them that would make them tired, and then they would become putty in his hands." 6

Yet, the worry, the "flustration," the bewilderment and the anger he forced upon his adversaries were not so simple a task to execute. It is the constant barrage of noise, of nagging insults and incessant rantings, that is key to his unique stratagem for success in the ring. Plimpton pointed out that no one was better at bringing psychological pressures to bear than Ali. Many people believed that "Liston's ineptitude in their two fights was a result of the constant, nagging awareness that Ali's strange looney thought process was absorbed by Liston" (304). What must have been most debilitating to Liston was the constant ranting and badgering from this challenger whose most difficult fights to date were against a 42 year old Archie Moore, a tough journeyman named Doug Jones, and a plodding yet gallant Henry Cooper. These victories were hardly indicative of a number one contender challenging for the belt. Liston was the heavyweight champion of the world. Who was this young, untested, loud mouth stealing his thunder? More than that, Liston was not receiving any 
kind of respect from Ali (Sammons, 181).

\section{Ali as Debater.}

With the power of voice in full operative strength in a ring or on a stage, the potential for debate, change and complexity becomes very accessible and highly identifiable. In the film, Aka: Cassius Clay, there is an engaging and lengthy debate between Ali and D'Amato that takes on the atmosphere of two actors in rehearsal, trying different looks and stage actions, but still allowing their characters to express a generous degree of authenticity. The debate involves the imaginary and historical encounter between Louis and Ali, with D'Amato and Ali in profile, eye to eye, center stage. What significantly stands out from this acting exhibition is the overwhelming impression one receives from Ali's natural gifts and strengths as a performer and debater. He speaks his lines and performs his role with certitude, veracity and articulateness. It is quite strange that it does not occur to the observer to question the plausibility of this athlete invading a different established mode of performance. In fact, the observer, lost in the intensity of the debate, is easily able to overlook the obvious, that one of the participants is a boxer, and, instead, finds himself convinced of this performer's ability as an actor. There is, at no time, the realization to ask: What is Ali doing speaking lines on a stage? What does this boxer think he is doing "talking" outside his normal speaking turf, the ring? It is a natural setting for Ali. His mouth seems to have transcended different performance areas.

Moreover, this verbal combat between Ali and D'Amato becomes a case study in ideology, where physical combat, with which both the two performers 
are indeed familiar, is now shifted to another mode of performance: theatre. The vocal action on stage is ideologically analogous to the physical action that is performed within the stage-like ring. The debate, involving a man who has estranged himself from the normative atavism of the boxing ring, seems all the more poignant and significant. One gets the idea that fighting and acting are modes of performance not too distant or dissimilar from one another, at least when Ali excels and succeeds in both.

Another example of Ali's debating skills can be seen in the film, The Championship. As part of the promotional hype for their forthcoming bout, both Ali and Liston participated in a "staged" verbal encounter, a mock debate between fighters in their boxing attire and from their respective training quarters via quick-edited camera work (which was shoddy). Each performer had a hand mic and an empty space (a stage?) on which to perform his role as antagonist to the other. What the camera captures is Liston's inability to articulate and even to remember his short lines, as the camera (again, through shoddy editing) revolves from one gym to the other. Ali is able to spout out bombastic and selfrighteous poetical forecasts. Liston is reduced to mumbling and stumbling through his lines to the point of not making logical sense as to the content of his words. The observer is left with the impression of Liston: a great big hulk of a mumbling man, inarticulate yet still intimidating and imposing. It is interesting to note, as far as "image" and "perceptions" go, it was obvious to the public that Liston did nothing to create an atmosphere of fun or innovation. He rarely spoke to white reporters and seldom was able to communicate a complete, grammatically correct statement in front of a mic or camera. It was also obvious that Liston chose menace and intimidation for his "image" perhaps because 
illiteracy and a life of violent behavior prevented him from doing otherwise.

In the early 1960's, Ali's mercurial rise from Olympic "athlete" to popular "performer" was established by his ability to articulate an image that was not based on stoicism but escapism. His performer code had differentiated itself from the normal performer code of the boxer. He achieved this estrangement by successfully performing in different contexts such as in the preceding examples with Ali debating D'Amato and outgunning Liston. These purely vocal and nonphysical encounters defined a significant de-constructive element of Ali's estranging performer code.

\section{Ali as Hypnotist.}

In analyzing this historic fight between Liston and Ali, a fascinating notion arises concerning the generative and operative powers of Ali's voice in (and out of) the ring. In short, Liston becomes "mesmerized." It is the contention of this thesis to present the view that what happened to Liston in the ring against Ali extended beyond merely a simple sporting psyche-out, or a ruptured tear of a shoulder muscle. ${ }^{7}$ Instead, Liston was put under a kind of "hypnotic" trance, by the power wielded by Ali's performance persona, particularly his vocal forays. Liston was voiced-out. The evidence is the fight itself.

As Steve Ellis called the action, the observer can witness Liston's trancelike, "flustrated" and psychologically-beaten performance. Ellis commented:

In round six we note Sonny's flat-footed stance most of the time. Easy target! Easy! Clay with a variety of punches, with all them combinations, putting punches together; that's his strong point. With slightly less than a minute into the sixth round, the champion has slowed down. Sonny can't seem to slip or knock down that jab effectively. Cassius! Cassius throws them from all angles, very 
tricky left lead and left jab. (The Championship)

Basically, Liston was unable to react fast enough. He lost focus and concentration, and, like a rabbit blinded by a flashlight, he froze. When it became apparent that he was unable set up standard combinations (lead jab, right cross), he began to execute a one-dimensional offense: plod forward and hope Ali is in front of him. He missed wildly and began to lose steam and confidence. Speed was the next thing to fade; he could not catch his elusive prey. If these descriptive weaknesses on the part of Liston are the profound result of Ali's "mouth" getting to him, then this revelation creates a complex and compelling situation. It showed that the normative power of the boxer has to contend now with an estranged mode of power in performance, that being wielded through language.

Concerning this issue of hypnosis and its relevance to this study, Richard Harland wrote:

Hypnosis, as used for psychological purposes, reaches down to the underlying levels of mind below the unconscious...Twentieth century hypnotists no longer believe that concentration-on-anobject is in itself the crucial factor... What is crucial: the words of the hypnotist [italics mine]. Hypnosis, it is now believed, works primarily by verbal suggestion; and there is a continuum between hypnotic trance and working verbal suggestion. The Unconscious that hypnosis reveals is an Unconscious that answers to Language. In so far as the Unconscious answers to language, language acquires remarkable powers [italics mine]. (Superstructuralism, 34-5)

Perhaps the link between hypnosis and Ali is made out of context. But if "language acquires remarkable powers," then the actions (our theoretical contention) of Ali---the whispering as he clinched inside into the ear of Liston 
(Foreman will be the recipient of this as well), or the proclaiming, as he finished a slashing combination to the face of Liston, "You can't punch! You're a sissy! You got nothing, and you're losing the fight!"---effectively take on a more generative and operative role in ring contests.

Certainly, Liston was not only entranced by the verbal barrage Ali was displaying, but, most assuredly, he was awed by the challenger's speed and elusiveness. Liston had never been in the ring with a boxer so quick and so big. Patterson, Liston's only previous recognized opponent, was flattened in the first round of their first fight. Then, as if once was not enough, Liston, again, demolished Patterson in the first round of their return match. ${ }^{8}$ With this mind, it is not difficult to fault Liston for having come to the Ali fight overconfident, unfamiliarized and unaware of his challenger's devasting potential. But the outcome of their first ring battle was determined far before they even stepped into the ring.

Before their first encounter, Contrell cited Joe Louis's opinion on the Liston-Clay relationship. Louis said, "Cassius is a master of psychological warfare. He irritates and disturbs, and whatever Sonny says, I think Clay bothers him" (151). Ali had begun "disturbing" the champion as early as 1962 by referring to him as a "that big, ugly bear," and by upstaging Liston with an impromptu entrance into the ring after Liston's second victory over Patterson. Ali was disrespecting the sacred space of the champion. More important, he was providing a most needed injection of excitement.

Illiteracy and Liston.

As a subject for the challenger's "hypnotic" powers, Liston was indeed 
tailor made. Dr. Joseph Blonstein suggested, in an exclusive interview from a London Daily Herald article, ${ }^{8}$ in Liston we were dealing with "a man of low intelligence who would naturally be rattled by these antics." Here, Blonstein was not only referring to the self-conscious and vocal antics displayed during the fight itself, but more specifically to those histrionics at the ceremonial weighin on the morning of the fight. Similarly, Sammons concurred that Liston was illiterate, having had no schooling or direction. According to Sammons, Liston, if given a check, would not be able to determine its amount (180). In addition, Blonstein raised several very significant questions concerning the boxers as beings of "low intelligence." Did Ali fight only dim-witted opponents? And was Liston a "bum" like the "bums" Louis fought? Was Ali only successful because he opposed foes who were tough but stupid, and therefore capable of being manipulated? Most importantly, what if Ali had entered the ring against another Ali? Could Ali have successfully defeated another boxer who was able to talk and fight as well as he? Could Ali have disposed of another boxer who was his intellectual superior? These issues also add further complexity to the rationale of the performing code of the boxer. This is important because boxing would certainly be perceived differently if the norm of the boxer was one in which voice and intelligence were normal elements. In other words, if Liston, not Ali, was the estrangement.

Blonstein, as medical officer in charge of boxers at the 1960 Olympic Games, had examined Ali in Rome, and, thus, was familiar with the physical and mental attitudes of athletes before competition. His comments revealed a most significant impression:

I would not have bet on Liston after seeing the pictures of the 
weigh-in where Clay had staged his ranting, hysterical act. Liston's eyes were wide, staring and perplexed. The eyes of a frightened animal. It was Liston, not Clay, who was frightened ...Clay is a magnificent athlete. His pulse rate is slow, his blood pressure is low. His slight reaction to reflex tests showed what perfect control he has of every muscle. He is $100 \%$ in control of himself, astute and sharp and unflappable. All the ballyhoo of the weigh-in was planned to intimidate Liston, (who as) a slow-witted fighter is perhaps more disturbed by delays and commotion before the contest than a man of quicker wits. (Man of Destiny, 153)

This passage helps substantiate a most fascinating scenario concerning psychology, "hypnosis" and "verbal suggestion" in relation to physical combat. An old adage in professional boxing is "hit the body and the head will fall." With Ali and his newly created performer code, a modified play on that adage would probably go something like: "psychological punishment through voice and the mind will fall." This was what occurred when Liston met Ali in the ring. Liston had gone through, by fight time, a great deal of psychological punishment from Ali, and was quite susceptible to Ali's verbal suggestions. Enough so, Liston was resigned to quitting on his stool at the end of the seventh round.

According to Blonstein, and reinforced by Contrell, Liston and Ali were engaged in more than just a simple and routine match. Rather, it represented a phenomenally significant psychological and cultural ring encounter signified by the ideological scenario of the "bully" and the "fool." Taken further this bout pitted a mixed-up hoodlum of simple mentality (slow-witted) against a complex, hyper-emotional egotist (quick-witted) resulting not only in a victory for Ali, but also in a radical shift in the manner by which boxing would be perceived. Boxing, like wrestling or football, is associated with a "democratic" ideology that affects and establishes our particular perceptions regarding performance- 
oriented and combative mediums. This Liston-Clay performance contained an essential aspect of this ideological symbolism. Both Liston and Ali were cast in roles of high moral dilemma and drama, and it was with Ali's "fighting act," which imposed "voice," that proved to be the superior physical catalyst.

\section{Death, Madness and Escapism}

To fully interpret the significance of the Liston-Clay ceremonial weigh-in in relation to Ali's "master plan" and his psychological warfare, one must experience a taste of the atmosphere that existed at the time. In the year before Clay-Liston I, there had been two-boxing related deaths. Mailer, in "Ten Thousand Words a Minute," described the fight between Emile Griffith and Benny Paret in 1962. In an off-ring performance, not too dissimilar from the kind of off-ring performance that was just beginning to be a part of Ali's "act" (loud, ecstatic, confrontational, "out-of-control," and very excitable), the two fighters, at their weigh-in for the World Welterweight Championship, immediately developed a great and seriously intense animosity towards one another. Paret had made some undignified references to Griffith's body and clothing, culminating in calling Griffith a "maracon," which in its English translation refers to a person who is homosexual. That night Griffith "killed" Paret in the ring. The fight itself was brutal with both combatants giving and taking a great deal of punishment. It was not until the twelfth round (scheduled for fifteen) that Griffith caught Paret. Mailer's account is as follows:

Paret got trapped in a corner. Trying to duck away, his left arm and his head became entangled on the wrong side of the rope. Griffith was in like a cat ready to rip the life out of a huge boxed rat. He hit him eighteen right hands in a row, an act which took perhaps three or four seconds, Griffith making a pent-up whimpering sound all 
the while he attacked, the right hand whipping like a piston rod which has broken through the crankcase, or like a baseball bat demolishing a pumpkin. I was hypnotized. I had never seen one man hit another so hard and so many times. (115)

Besides the Griffith-Paret tragedy, a year later, Sugar Ramos and Davy Moore engaged in battle for Moore's featherweight title. The end came with Moore being knocked-out and never regaining consciousness. In Beyond the Ring, Sammons stäied:

When featherweight champion Davey Moore was killed the antics and ring artistry of Cassius Clay diverted my attention and society's from the tragedy. With his stunning knockout of Liston, even Clay's detractors had to agree that the loud-mouthed kid was doing more to elevate boxing to its mythical status as a "sweet science" than anyone ever had. (xiii)

Of the performance mode created by Ali, Angelo Dundee admitted in an interview from The Championship. "Let's face it---look at the fun this kid created, and fun is what makes you excel at what you do. If you don't have fun or make it fun, it turns ugly." In a very clear sense, Ali's "created" persona was one based on escapism for the spectator and psychological confusion for his opponent. The definitive example of this theatrical exhibition of escapism and confusion occurred at the official weigh-in. As Pacheco emphasized:

If the training was a rehearsal, then the weigh-in was a dress rehearsal for the plan the young Cassius Clay had in his mind. The serious citizens of the boxing establishment descended on the little boxing camp and they said to Clay: Stop all the playing around, stop all the nonsense, get serious and preserve the dignity of the weigh-in of the heavyweight championship of the world. (The Championship)

Ali did "agree to keep the dignity of the Heavyweight Championship intact." This action would be performed by having his "normal" mode of 
performance being quieted, if not completely silenced. In other words, Ali initially agreed to keep his big, Louisville mouth shut! Hence, he agreed to "estrange" himself from his normative role.

By acquiescing to "their" demands, Ali would be satisfying the White Establishment's hold and control on not only the institution of professional boxing but also every contracted participant. In short, "they" wanted him to keep his mouth shut, "like a proper champion," not like that renegade Jack Johnson, but like Joe Louis. However, this suggestion "to stop all the nonsense" was nothing less than the continuum of white-over black subjugation, and Ali would have none of that. He was not about to fight out the Joe Louis tradition in which, as Gerald Early pointed out, "He must be responsible, and he must acknowledge the larger white society whom he is forced to represent by virtue of his position" (1988a, 116). It cannot be over-emphasized that for Ali, his escapist, mad-cap, and loud-mouthed performing manner began with and came from his "marvelous mouth." Concerning his fighting success, his growing popularity, not to mention his profitable financial status, his mouth was extremely significant. It was the key to his act; it was the dominant sign to his estranged performer code. It was 1964 and white America would not put shackles on him, his livelihood, and especially not his mouth. The question was: would Ali be controlled?

\section{Control and "the Crazy Nigger."}

As a slight but no less significant tangent to the escapism and confusion aspect, it is important to raise the issue of racial protectionism. Historically, African-Americans are an oral people. They have also been forced to play various roles in order to survive. For them, control is key. Slavery was a form of 
control. From that institution, African-Americans were forced into putting on different faces as a survival tool, such as "the crazy nigger." Here, with this role, the black man would be left alone because he was deemed as crazy; everyone stayed away, for this boy was trouble. No one else followed him because he was bound to cause problems with the controllers, the slaveowners, unless he was providing economic gain. Ali was providing economic gain not only for the twelve white owners who he "belonged" to, but also for boxing in general.

However, the issue of control and power was prominant for Ali and within the Black community. Mentally, Ali could not be controlled. His mouth assured him of that. But it is important to note, that he did not put on a different face. The mold of the boxer, specifically, that of a black boxer, was easily identifiable: the Joe Louis, "good nigger" tradition. Black boxers like Moore and Patterson followed this because boxing was a White-dominated sport, and the rules were you did not show your true face. Ali broke that mold. He showed his true face which was based on an oral tradition, specifically, that African tradition of the story-teller, "the griot."

The idea that "it" just popped into his head, "I will talk and be outrageous and then become champion of the world," when he turned professional in 1960 is a significant misnomer. Within the Black community, it was not so unusual to find other blacks mastering the oral tongue like Ali. It was only when these others entered the white man's domain that they put on a different face. But not Ali. He could not be controlled. His role-playing was a strong proclamation: I do not care about following the rules and regulations like Moore, Patterson and Liston. I will show my true face. They do not control me (Walker). 


\section{The weigh-in.}

Murray Goodman, a closed-circuit promoter for the fight, said in an interview, "The weigh-in was a sham and Ali put on histrionics that were unbelievable" (The Championship). As Ali entered the room where the weighin was to take place an unthinkable and unprecedented event took place. He literally and figuratively (and historically) said "No!" to conventional standards and norms, and "Yes" to chaos and escapism. What Ali had done was change his mind to the agreement he had made earlier concerning the dignity of the fight game and so forth, and instead reverted back to his "normal" performing persona: his mouth was moving and his voice was screaming and his body was jumping. The stage was set for his act to begin:

In pranced a corps of teen-aged girls--."foxes," in Cassius" vocabulary---carrying signs that read: MOMMA, MOMMA, CAN WE FIGHT! Clay's eyes rolled. "This is my show! My show!" he raved. 'I'm ready to rumble! Ready to rumble! He began screaming and shouting and threatening Liston: "I'm here! I'm here with Sugar Ray! Joe Louis was flat-footed and Sonny Liston is flat-footed. Me and Sugar Ray are two pretty dancers! We can't possibly be beat! You' nothin'! You're a chump and a sucker! I'm gonna eat you up!" (Newsweek, 93-4)

As far as the boxing authorities' reaction to this mayhem, Ali was fined $\$ 2500$ by these "serious citizens of the boxing community." Even Sugar Ray Robinson, Ali's mentor, could not keep the brash challenger in line. Prior to their entrance into the Miami Convention Center, Robinson told Ali to keep his cool and do not make a scene. To this, Ali again agreed, until he walked through the doors of the arena. Then pandemonium ensued. Boxing had become a live theatrical peformance. There is film footage from several different sources that exposes the degree of chaos and hysteria Ali's act 
caused. One such film showed Robinson valiantly trying to hold Ali down and covering his mouth, but his efforts were futile.

Aside from this intense and crazed atmosphere, the Liston-Clay weigh-in exposed another element of unpredictability and excitement: the champion, Liston, caught by all available cameras, displayed a look of bewilderment. This is significant because Liston had never expressed anything other than stoicism; he had always been consistent in displaying the role of a cold, staring, and unemotional fighter. However, in this war of psychological attrition between he and Ali, Liston had been forced to blink. Moreover, recall what Blonstein stated earlier, that it was not the young contender who looked unsettled and frightened, but Liston.

It can be effectively determined, that from this point on, Liston was no longer, in the eyes of Ali, invincible or invulnerable. As Pacheco explained in an interview, Ali never once doubted his belief that he would beat Liston. In fact, Pacheco added that when he came on as Ali's personal physician, "( $\mathrm{He})$ was struck by (Ali's) athleticism, by his charisma, and by his blinding faith that he could not be beat" (The Championship). This is a significant aspect of Ali's mode of performance: a self-conscious and self-confident spirit of blinding belief in his own vast unlimitations.

Furthermore, Ali was savvy enough to realize that there were certain ways you fight certain fighters. Styles make fights. With Liston it was easy: confuse the bully and you take him out of his game plan. As Pacheco insisted, "It was all part of young Clay's master plan, to appear to be crazy and therefore render himself immune to Liston's bullying tactics" (The Championship). Even Milt Bailey, a second in Liston's corner said, "Sonny thought he (Ali) was crazy. 
Sonny had a violent side that everyone knew about. But Cassius was smart and clever and he could get under Liston's skin more so than anybody ever knew." Another second from Liston's corner, Willi Reddish, who had trained Liston, added, "That kid is crazy...Crazy like a fox" (Robinson, 343).

Another example that clearly showed the psychological prowess and theatrical skill of Ali was the explanation Dundee gave in an interview:

Liston didn't know what to expect. What came into play there: tough guys are afraid of guys who are a little goofy, guys who fly over the cuckoo's nest, those kind of guys. Tough guys don't know where to go with that. And he was a tough guy, Liston. So Liston's looking at (Clay) like this...and Clay is screaming and he's hollering! Dr. Robbins's taking his blood-pressure, saying: "Angelo your guy is scared to death. This guy's scared to death. He's scared. I ain't gonna make the fight go on." I'm listening to the guy and saying, "He's only playing, he's only playing. We're having a little fun here." (The Championship)

In viewing Ali's physical conduct from the time of his entrance until the commission doctor examined him, it is quite fascinating to realize that here was a staged performance whose motive was simple and direct: stir Liston, cause chaos, provide excitement, and become heavyweight champion of the world.

\section{Success in Madness.}

In the chapter, "An Individual and His Society," Wilson raised some fascinating possibilities concerning the nature of identity, "madness" and the power to control. It is not difficult to equate the individual named Oscar, a native on a Caribbean island, and Ali, for both are "practitioners of language," and both create, through their chosen livelihoods, a significant dilemma: "identity versus the problem of identity." In relation to Ali's madness as a successful 
aspect of his mode of performance, Wilson wrote, "I'm concerned to point out that when we call a man mad, we acknowledge that by the evidence of his behavior he has reached a point at which he is beyond our power to control. We submit to him, for he achieves a complete authority over us" (141). This was never more true than at the Liston-Clay weigh-in. Ali's behavior unleashed on Liston, so befuddled him, that Liston, as his look of bewilderment will attest, submitted to Ali's authority. Liston, the bigger, stronger, more intimidating figure lost the seemingly limitless "power to control." Liston had blinked in the psychological war of attrition, and in blinking gave up the power to assert his normal and expected fear-mongering tactics on Ali. It is my contention that through a sophisticated mode of performance whose catalyst was voice, Ali, for all intended purposes, had won the fight, here, at the weigh-in; he had usurped the belt from Liston literally before they stared each other down in the ring.

Pacheco concurred with this assessment when he wrote:

Remember Ali's explanation of his prefight weigh-in shenanigans? Why was his pressure so high? Why had he gone out of his way to look crazy? To make Sonny Liston think he was crazy. To spook him. To frighten him. Ali had won both fights (the rematch was a year after this first encounter) at the weigh-in. (A View From the Corner, 85)

Liston himself elaborated on Ali's "madness" in performance. After Liston-Clay II, Liston was summoned to answer some questions in regard to allegations that that fight may have been unethically served; a fix may have been on. When asked why he did not get up if he was indeed hurt (Liston had gone down about a minute into the fight following a quick right "anchor" punch), Liston responded:

Commissioner, Muhammad Ali is a crazy man. You can't tell what a crazy man is going to do. He was standing over me, Jersey Joe (Walcott, the referee) couldn't control him, and if I got up, I got to 
put one glove on the canvas to push myself up, and as soon as my knee clears the canvas Ali is going to be beating on me. The man is crazy, and I figured I ain't getting up til someone controls him. (Pacheco, 85)

Significantly, these passages from Liston expose a very crucial element within the Afro-American folklore that was briefly touched upon in the subsection "Control and "the Crazy Nigger." As Ethel Walker (lecturer at San Jose State University) points out, in the time of slavery, when the black man did not wish to follow what the white owner said, he went his own way; that of the way of the "crazy nigger." Everyone left him alone. He was very dangerous and unpredictable. Most importantly, he was not being controlled by anyone. Within the Black culture, the key has always been control. Similarly, when Ali invoked the characteristics of this "crazy nigger," it was, in effect, an effort to be in control. Also, his role-playing was providing a great deal of economic gain and media coverage, which was great for the sport. The white owners of professional boxing must have been both stunned and thrilled. Patterson, Liston and Moore had not provided such profitable escapism.

Ali's prophesy and declaration---"You must listen to me!"---though ridiculed and ignored by the mass media and the general public before the fight, became a display of bravado, confidence and control. Indeed, it demonstrated elements of profundity in his character. Quite difficult to fathom if not for hindsight, but Ali had instilled the fear of himself in Liston; he had forced Liston to listen and then deal with the debilitating effects of pandemonium in Liston's own mind. Certainly, it was too much for Liston. Ali explained the method of his madness:

One way or another, I made my poirit. I made Liston listen. And I'II do the same to him again or to anybody else I fight. The thing is, I 
bury them to a sizzle and they don't go in against me the same as against anybody else...At the weigh-in there I was, storming around, shouting hoarse, looking goggled-eyed. It was an act, and I was quieter than all the suckers feeling sorry for me...my finest piece of acting. It fooled everyone. (Contrell, 155)

Even Ali admits his madness is based on role-playing and forcing people to listen.

As a closure to this segment on Ali's success in madness as an element of his performer code, it is, perhaps, most appropriate, to establish once again just how identifiable Ali's major signifier, his mouth, was in the aftermath of his triumphant victory over Listen. Film footage to the actual closed-circuit broadcast showed Steve Ellis and Joe Louis trying to get to Ali in the ring. Ali could not be contained nor could he be controlled. It was the weigh-in revisited. It was a mob scene, and he was hysterical, overzealous and completely consistent to one who has told everyone what will happen, and it does, and no one had believed him. He was not listening to any questions being asked of him; instead, he was shaking his head, signifying with his glove up to his opened mouth, as if to say: this did it. When he did speak it was to every sports writer at ringside, at every disbeliever, pointing his finger, "I told you! ! I told you! I told you what I was going to do!" (According to Jacobs, from Ali: Skill, Guts, and Brains, there were only three journalists at ringside that gave Ali the nod!). He was being partially held by his entourage but he was ecstatic and uncontrollable, and he screamed into camera and fan alike, "I shook up the world! I am the greatest thing that ever lived! I'm so pretty! I don't have a mark on my face, and I upset Sonny Liston, and I just turned twenty-two! I must be the Greatest! I told the world!" Ellis, throughout this mayhem, had been trying to 
interject a question to the new champ. But he was unable to make any progress. Ali continued to signify; he was shaking his head "No!" and gesticulating with an ever-open mouth: "Here, look, this is it, this is what did it, this is what made Liston listen." Ali's mouth was perpetually open, effectively in tableau, and Ellis, still trying to say something, was again silenced by Ali's screeching and excitable behavior. Ali shook his head defiantly and shouted: "No! No! I shook up the world! I shook up the world! I shook up the world! I shook up the world! You must listen to me. You must now listen to me. I am the Greatest. I am the double Greatest. I can't be beat. I'm so pretty." This scene, captured in Ali: Skills, Guts and Brains, is a profound example of Ali's constructive power that elicited a new mode of weaponry for the fighting performer operating in performance.

Structuralist Richard Harland wrote of the ego and "individual selfhood" that:

If the loss of individual selfhood is the ultimate fear, then the confirmation of individual selfhood is the ultimate desire. In Lacanian psychoanalysis, this desire surmounts and wholly dominates over the supposedly "basic" needs of the organism. Instead of the Ego merely helping the Id to achieve satisfaction in a more rational way, the egotistical sense of being an individual self now produces its own thoroughly irrational kind of desire. Lacan demonstrates this new kind of desire specifically in relation to the language phase. (Superstructuralism, 39-40)

Ali's material objectives from the start were, naturally, fame and recognition. However, his major objective, with the inescapable success of his gifts in and out of the ring, was to establish a stronger, morally fundamental ambition. The ring and those conflicts resolved within concerned a struggle for "individual self-hood." For Ali, it was this "ultimate desire" to win in the ring by any means 
necessary (psychological punishment in particular), in full view of the public, regardless of controversy or unpopularity, that enhanced the expansion of the role of self and individuality in performance. If anything, Ali spoke to the public on behalf of his individuality, exclaiming a "declaration of independence"---You must listen to me! It is thus in Ali's intense and vocal desire for self-hood that his estrangement from the normative public perception of the boxer essentially began. 


\section{Chapter 4}

Voice and Spectacle

\section{Introduction}

This chapter will introduce the notion of mimicry and parody in performance, and Ali's use of them as elements of a new mode of weaponry in which he challenged some very traditional negative stereotypes of blacks. Key to this discussion will be Ali's possible motive behind both his mocking of the black "fool" and his casting of Stepin Fetchit as a principal player in his entourage. Also included in this chapter will be a discussion on Ali's development of his mouth both as a powerful weapon against racism and as dominant sign to his growing ideology. His mouth had become a symbol of his performing persona. A systematic analysis of an Ali monologue-interview from his 1963 return trip from England will explore and describe this performing persona.

Furthermore, he was society's newly appointed poet laureate; much like the singer of songs in Ancient Rome, his reading of poetry and rendering of songs impressed upon the consciousness of popular culture that which was relevant and significant; namely, himself and his act. Beneficial to this will be a discussion on the unique musicality of his persona; the indulgence in poems, the Elvis-like rhythmical style, and the precision in prophesying his future success. In fact, it was this precision of predicting the results of forthcoming battles that initially set Ali's vocal act into gear.

Lastly, this chapter will introduce the influence of Gorgeous George, and, consequently, Ali's use of spectacle as part of his developing performing persona. This will be very beneficial in showing Ali's ability to situate the voice 
in other aspects and areas of performance, specifically, in relation to other genres and their performance codes.

\section{Ali's New Mode of Weaponry}

The notion of weapons used in performance does intensify the rationale that boxing permeates a most volatile dramatic code. The term inspires violence and combative conflict. Often there is reference to fists or hands being recognized as a form of legally sanctioned weapons much the same way guns and knives are perceived. In fact, boxers, when not involved in statecommissioned ring contests, are considered possessors of "lethal" weapons via their "fists." Thus, it is quite interesting that with the arrival of Ali onto the professional boxing scene a new type of weaponry is introduced and is proven to be just as dangerous in the ring to opposing foes as are, say, the mythical and normative signifying fists: the mouth.

It must be understood that Ali's mouth and vocal histrionics would, alone, have had a difficult task in the destruction of his opponent's fighting will if he did not possess, as well, a terrific boxing repertoire to back him up. Significantly, it was Patterson who informed the reader that Ali is not all mouth. He said, "People underestimate Clay. He talks so much about himself that people figure he can't possibly be that good. Believe me, he's a terrific fighter" (McCallum, 315). And it was Pacheco, in regard to Ali's potpourri of skill and talent and mouth, who indicated the signifying effects Ali's newfound weapon had on performance when implemented:

Ali turned his faults into advantages. His great hand speed made it possible to hold his left at his waist. His leg speed made it possible to lean back, away from a punch (slip). To hit Ali when he 
leaned back, you needed a stepladder and blinding speed. Ali gave you the body, and while you busily worked it, he pounded your head. (See the Frazier fights; study the Foreman bout.) And he had the leg speed of a welterweight. And hand speed. And radar for incoming punches. And a granite chin. And one of the greatest boxing brains ever seen in a prize ring. What else can one ask of a fighter? One thing: a mouth. Non-stop talking, bell to bell, to frustrate you, to wear you out, to confuse you, to befuddle, distract... He was a master of fight psychology. He knew what to say. He used it like a weapon. It had never been seen before [italics mine]. $(1992,16)$

It was the implementation of this weapon in the performing arena, Ali's mouth as an operative power force, that signified the change in the perception the public held for boxing. As noted before, prior to Ali, the voice of the boxer was treated as a sign of weakness, vulnerability, or defect in the identity of the boxer. As such, the voice negativized, neutralized, or marginalized the power symbolized by the boxer. Without "voice," one might say, the assertion of power was merely brutal, at least in the professional arena. ${ }^{10}$

What Ali introduced into pop culture was an ideological complexity to the already popularly perceived mode of physical performance. He imposed, much like Gorgeous George or Clyde Beatty, a moral dilemma that extended beyond the atavistic physicality usually associated with the sport. With Ali's estrangement, physical performance was now transferred from the normative and dominant dramatic code, reflecting brutality and brain-damaging ugliness, to a new mode of entertainment, demonstrating not only fistic combat but also showmanship and intelligence. It was the deployment of voice and histrionics in and out of ring contests that ensured Ali's public controversy and mass media appeal. 
An analysis of one particular monologue will show Ali's use of and demonstrated power over language that separated him from other boxers. A year before the Liston bout, Ali went to London to battle England's 'Enery,' Henry Cooper. On his return, Ali gave an interview. Film footage shows an interviewer asking Ali to give a description of his recent victory over Cooper. Ali reacts in the following fashion:
Ah, man, that was something! You should have been there. I walked into London, England, I jumped out of the airplane [Ali is indicating with his mouth wide open and his right hand raised to head level the numerical symbol "five," inferring his pre-fight prophesy of a five round stoppage of Cooper.]. Picture cameramen everywhere I go. [Ali is indicating] You can look in the gym today, the TV, the cameramen, everybody follows me I'm so great!. And fifty-five thousand people came that night! You should have seen the people! One layer. [Ali is signifying with the sweeping motion right hand.] Two layers, ten thousand on each, fifteen and twenty on some. Four layers and a fifth layer; people looking down on the ring! Fifty-five thousand and Cleopatra [Elizabeth Taylor] was at ringside to witness: "Can this 'Louisville Lip' come over here and call the exact round again?" We don't believe it! The fifth round came... [Ali is signifying a mock ring performance] Ugh! I hit him! I said, "C'mon sucker!" The man [referee] said, "Break it up," and I said [his face and eyes indicating a parody of the stereotypical, Hollywood "Negro actor."] "They he is! They he is," and walked on out of the ring. (Ali: Skills, Brains and Guts)

His mouth in performance did cast a vastly different mode of perception than the public at large was used to when observing the actions of a professional athlete. What he is doing is playing with stereotypes; he is using them. It is important to note the shifts in his language. He goes from grammatically correct English to deliberately incorrect. He uses bad grammar in a way that says: "I'm gonna do whatever I want with the language; I'm not gonna do it as somebody else wants me to do it." So, he will say "ain't no way," "he don't," or "they he is." 
He deliberately mocks or plays with the language. He implies, "I own this language. I can do whatever I want. If I want to break the rules---like I do in boxing---|'Il do it. I don't need no badge or whatever." He does what he wants. No one controls him. This is part of his persona.

Moreover, it is the way he uses the words. He quotes and speaks for other people. Referring back to the above passage, "Ah, man, that was something! You should have been there!" Who is he talking to? "You" should have been there. "You" missed a great performance. "I walked into London, England, I jumped out of the plane!" He sets up this visual scene. He does it verbally and he does it physically. From "Picture cameramen everywhere I go..." to "I'm so great," this scene is nothing but self-congratulations. He determines the direction he will take the interview. He then decides to dramatize himself and the scene. He starts by informing his audience that there were "fifty-thousand people came that night." Then he is back to selfcongratulations with "you should have been there." At this point, he uses more than just his mouth, he introduces the non-speaking part of his persona, his body. He indicates the visual depths of the stadium and the sheer enormity of the occasion with the sweeping motion of his right hand: "One layer...Two layers, ten thousand on each, fifteen and twenty thousand on some...Four layers and a fifth layer, people looking down on the ring!" He then makes mention of the magnitude of his performance by informing the audience that a queen (Taylor) "was at ringside to witness" his prophesy: taking Cooper out in the fifth round. He does not just comment. He dramatizes. He sets the scene; he dramatizes it for everyone. He continues, "We don't believe it!" He knows what other people are thinking. He puts in his mouth their thought: "Can this 
'Louisville Lip' come over here and call the exact round again?" He anticipates what other people think of his performance and speaks for them.

He then closes this performance by appropriating other characters and voices such as the "bad nigger," the referee, and the stereotypical, Hollywood "Negro": "Ugh! I hit him!...C'mon sucker!"; "Break it up..."; and "They he is! They he is!"

This analysis has attempted to demonstrate Ali's ability to use the language in any fashion he chose. Whereas other boxers may not have been able to exhibit such control, Ali could. And it is in this particular light, that an interesting analogy between Ali and the rap "artists" of today can be put forward. Blacks in rap culture, it seems, are saying: "We want to say whatever we want to say, and we choose these words as we want to use them, and not as white culture has told us how to use them." This is exactly what Ali did through his performance persona. Of course, there are differences between the two relations. Unlike the rap performers, Ali never used bad, or four-letter words. The rappers tend to use offensive language all the time, and their lyrics tend to intimate violence. ${ }^{11}$

As a closure to this section, a recent National Review editorial has SouthCentral L. A. Congresswoman Maxine Waters being quoted as saying of the black rappers:

It scares the hell out of people when young black males get aggressive. Before rap, there was no other platform for talented people like Snoop [Doggy Dog, under a murder indictment in Los Angeles], or lce Cube, or Latifah to speak their minds. These are artists with a message and they're forcing America to listen.

Aside from the obvious criminal aspect, Waters, unknowingly, makes a direct 
relation between these "artists" and Ali. Like "the foul mouths of rap," Ali forced America to listen to his aggressive use of the English language.

\section{Parody and Stepin Fetchit.}

In Stephen F. Zito's "The Black Film Experience," he exposed a critical idea encompassing the possible motive behind Ali's mock playing of the "fool." Ali's harsh enhancement of the poor, dumb, fool emphasized his awareness of negative stereotypes, not only of blacks by whites, but also of blacks by blacks. His parody operated as a type of wake-up call to the traditionalists. Zito wrote:

The recent films dealing with black experience take on a special meaning when they are viewed within the context of the past history of the Negro in films. The Negro traditionally had but three roles to play: the savage, the fool, and the castrated Uncle. And the Negro actor playing the roles has less inhabited them than been bound and gagged by them. Black character has been dictated by popular stereotypes, and these stereotypes have been created out of a very few histrionic elements: The shuffled step; the molasses-slow, stumbled-tongued patterns of speech; the razor in the torn pocket; and the watermelon grin. (61)

Questions arose early in my research: Could Ali's performance persona be an outright attack and challenge on white America's denigration, through his outlandish stereotypes of the Negro? Is Ali perpetuating an all-out parody on the roles in which blacks have forcibly been cast? By examining the signifying practices of his performing code, one can deduce that what he does is indeed a take-off, a reaction, albeit mockingly so, of the stereotypical black perceived by white audiences. More precisely, Ali deconstructs white stereotypes of blacks, but also, and this is significant, he deconstructs black stereotypes of blacks. He wants to change not only the black perception of blacks but the white 
perception of blacks. As Zito indicated, "White audiences thought the role played by Stepin Fetchit was a realistic interpretation of the Negro character" (69). Ali mocked "the shuffled step" by eliciting the "Ali Shuffle," recalling Lipsyte's description: "a little soft shoe that broke the monotony with as gaudy a bit of black jock style as the heavyweight division had ever seen" (119). Ali parodied the "molasses-slow, stumbled-tongued patterns of speech" by talking with such animation and bombastic severity that it is no wonder so many people ostracized him. His parodies were so aggressive that, much like what Waters said of the rap performers, he scared "the hell out of people." And yet, as noted earlier, his grammar was often terrible. Apparently, it did not matter. His was a sophisticated mode of performance and very shrewd in the use of stereotypes, for which he attempted, with great success, to change the black perception of blacks as well as the white perception of blacks.

As can be seen in his grammatically incorrect description of his fifth round knockout of Henry Cooper in England, Ali is calling attention to the past stereotypes of the Negro character when, at the end, he exclaims: "They he is! They he is!" Significantly, it is at this juncture of the quoted passage that Ali "kills two birds with one stone"; he challenges another held stereotype of the black character: the rolling of the eyeballs. By rolling his eyeballs with perfect exaggeration, he easily and clearly evokes what Zito indicated as "the usual Negro roles (cooks and servants) and the accepted Negro characteristics (childish, easily frightened, cowardly, stupid)" (62). Added to this is Donald Bogle's depiction of the stereotypical black man, "When the darkie is frightened he is apt to roll his eyes and shake like a jelly, and the effect is nearly as funny as when he is pleased" (41). Ali's parodies were elements of a performance 
code that emphasized vocal confrontations with traditional norms and values. They were loud and harsh, and they turned heads.

It is most interesting, if one is to believe that Ali was keen and bright enough to cast such a new characterization onto both white and black America, that this sophisticated notion of performance and parody was in effect a new mechanism of rebellion, a new sense of identity through "voice," counter challenging both the normative boxing mode of the boxer and the normative public perception of the black character. An interesting question arises when considering the sophistication behind such a performing style: Was this a conscious act?

As Ali developed a firmer stand on segregation, and as his association with Elijah Muhammad and the Nation of Islam grew, it became apparent this mode of performance was not merely an act of playful or angry buffoonery. It was a conscious effort on his own behalf to effectively, if not radically, express, through the exaggerated and severely bloated images of mockery, that society in general was going to have to deal with the fact that there was cultural prejudice.

Furthermore, his act could be said to be a shrewd and most effective undermining of the prevalent mood of the country toward blacks. And his act in and out of the ring was shown to change and rectify that unrealistic and unflattering perception. In fact, it was Ali's image and sayings that inspired the 1960 's "Black is beautiful" movement. For years, he had been boasting how "pretty" he was, and how the heavyweight champion should be "pretty like me." Part of his usual rhetoric when he was interviewed contained how fast he was, how young he was, how great he was, and, most assuredly, how pretty he was. 
So, his "I'm as pretty as a girl" was an instrumental influence on the movement and not the other way around.

Interestingly enough, Ali added to his inner circle, "Hollywood's leading exponent" (Wilson, 49) of the stereotypical black character, Stepin Fetchit. In his "heyday," Fetchit had been recognized and respected in the Black community. He had made a million dollars playing the same role for several decades. And in 1964 he became Ali's "secret strategist," and exactly what his function was in camp no one save Ali knew.

According to Carolyn Alberta Poe, "As a character type, the Coon was considered one of the most offensive portrayals of American blacks through stereotyping. This type was depicted as dim-witted and illiterate. A Coon was an object of amusement and used primarily for comedy relief" (84). Her historical analysis of black stereotypes in Hollywood films detailed the appearance and introduction of Lincoln Perry, alias Stepin Fetchit, as the prototype of the lazy Coon. Significantly, he gave the appearance of being a simple-minded, slow-witted, and lazy man (84). It was through Hollywood, a white institution, that this impression was readily accepted by audiences. There were black films made outside of the Hollywood system, but for the most part, the caricature of Fetchit as the embodiment of the nitwit, colored man became the stereotype for white audiences.

His relation to Ali was significant, especially with his arrival just prior to the second Liston-Ali fight. If one were to study Fetchit's popularity during the 1920 's and 1930's, one could see Ali's intellect and strategy at work. As Poe explained, "He popularized the mentally inferior, tongue-tied stammering slow moving, lazy black man. Always forgetful and unable to pronounce a word with 
more than one syllable, Fetchit's screen appearances served to reinforce the Coon image" (84). Ali was mocking not only the Coon image, but also Liston, for signifying that image, and white America, for actually believing that accepted reality of the black man. Ali was qualifying the ineptness and ignorance of this black stereotyping by having at his side, as his "secret strategist," the archetypal Coon image.

Through this caricaturing of, and harmonizing with, Fetchit (as depicted in AKA: Cassius Clay), Ali was clearly sending a message of challenge and controversy. Through a performance code that was already eliciting plenty of controversy, Ali was seeking to change the perception of popular culture, as well as challenge those prevalent myths about blacks as well as whites. In examining Fetchit's significance to Ali's act, Lipsyte wrote:

There was another glaring inconsistency about Ali in Boston that disturbed American newsmen. During workouts, Lincoln Perry, the Black movie comedian whose screen name, Stepin Fetchit, had come into the language to characterize the lazy, dumb, cowardly black stereotype, lounged on the ring apron in a rubber skull cap and white turtleneck sweater. American reporters were offended, and sat stony-faced thru [sic] the 72-year old Fetchit's old jokes and occasional comic mimes. Once, when the phrase "Uncle Tom" was brought up at a press conference by a reporter, Fetchit began yelling, "Uncle Tom was not an inferior Negro. He was a white man's child. His real name was McPherson and he lived near Harriet Beecher Stowe. Tom was the first of the social reformers and integrationists. The inferior Negro was Sambo!" (94)

The last several lines of this passage are crucial to how Fetchit was seen in the Black community. Even though he played the fool Coon for the white audiences, he was still held up exceedingly high among his own people. He was "the first social reformer" for the blacks. He made millions of dollars from Hollywood, and when he came into a Black community, it was the conquering 
hero returning. No doubt as a boy in segregated Louisville, Ali must have seen many of Fetchit's films.

It seems through inconsistency and controversy, both Fetchit and Ali were laughing at the superior intellect. Also, by presenting Fetchit as a signifying aspect of Ali's performing circus, Ali was inviting the traditionalists and critics of the mass media to ask themselves a serious question: What is the relation between Fetchit, a man who was the quintessential black negative stereotype, and Ali, a man who is parodying and mocking that same black stereotype? Ali may have been black, but by the sheer severity of his mocking performance, he was not going to be perceived as blacks had been perceived in the past. He was creating his own language, his own perception for America.

\section{Ideology and Spectacle}

By speaking out into a performing medium not normally recognized as a vocal playground such as the theatre, television and film, Ali devised a new and evolving rhetoric transcending the normative notion of masculinity in ring combat. His declarations ran the gamut from incredulous audacity to profound accuracy: "I am the Greatest"; "I will shake up the world"; and, most significantly, "You must listen to me." Other fighters, such as Marciano, Louis, Liston, Foreman, even Frazier, and in recent times, Tyson, instead declared with monosyllabic denunciation: "Let's fight." These fighters, certainly gifted and popular in their respective eras and in their mythically simplistic boxing style, had no social morality past the cauldron of the ring. The masculinity that they personified exhibited, or cast, no moral dilemma. Their fighting was, indeed, purely the fight itself. In the performance of battle their function was to fight and 
nothing else.

Furthermore, their existence, socially and culturally, was as fighter. It was all physicality and it was all brutal, as can be realized most recently by Tyson. After his fight against Jessie Ferguson, Tyson gave the sporting media the following poignant and telling statement on the objective of his function as fighter: "I try to catch my opponent on the tip of his nose because I try to punch the bone into his brain." Clearly, there is no moral dilemma, no democratic ideology. Perhaps it is the absence of an ideological and moral contention that establishes the powerful dramatic code that aligns the public perception of professional boxing as being insane, inane and barbaric.

However, and this is imperative, it is popular culture's identification with Ali's public persona and his vocal philosophy, "I am the strongest and baddest because I can talk and win," that significantly altered the operative power of perception over the complexity of the dramatic code. A ring performance (inclusive are the ceremonial weigh-in, pre- and post-interviews, the press conferences, the training "invasions," the actual fights, etc.) is now nearly heightened to a level of Greek drama.

Early states that, "Ali made fights other than what they were; he made them, both for blacks and whites who watched them, the metaphors they wished the fights to be, principally the battle of good against evil" (179). It is Ali's connection with the audience that enables boxing to extend beyond sport and approach spectacle. Semiotician Roland Barthes noted:

In America wrestling represents a sort of mythological fight between Good and Evil... What the public is looking for here is the gradual construction of a highly moral image: that of the perfect "bastard." One comes to wrestling in order to attend the continuing adventure of a single man leading character, permanent and 
multiform like Punch or Scapino, inventive in unexpected figures and yet always faithful to his role. (23)

Barthes believed that the difference between Wrestling and Boxing, Spectacle and Sport, lies in the public and what it perceives. He wrote, "What the public wants is the image of passion, not passion itself... What is expected is the intelligible representation of moral situations which are unusually private" (18). It has been determined that through his performance persona, Ali managed to bridge the gap between the two popular mediums. He maintained, much like Scapino and Punch, a consistency and an inventiveness to his proclaimed role as braggart, poet and prophet. And much like the wrestling fan, as Barthes related, one came to a boxing contest involving Ali "to attend the continuing adventure of this single major leading character" (Barthes, 23).

In an early interview with Jim Jacobs, Ali is asked about his influence upon the attendance of the paying public coming to see him fight.

JACOBS: What percentage of the fans who are coming to see you fight Sonny Liston, what percentage do you feel will be coming to see you?

ALI: Well, a hundred percent will be coming to see me, but ninety-nine percent will be coming to see me get beat. Because they think I talk too much. (Ali:SBG)

As he delivers these lines, Ali's chin is raised in defiant and arrogant fashion. Later, from the same film, Ali is asked, this time by a different interviewer, to try and keep his mouth shut for just ten seconds. He says, "That's impossible. I'm the Greatest. And I'm knocking out all bums and if you get too smart l'll knock you out." Ali commands the scene. Even in humor and parody, the key to Ali's effectiveness is in his control and power over the situation. He commands and dramatizes the scene. Within the scene he is the hero and righting past wrong. He is mocking the white man and creating his own 
scenario of getting even with the "white massa." Incidentally, this interviewer, like Jacobs and most all of the sport journalist of the time, was white.

In addition, "I'm knocking out all bums" is italicized because it proves a significant cornerstone in the new bantering rhetoric Ali had created. For example, in his very first professional fight against Tunny Hunsaker, Ali referred to him as a "bum." He did the same against all his early "ham n' egger" matches, and then on through legitimate contenders like Doug Jones, Henry Cooper, and "that big ugly bum," Liston. "Bum" became popularly recognized as an integral part of Ali's ring vocabulary.

\section{Ali as Prophet.}

In line with his banter of "knocking out all bums," Ali actually began the immodest act of predicting the rounds his forthcoming opponent would fall, which he spiced up musically with an outrageous rhyming scheme. In his public presentation of these prophecies (i.e., at interviews), Ali would begin by pointing his index finger in tune with the swaying up and down of his right arm, while circling about with legs in beat to the gesticulations. This can be seen in nearly every interview. ${ }^{12}$ "His rhyming couplets tickled people's sense of humor. 'If he wants to jive, he'll fall in five.' His ever-opened mouth, the popping eyes, the incessant boasting intrigued not just boxing fans, but the public at large" (Carpenter, 123).

Moreover, when making predictions, Ali had a habit of making reference to the "impossible"---the chance of him not winning (the word "lose" was not known in his unlimited ring vocabulary). The reader can observe, in scenes with Liston, Frazier and Foreman (to Ali, all were "big ugly bums" or "gorillas"), 
Ali continually, with his mastered, impassioned and ministerial mode of performing, exclaiming with his right hand and arm in perpetual back and forth motion, that, "If Sonny Liston [or Frazier or Foreman---the performance was always the same, just the name of the opponent changed] whups me, I'll get down on my knees, crawl over to him, kiss his feet, tell him he's the greatest and catch the next jet out of the country" (Ali: SBG). Or, if Ali was fighting an opponent out of the country, as in the case against England's Henry Cooper, Ali's prediction would go something like the following: "If this bum goes more than five rounds, I won't return to the U.S.A. for thirty days." The outcome, of course, was precisely as Ali predicted, Cooper did not finish the fifth round.

Furthermore, when he faced his former mentor, Archie Moore, he predicted, in simple verse, that "Moore would fall in four." And, naturally, Moore was stopped in the fourth round. To create some excitement for the Clay-Moore battle, Ali entertained the Los Angeles area by appearing with Moore for an unprecedented televised event: a dueling debate. Moreover, Ali began the humorous campaign to "get some kind of pension for that old man." Film interviews show Ali as playing the sympathetic, young protege not wanting to cause injury to a man "old enough to be my granddaddy." It is accurate to state that Ali's was an unprecedented and much needed persona that "rocked" the early 1960's, especially in the aftermath of the presidential assassination and the two already-mentioned boxing-related deaths in the ring. Sammons notes:

Although his publicity-seeking banter was harmless, Clay's antics polarized the boxing community and the public: the man inspired either adoration or contempt. Still no one could deny that had given a much-needed spark to a static sport. What mattered most was that both friend and foe would gladly pay to see him fight. (91) 
Ali gave another interview to Jacobs just days before the historic and culturally significant boxing match between himself and Liston. It had been captured on film and successfully exemplifies some essential signifying practices that have gone into the making of Ali's performer code: the physicalness and reflexiveness of his hands and eyes and mouth; the blaring, bombastic, poetic, undaunting and self-assured style of his performing rhetoric; and the uncanny, street savvy, spontaneous and purposefulness of his creative and psychological powers. It is the definitive "performance" by Ali, and its cumulative effect elicits the crucial phenomenon of voice, power and escapism ("fun") in male physical performance. Interviewed by Jacobs inside the Fifth Street Gym in Miami, Ali, shirtless and slightly sweaty, was captured by the moving camera just after the completion of his workout on the speedbag. The dialog was as follows:

JACOBS: Ladies and gentlemen, this is Cassius Marcellas Clay (indicating). He's young, he's handsome...(Clay interrupts). CLAY: They know it! JACOBS: (continues)...He's a poet, a prophet, and many believe he'll be the next heavyweight champion of the world. (Pause) Can I ask you how you're feeling now at this point in your training?

CLAY: I'm feeling great! I'm ready to go to war right now! JACOBS: Well, when you say you're "ready to go to war right now"...(Clay cuts him short).

CLAY: If I see that big ugly bear on the street, I'll beat'em befo' the fight! JACOBS: You'd actually take him on before the fight?

CLAY: Beat'em like I'm his daddy! (Laughter from entourage in background). JACOBS: I saw Sonny Liston a few days ago...(Clay breaks in). CLAY: Ain't he ugly?! JACOBS: (Attempting to keep his own laughter in-check) He's... CLAY: (Now in an emphatic and excitable kind of tirade) He's too ugly to be the world champ! The world champ should be pretty like me!

JACOBS: Well, he told me to bet my life that you wouldn't go three rounds.

CLAY: Well, if you wanna lose your money, then bet on Sonny! JACOBS: May I ask...(Clay is now on a roll and cannot be silenced). CLAY: 'Cause I'll never lose a fight! It's impossible! (He now directs his 
attention to his entourage, specifically confidante Bundini Drew Brown) Tell'em! It's impossible!

BROWN: Never lost a fight in yo' life!

CLAY: Ask any of my fans: when was the last time I lost? I'm too fast...

BROWN: Champ from the crib...

CLAY: I'm the king...

BROWN: Born the champ! Born the champ from the crib!

CLAY \& BROWN: (In unison, with mouths agape) Agghhhhh!

CLAY: I'm not only a fighter, I'm a poet, I'm a prophet, I'm the resurrector, I'm the savior of the boxing world. If it wasn't for me the game would be dead.

As the above interview should exemplify, there was something very exciting and distinctive taking place between, not only the interviewer and interviewee, but also with the receiver of the message, the spectator. The spectator, for this time period (1963), was experiencing something quite unprecedented and wholly original. Here with the help of camera, microphone and audience, the brash young man being interviewed has created a significant mode of performance which was as estranged from any one category as one might imagine.

Interestingly, Ali's use of a particular black mode of discourse found within the Afro-American oral tradition enhances this performance greatly. He along with Bundini Brown have synthesized their lines and cues in what is referred to in Black English as "call-response." It synthesizes speakers and listeners in a unified moment, taking on the appearance of an interactive network in which the fundamental requirement is active participation of all individuals. In the passage, Ali invites Brown into the interview thereby beginning the process of call-response. As Smitherman indicates, "The process requires that one must give if one is to receive, and receiving is actively acknowledging another" (108). This is effectively communicated in the give 
and take rappport that proceeds after Ali invites Brown to "Tell'em." Brown begins, "Never lost a fight in yo' life." Acknowledging that, Ali gives, "Ask any of my fans...I'm too fast..." and so on, each calling, the other responding until, in complete unison, both scream "Agghhhhh!" This is a very effective communicative device in the Black vernacular not touched upon at all in any previous discussion of Ali.

By de-contextualising certain moments of Ali's performance and persona both in and out of the ring, by taking the "signs" out of their narrative context, we have been abie to determine and identify a distinct pattern: particular modes of power find their optimum expression through voice, and this, in turn, has a dramatic effect towards the success of the boxer in the ring.

Furthermore, by allowing, through the powerful mechanisms of voice, self-affirmation and self-confidence to be significant aspects of his "act," Ali's performing code profoundly subverted the normative performance code of professional boxing.

\section{Ali's Invasions and Knightings.}

Another signifying aspect associated with Ali and his "performance code" should be mentioned: his "invasion" of the private training quarters of his opponent. He did this with Liston, Frazier, Chuvalo, and Patterson. However, it was with Liston that this identifiable pattern begun. "It was unheard of, unprecedented up to that time (1963), for any challenger to actually invade the champion's training. Clay's bravado was never more evident" (Ali: SBG). What film footage shows is the immensity of media coverage, Ali generated at these events. As Newsweek reported, Ali was followed by hoards of cameras 
and sportswriters, "his unwitting accomplices." He led them all on "a merry chase." As further film footage indicates, the intensity of this staging took on an element of unpredictability when the champ (Liston) took off after Ali, trying to get a hold of him, trying to throw an effective clubhouse swing at him. It is not difficult to imagine or fathom the sheer marketability and magnitude this kind of promotional hype and excitement created. Recall that this had not happened before Ali, and also note the descriptive word "bravado" that was applied to Ali. He was challenging many traditional institutions, and with each challenge, Ali estranged himself further and further from normative perception of the professional boxer.

Often times, his "invasions" took on a tone of lightheartedness. He would enter a boxer's private training quarters to bestow onto his foe a nickname, with the press core present to record this newly created mode of "knighting." It seems a certainty that Ali had an excellent sense for showmanship and hype. He made every aspect of the ring performance a promotional gimmick. Everything had a name or a meaning: Liston was "that big ugly bear"; Frazier was "the gorilla"; George Chuvalo was "the washer-woman" because he fought like a woman washing clothes on a washboard; Leon Spinks was "the vampire" because when he smiled his missing top front teeth gave the image of a fanged vampire; and Patterson was "the rabbit" because when you shine a light on or corner a rabbit (like Liston did to Floyd, twice) the rabbit freezes still and scared. It was at the invasion of Patterson's camp that Ali not only bestowed the new name, but also commemorated the "event" by presenting to Patterson a bunch of carrots and said, "From now on, you are 'the Rabbit" (Ali: SBG). Clearly and effectively, Ali's new modes of weaponry and rhetoric are in evidence here. 
Also, in effect, here, is the striking image of Ali playing the "crazy nigger" role, again.

\section{Gimmickry and Gorgeous George.}

Ali's role as poet, prophet and savior of the boxing world did not come all at once. There is no question that Ali, from his earliest years, expressed both a talkative nature and confident demeanor. In Contrell's study of Cassius Clay, Joe Martin, who had taught Clay how to box (along with Fred Stoner), said, "(Clay) always talked too much. He was always mouthing off...Contrary to many reports, Clay's braggings are not of recent origin, but date back to his earliest days" (12). Contrell then writes:

His failing was his mouth. $(\mathrm{He})$ made himself unpopular with the other boys in training at the Columbia Gym. He told them he was the best fighter in the program. In the dressing room before his fights, he always told the opponent he was going to whip him. Clay announced to many a bewildered young amateur fighter that he was going to become the heavyweight champion of the world. (12)

Indeed, as Martin and Contrell related, "his braggings" were an integral part of his character. However, Ali had not the tools (namely, maturity and experience), at this early stage to discipline and define this active "character" that was surely present but only in embryonic development. What was lacking was a gimmick.

In my personal interview with Menendez, "Julie" mentioned that in 1960 the kid (Ali) was very "cocky." So, arrogance and braggings, though integral aspects of Ali's youthful character, do not capture or define Ali's later (1964), more comprehensive and complex "persona."

In an inverted play on the title to Pirandello's Six Characters in Search of an Author (1921), Ali, in 1960, was himself an author in search of a character. 
As early as 1961, Ali had begun the highly successful "gimmick" of predicting rounds in which his adversary would fall. He also introduced a most compelling ideology onto the sporting world: the recitation of poetry.

"Boxing," writes Early, "is, like wrestling, about showmanship. And the greatest showman and boxer in the history of the sport was Muhammad Ali....It was not an accident that boxing's greatest showman was heavily influenced by professional wrestler Gorgeous George" (179).

On 4 May 1976, when Ali appeared on "Face the Nation," George Herman of CBS asked him, "You've said: 'I've always got to talk. People expect it of me.' Is that a role that you play? Are you trying to be an actor?" Ali replied, "I used to watch a wrestler named Gorgeous George and he would always talk about how he would do this and do that and how he was going to annihilate the bum and people came to see him get beat. And this is where I got the idea" (Cong. Rec., 12374).

It is fundamental to understand that the enormity and the profundity of Ali revolves significantly around the idiom of gimmickry and showmanship. In his extensive article, "The Marvelous Mouth," Tom Wolfe wrote of Ali:

He may have a showman's perspective on his pitch---"I am the greatest"---but he is hooked on the attention and worship it has brought him. I think Cassius Clay is already worried about the fact that this part of his life could end with his boxing career.

$\mathrm{He}$ is starting to talk about himself as a show-business figure. "You know, everything now is the talking, going on television, building up the fight," he told me. "Sometimes it seems like the fight ain't anything. It's not even any fun to win anymore. It's all the buildup. I don't feel like I'm in boxing anymore. It's show business." (147-8)

Pacheco recalled Ali's earliest pursuit and formulation of an effective and 
accessible gimmick. He explained:

His first formal thoughts about the synthesis of his persona came after a visit to Gorgeous George in Las Vegas. Gorgeous George was the most successful wrestler in the country. He dyed his hair a Marilyn Monroe blond; he came into the ring with a dresser, whose job it was to take the curlers out of George's blond hair, comb it out, and spritz it with hair spray, then help George out of his sequined robe and spray him with perfume from a gigantic atomizer---after which George would go out and beat the hell out of his opponent. Clay's eyes were wide as they took in this spectacle. He noted that the place was sold-out and that half the people loved Gorgeous George and half hated him.

After the show, a rapt Clay listened as George gave him a lecture on showmanship: "You gotta have a gimmick, kid. You got your good looks, a great body; they tell me you can fight like a dream, and you can talk even better than you can fight. You've got your act, now you need to polish it. Always dress in white. White robes, trunks, and shoes. Especially white shoes; makes you look even faster, and it'll make the purists hate you. $(1992,49-50)$

Here is a perfect example of the normal boxing image at the time of Ali's

arrival. Boxers were expected to wear black or dark trunks and black shoes. ${ }^{13}$ They had no desire to do anything that might diminish their role-model status nor upset the strong and powerful "senior citizens of the boxing establishment." In this particular instance, I refer the reader to Art Evan's "Joe Louis as a Key Functionary: White Reaction Toward a Black Champion," for a very enlightening revelation on the sacrifices and subjugations of Louis and other black champions. The key to Louis was his "persona" and role-model status which expressed a silence and politeness bordering on the pathetic. It is assumed that this was his image: "humility" and humbleness. What Evans revealed was quite sad and downright inane on the part of the establishment, but of course, the times were the times: Some compelling questions arise in 
this study: If he was capable and if he had the street savvy (a la Ali), could Louis have talked himself into prominence? Could he have made the senior citizens of the boxing community listen as Ali did? Did he have the tools to do or act in any fashion or manner other than that of the "humbled" black champion?

Furthermore, Pacheco wrote that, "A champion did not brag outside the ring, but let his fists speak for him in the ring. A champion was a model of decorum. A champion was circumspect" (50).

Important in the eyes of Ali, was the success "image" had in selling tickets. As he began his professional career in 1960, Ali had wonderful skills in boxing but was lacking an accumulative performance persona that would lend success equally outside the ring as well. George aided him in acquiring this powerbase of greatness both in and out of the ring. He asked Ali:

Did you see the crowd out there? Half of 'em want to kiss me, half of 'em want to see me get killed. This is what you want. They all pay ten bucks to see what they want, but the bottom line is asses in the seats at ten bucks a pop. Now, you've got a great mouth. Lots of people love your brash, cocky style, and a lot of people will pay to see someone shut your mouth with a leather glove. So, keep on sassing, and always be outrageous. $(1992,50)$

Gorgeous George made wrestling, as Barthes defined it, into spectacle both assessable and lucrative. He helped accentuate those moral dilemmas which define a culture, for example, the "democratic" ideology of good and evil. In much the same fashion, Ali mixed the roles of both sport and spectacle, giving to the spectator a "single, major character," estranged and identifiable through "outrageous" acts of performance, especially in the espousing of voice.

Lastly, what this vocal gimmickiy and audacious ring act imposed on a 
large percentage of the popular culture was the following compelling dilemma: Does the boxer really have a world or does he simply occupy a very traditional and related room in a masculine complex? Is he next door to the gloried discipline of the marine or perhaps the psychosis of the street corner gang leader? ${ }^{14}$ What does a man who espouses lines of versed poetry out of the ring, then goes on in the ring to do battle, tell us? It tells us that the distinction between the mythical image of the boxer and that of Ali, the perfect performing "bastard," lies in the voice, its composition, its musicality and its practice.

\section{The Musicality and Practice of the Voice}

Perhaps the most pronounced element in the performance persona of Ali was his role as poet. It has been determined that the very nature of boxing is a "self-referential world in a masculine complex" (Oates), where voice, let alone poetry, has been incongruous to the power of fists in combat. Furthermore, Oates wrote that, "Each boxing match is a story---a unique and highly condensed drama without word." Ali compounded this myth not only by making boxing a drama with words, but also by invigorating this "unique and condensed" arena with poetry. The mixing of roles between poet (writer) and boxer has often stirred the public's imagination: the notion of the poetic and sensitive writer putting down his pen and putting on the leather gloves and partaking in the harsh and barbaric sport. The complexity between the two worlds and roles is apparent. One voices his "being" with the pen, the other with the fist. How ironic that it was Ali who was able to mix the roles of boxer and poet so successfully. Writers such as Hemingway, Mailer and Plimpton have all attempted the complex mixing of roles, but seemed to have fallen short 
in establishing this mixing as a continuum in their image as cross-over artists.

Ali's success lay not so much in the words he recited but rather in the manner in which he spoke, and in the nature of his Afro-American background. His very nature was ministerial and gospel-like, especially when trying to convince the boxing community that he was for real. His style was much like the times he was living in: rebellious and militant. Much film footage captured Ali's intense concentration on the building and creating of his speaking character. The eyes widen and light up; the face and chin raise definitively; the hands wave back and forth in declaration of the next words to come; and, most essentially, his voice expresses a hip-ness, a musical-ness that is gyrating, upbeat and revolutionary. His voice sounded like a gospel preacher who could not contain the power and life force inside his being any longer. With ministerial precision and passion, Ali recited his poetry to the public. It is important to note that a major characteristic of the "Black preacher"-Afro-American oral tradition is the use of talk-singing and rhyme-scheming. As Smitherman points out, "Talksinging in tonal semantics achieves its meaning from the listener's association of the tone with the feeling of being 'happy' and gittin [sic] the Spirit. That feeling is behavorially expressed in the black cultural ritual of 'shouting'" (137). Perhaps, no better example of Ali's gift for this "black cultural ritual" exists than in the following passage:

For those of you who won't be able to see the Clay-Liston fight, here's the eighth round exactly as it will happen:

Clay comes out to meet Liston, And Liston starts to retreat; If Liston goes back any further, He'll end up in a ringside seat. Clay swings with his left, Clay swings with his right; Look at young Cassius 
Carry the fight.

Liston keeps backing,

But there's not enough room.

It's a matter of time:

Ah! Clay lowers the boom!

Now Liston disappears from view.

The crowd is getting frantic,

But our radar station has picked him up.

$\mathrm{He}$ is somewhere's over the Atlantic.

Liston is still rising,

And the Ref has a frown,

For he can't start counting

Till Sonny comes down.

Who would have thought

When they came to the fight,

That they would witness

A launching of a human satellite?

Yes, the crowd did not dream

When they put down their money,

That they would see

A total eclipse of the Sonny. (Ali: SBG)

What makes this such an effective performance is Ali's ability to combine straightforward talk with the cadence and rhythm of the traditional black preaching style. Moreover, it is quite compelling to realize that Ali, in the film, held a piece of paper in his right hand which we assume to be the written (scripted) lines to the extensive poem he read. However, it is obvious that Ali's eyes were not on the paper he held. Rather, his eyes were on the camera; they were directly focused on the camera. His eyes were like those described by Tom Wolfe, "150 watt eyes;" bright, big and illuminating. The significance of this point pertains to the minuscule attention and memory span of the perceived boxer in society. The perception of the boxer, no doubt by now realized, had been simple: he is physical, not cerebral. Convincingly, Ali estranged himself from that myth. 
Moreover, his recitation was audacious and outrageous and thoroughly entertaining. Aside from these unique qualities, Ali's poetic style also had a freshness and lyricism to it. The texture was alluring and sensual. Interestingly, it was not the quality of the poem itself that evoked such attention and popularity. Rather, it was the manner in which Ali displayed his poetic attributes. He was an orator, a singer of songs; he was an effective dramatic actor who breathed life into the written word.

In an article entitled "Punching Brag," Ali was said to be "no threat to Eliot or Pound," and that put simply, his poetry was "bad." There is no doubt or argument that his verse was not the greatest contribution to the English language. However, as I have just explained, it was not the writing that was key to voice in performance. It was the nature of his voice itself, the texture, the sound and the response it generated that was significant. Ali's was immediate, lyrical, and fresh. In "Punching Brag," he pointed this out in the poem he wrote and recited at The Bitter End, a Greenwich Village "espresso haven," in March, 1963. Before he began, the article noted that "Clay appeared awed by his latest gimmick: a competitive poetry reading." He then recited his magnum opus, "Ode to a Champion: Cassius Marcellas Clay, by Cassius M. Clay":

The words been passed around That I'm a very charming guy, The greatest fighter that ever lived And l'll gladly tell you why My secret is self-confidence--A champion at birth, I'm lyrical, I'm fresh, I'm smart-..My fists have proved their worth. (Newsweek, 93)

Apparently, Ali really had a setup at this competition; his opponents were six beat poets, whose bizarre metaphors and spooky images made his forced 
rhymes sound and look good.

From this particular rendering, a poem conceived and written by Ali, we are able to ascertain some very revealing data. Ali had revealed his own perceptions fostering his newfound celebrity: self-confidence, intelligence, lyricism, and freshness. These were also accurate descriptions of the nature of his voice; how it sounds in performance. Moreover, these perceptions were dominant signs of his developing performer code. He was making press because he was different. His elements of performance and of his public persona were clearly distinct from any other heavyweight boxer.

Ali and Presley.

An interesting concept raised by Tom Wolfe was the idea that Ali was essentially doing nothing more than mimicking Elvis Presley or Little Richard. In fact, Wolfe was right on in this assessment, especially when one considers the similarities between the two in performance (inclusive are interviews and press conferences). Presley's voice and style were loud, fresh, lyrical, rebellious, and perfect for his time. His voice spoke to the masses; his sound was raw, sensual and original. Ali's "musicality" was near identical. What was more compelling was the controversy and popularity each artist's particular manner in performance generated. Wolfe wrote:

Peel away the discipline, turn down the loud mouth and you see a rock-and-roll singer, just like Elvis Presley.

One minute I can comprehend the picture. There is Cassius Clay in a shiny white gaucho shirt and tight pants of the Elvis Presley fashion, with an electric guitar in his hands that has more chrome and exotic fretwork than a loaded Harley-Davidson hogback motorcycle, and a group of four Adam's-appled singers with fading deltoids bunched behind them, going, "Ah-ah-unnnh, ah-ah-unnh, ah-ah, yuh-annh, annnh," while he sings, but then the 
next minute I can't see it at all. (196)

Also of interest, from the documentary film Aka: Cassius Clay, was an interesting snap shot of Ali caught in profile. The significance here is what Ali was symbolizing. He was in a singing position, mouth agape and lifted up to a hanging microphone, that piece of machinery synonymous of the 1950's recording studio. $\mathrm{He}$, in fact, was emulating a popular album cover of Presley's (his second) in which Presley, in profile, is depicted in profile, mouth open, and raised up to a hanging microphone. In both instances, each tableau gives the impression of the mouth in perpetual motion, blasting away a tune, with intense ferocity. Significantly, both lives were symbolized and remember by their respective voices in performances.

Furthermore, Wolfe mentioned Ali's press conference after he won the Olympic gold medal. He wrote:

The reporters zeroed in and started handing Cassius the whole waxed poke full of gooey questions, the first one of which is, "How does it feel to be the champion?" and the second one of which is, "What is your main ambition in life?"....There is no record of what Cassius said to the first question, but to the second he said, "I want to be a rock-and -roll singer like Elvis Presley." (193)

Ali arrived in New York in the fall of 1963 to record an album at Columbia Records called I Am the Greatest. This project consisted of singing skits, poetry readings, and lyrical monologues. Ali's act was "en vogue"; it was hip; it was cool. Much like Presley, Ali was a national phenomenon. Wolfe speculated:

You have to ask yourself what higher pinnacle the press expects a Negro, with a high school education, from Louisville, Kentucky, to aspire to than to be a rock-and-roll singer like Elvis Presley. After all, Elvis Presley came on as the white hope of the recording industry because he was what they had been looking for all these years: a white singer who could sing like a Negro. Maybe 
Cassius has the right ambition: to be a Negro who can make money like Elvis Presley. (193)

Wolfe's article operated on a simple concept: "spend the day with Ali in New York and see 'the act' up close." Throughout Wolfe's encounter/interview Ali was often humming or singing or talking about the songs and styles of Sam Cooke or Aretha Franklin or Lionel Hampton or Presley. Ali boasted, "I'm just a boy from Louisville---I dig rock and roll" (146). It was apparent that music, natural rhythm, "a pounding bass" and a cool, rock-and-roll banter lent themselves significantly to Ali's manner of approaching and performing his act. This was perhaps Wolfe's most distinctive and effective aspect of the article; the gist behind the performing spirit of Ali: a pounding musicality.

Wolfe also made note of the fact that Ali "is only twenty-one years old, but the latter-day career of Cassius Clay is going to be one of the intriguing case histories of American boxing or show business or folk symbolism or whatever it is that he now is really involved in" (146). In a very lengthy passage, Wolfe attempted to interpret the mixing of roles between the man and character, the boxer and the actor (writer). He remarked of Ali that:

He never did feel the impulse to turn off his gloriously bored look and be a star. Which points up an interesting thing about Cassius' attitude toward his own fame. On the one hand, he knows that one reason the public loves it is that they know no man could possibly mean it. It makes him a clown, a jester like Bobo Newsom, the bragging baseball player, who used to speak of himself in the third person, saying, "Ol' Bobo is going to do such and such." But on the other hand, Cassius doesn't want the fuss to be made over him sheerly in his role as a clown. He wants to be thought of as a man who does the clown act consummately well, which is to say, an actor.

So when Cassius goes into a place he doesn't come in waving, mugging and cutting up. He comes on gloriously bored. He wants to see the people come to him as the man who can do that act 
called "I am the greatest," not as the man who is doing the act. If Cassius really wants to go into his act, if he is in front of a crowd he thinks will really appreciate its Pantagruelian overtones, he turns on a pair of 150-watt eyes and suddenly becomes a star. That is the only way I can think of to describe it. It is in the eyes and in the facial muscles around the eyes, an ability to come alive upon demand. I think that is what people usually mean about an actor or a singer when they say he or she has an intangible "star" quality. (189, italics his)

Like the singer or actor who exuded charisma and magnetism, so, too, did the boxer. Ali was perceived not merely as an athlete, but like the movie star and the recording star, as a personality; he was a new kind of star. His appeal was physical and immediate. And like the diplomat and the politician, Ali's words were fresh print. The operative power of his personality was what he said and how he said it.

As a closure, and as a transition to the next chapter, "Voice and Sexual Identity," it is important to note that Ali's "star" quality and image were highly based on his sexuality; his self-conscious and self-indulgent proclamations that he was indeed the handsomest man in the sport, that he was as "pretty" as a girl, and that he was the "onliest" man pretty enough to be champ of the world. His image of a fast and sweet-talking braggart raised many eyebrows; women perhaps knew how to take him, but men were not sure. When he confronted Sonny Liston, who was thought of as the ultimate man's man, interesting and compelling notions came into play. 


\section{Chapter 5}

\section{Voice and Sexual Identity}

\section{Introduction}

This chapter will introduce the issue of sexuality and gender in relation to Ali, and the emasculating effect his complex nature of sexuality had upon Liston. This complex nature of sexuality in and out of the ring contrasted sharply with that of the simple image of masculinity and physicality offered by Liston. Also beneficial to this chapter will be the inclusion of George Foreman, who confronted Ali in 1974, and, like Liston, was emasculated by Ali's complex sexual identity. It is significant to note that in bouts with both Liston and Foreman, two big ugly bears, Ali was successful in implementing both a complex "voice-out" and a new, unsettling "masculinity" that perplexed both these silent and stoic figures into an humiliating submission. Indeed, the parallels between both opponents run far; in essence, Foreman in the 1970's, was, to Ali, what Liston was in the 1960's: a perceived unstoppable force, a pure physical and aggressive beast.

Furthermore, this chapter will discuss how Ali used voice as a sign of individuality and progressiveness. This will effectively be seen in his remarkable performance, captured on film, at the press conference announcing the upcoming fight with Liston. Key to this discussion will be Ali's use and play of the "feminine," which created unsettling complexities, especially since the boxer and boxing had always been a forum of masculinity and machismo.

Lastly, this chapter will introduce the fascinating notions of sensitivity and homosexuality in relation to Ali and male-combative performance. Beneficial to this discussion will be works of Mailer, Messenger and Gutierrez, and their 
elaboration on Ali's voice as a signifying element of power in performance.

\section{Sexuality and Complexity.}

The mixing and merging of different roles is a complex process, and Ali was no exception. In fact, his mixing of boxer and actor (poet and singer, too) was a structural quagmire of complexity. The voice of the poet and the physicality of the boxer created a most unprecedented dilemma and relation: sensitivity in ring combat. The voice, the recitation of poetry, the egotism and the narcissistic appreciation of his own greatness and attractiveness all compounded an estrangement or rift in the normative dramatic codes of masculine and physical encounters. Perhaps, Liston exemplified it most effectively when he was asked if Ali's mouthing off and poetic endeavors bothered him. He responded: "His goading don't get behind me. He's a fag and I'm a man" (Lipsyte, 84).

Furthermore, Ali's complexity (and popularity) was greatly enhanced by his incessant and ceaseless discourse on physical beauty as an integral aspect of ring combat. For Ali, the champion must be "pretty," young, poetic, fresh and fast. Ugliness, a long time normative feature of the "mythical" and menacing fighter, needed to be replaced. The "Champ," if he was to be representative of the superior male species throughout the world, must not be ugly. "The world's champ should be pretty like me." To Ali, the notion of being ugly and being the heavyweight champion of the world was an outrage and an outdated ideology and had to be rectified. This was a significant aspect of his outrageous "I am the greatest" act. It also was a precursor to the growing "Black is beautiful" theory of the 1960's. The whole notion that Ali could boast and claim that he 
should be champion because he was much handsomer than Liston certainly raised the consciousness of young blacks. They were observing that here was a black man telling this white-dominated sport, he will be champion because he was better looking than any other contender for the belt.

\section{Sexuality and Symbolism in the Ring.}

Christian Messenger was prompted by Mailer's many discussions of sexuality in male combative performance to comprise an elaborate (if not fascinating) analogy on the "meditation on the form of orgasmic competition between well-matched sexual athletes" (Messenger, 89). This analogy related to the "the homosexual accusation" of the character of Denise onto the character of Sergius, from Mailer's "Time of Her Time," and to "the direct mayhem and murder in the ring" of the Paret-Griffith fight, from Mailer's "Ten Thousand Words A Minute." He cited from "Ten Thousand":

Paret had insulted Griffith irrevocably, touching him on the buttocks, while making a few remarks about his manhood.... The accusation of homosexuality arouses a major passion in many men, they spend their lives resisting it with a biological force.....And Paret? Paret died on his feet. As he took those eighteen punches something happened to everyone who was in psychic range of the event. Some part of his death reached out to us. One felt it hover in the air. (243-4, ellipsis mine)

Messenger took Mailer's images to task and composed some interesting symbols and metaphors. He assumed that Mailer was implying that Griffith is "a homosexual man who does not practice homosexuality" but is "entitled to the dignity of his choice." Messenger took this a step further by intimating that because the "woman" in Griffith had been offended, Paret must be symbolically sacrificed for this offense to Griffith's manhood. He wrote, "The attack born of 
compensatory rage with sexual roots has yielded a bad kill. Paret dies, Griffith having killed the woman in himself with Paret a ritual sacrifice to Griffith's manhood" (92).

In very description fashion, Messenger was able to literally mix the dual existence of gender that Mailer alluded to in his perception of the "bad death of Benny Paret." He explained that:

The violent physical act, "honorable" in the sense of choosing not to become homosexual, as in Mailer's perception of Griffith, is the closing of the hole, the denial of the male bugger. (Griffith) has ritualistically murdered the feminine in himself, has crushed (Paret's) assertion, has by a murderous, tormented masculinity reclaimed his sexual identity in competition. (96)

This article is quite interesting in its discussion on a rarely trod nor seldomly discussed subject: the complexities of sexuality in relation to the boxing narrative. This article and Gutierrez's "The Champ of the World and the Champ of the Word," compared Mailer as a writer and Ali as a boxer from a sexually masculine-feminine point of view. These writers were more concerned with Mailer's insecurities and sexual metaphysics than they were of Ali's complex dualism. However, what they did very well, especially Messenger, was attempt to resolve the rationale behind Ali's estranged "sensitivity" from the normative "murderous" perception.

Messenger's piece was a very scholarly written project dealing with some elaborate and descriptive gender-filled symbols. His progression and consistency on sexual contraries demonstrated a keen insight into the art of boxing narrative. He did, however, err twice on important boxing data. Firstly, he indicated Foreman won the Olympic Gold Medal in 1972, which was incorrect; it was in 1968. Secondly, he was under the impression that Ali's 
"legendary lip" began after the weigh-in of Liston Clay I, while in fact, his "lip," the major sign in his performing code, began way before that staged encounter.

\section{Ali's Complex Sexual Nature.}

Moreover, it is this identification with the feminine, that Ali further estranges himself from the "purist" image of the fighter. Again, it is Ali who created a complex scenario for the public's perception to decode: I am fast, I do not get hit, I dance, I talk and recite poetry, I am pretty and I can fight. It was an ideology such as this that understandably "screwed" Liston's whole rhythm and, dare we say, identity. As determined earlier, Liston was not "the swiftest embodiment of human intelligence," and upon entering a ring to do physical battle, and beholding this "fag" across the ring, certainly must have seemed to him quite confusing: Is this a "punk" I see before my eyes? What is a man to make of another man who thinks the heavyweight championship should be determined and held by the prettiest man? Brute strength, some savvy athletic skill, and menacing masculinity have always been identified with professional boxing. Handsomeness and prettiness have not. The aspect of a man's degree of good looks was as much an estrangement from the norm of the boxer performing code as was his speaking out on his own behalf. With Ali, it became a prominent issue within his performing code. Not only was "I'm the Greatest" a popular and accepted aspect of Ali's new and estranged boxing ring vocabulary, but also phrases such as these: "the champ should be pretty like me," and "I don't have a mark on my face and I'm pretty as a girl" (Ali: SBG).

At a press conference and dinner announcing the Liston-Clay bout, Liston and various boxing authority figures were all seated at a head table 
facing the cameras and the press. It seemed Ali had arrived late and was followed in by a small entourage who played off his histrionic cues and beats. In normal fashion, he had a ministerial intensity in the way the words flowed from his mouth. His entire body was electric as he made his way to his seat, hugging and "giving skin" to those nearest him. "The annihilation is on!" were the first words heard by the spectator. Then, "Let's get it on!" It must be pointed out here that the mood and atmosphere in the room was not ugly nor was it serious. From the moment Ali made his entrance, an almost slapstick, rap-like joviality occurred. There was an expected "play" by Ali from the audience since he had not closed his mouth in nearly eighteen months. Ali seemed to be "testing the water" as he looked about at the faces of the assembled group. His tone was not yet bombastic nor was it insulting. As he stood, there was an instant of uncertainty on Ali's part on his next move. It was as if he had "lost" his lines in this play. Instantly, he was back on track, the lines in order, the "act" ready to continue. He decided, instead of taking his seat he would remain standing, and, with his head snubbed upward and a slight tilt of his body toward Liston, who was seated just to Ali's left with only the host separating them, asked, "You wanna go now?" He delivered this line in such a manner that a great rush of laughter generated from the audience. It was uproarious, unexpected and audacious. Was not this "puffed-up light heavyweight" afraid? How was he able to get away with this clownish behavior in the presence of the omnipotent Liston (who is obviously befuddled and uncomfortable in a suit and tie listening to these vocal and histrionic antics). Liston will kill him---there was no doubt. Ali was just a crowd pleaser. He could not really fathom the notion of entering the ring with Liston, could he? 
The Feminine in Ali.

What was fascinating about the side-show at the press conference was Ali's ability to shift from the feminine to the masculine. When he asked Liston (Ali's body was advancing toward the seated Liston and at the same time being held back by several of his entourage) if he wanted to settle it now, Ali's voice took on a most peculiar and complex texture. Although his body was halfmockingly assuming the street-fighting position, Ali's voice was calm and quite anxious, as if he was asking Liston out for a date and not a fist fight. It was in the delivery of these kind of lines that enhanced Ali's natural kinship to performing improvisation and ad-lib. He knew what would bring a laugh and what would not. As Oates indicated, he possessed "an extraordinary and disquieting awareness not only of his opponent's every move and anticipated move but of the audience's keenest shifts in mood as well" (9). He knew the very masculine mechanism of intimidation would not work with Liston. He could not stand toe-to-toe with him. So, he played the "crazy nigger" to Liston's cold menace. The "feminine" injection onto this purely "masculine" domain was a perfect foil to Liston or any other menacing yokel. Note the following lines Ali injected into the scene:

I'll whoop you now! Floyd Patterson was so scared he couldn't even walk. Man, I ain't scared, l'll come to your house at two o'clock in the morning lookin' for you. I ain't scared of nobody. It's gonna take a good man to whup me! You can look at me I'm loaded with confidence! I can't be beat. I had a hundred eighty amateur fights, twenty-two professional fights and I'm pretty as a girl. (The Championship)

It is significant to note that Ali was now restless, energetic, excitable and passionate. He has evoked that gospel-like fervor in his performance. He was 
so intense he could not sit down. He had a white napkin in his right hand, and as he gesticulated his arms and body, the observer can see the white cloth move with the force of a ministerial-like sermon. As he said, "I'm pretty as a girl," again the press and spectators erupted in an avalanche of laughter. It was at this point that he decided to take his seat giving a momentary rest to his act. However, this was short-lived for he was up again "exclaiming" his beauty and belief that he could not get hit or lose. He said, "I don't get hit! I don't get hit I'm so pretty!" The observer can note Ali's eyes light up and his hand indicate a wave across the face as if to say, "look at this face." At the same time, this display of narcissism mockingly borders on the effeminate (with the light wave of the hand, the eyes rolling, and the like). And yet, and here is the complexity, his rhetoric and intensity throughout were of such considerable strength, one can never really lose sight that what was being generated was a formidable power of masculinity and toughness. Gutierrez explained it very effectively and succinctly:

Ali was a master psychologist as a professional athlete, probably no one better in any sport at outthinking [sic] his opponent, and he achieved part of his splendor and triumph through a masterful combination "male" and "female" prowess that delighted those hungry for wit and iconoclasm in a violent sport far more than it did those who looked to boxing for bruises, blood, and pain. (22)

Furthermore, this dialog with the camera and the press was one of the most effective examples of Ali's close identification with the culturally-familiar image of the Baptist preacher extolling a heated and frenetic sermon on how "you must believe what I am saying for it is gospel." This ministerial quality was of a nature that was both mesmerizing and exhilarating, and indeed unprecedented at a boxing press conference. Significantly, this level of estrangement 
was phenomenal and further affirmed Ali's unquestioned power of success in ring performance.

\section{Liston: Fear in the Feminine.}

Liston is seated throughout this foray and, from the look upon his face, he was thoroughly befuddled and confused about his role in this "play". His appearance in a shirt and tie took on the nature of uncomfortability. He was being powerfully upstaged and could do little save smile. In fact, he could be seen smiling but it was a strained gesture, as if to indicate, "this 'punk' is stealing my thunder." Note at Ali's final line, "I'm pretty as a girl," Liston could only remark in a simple and sexually uninhibited manner: "Well, that's, that's, that's what I'm afraid of" [sic].

It is at this juncture that the focus shifted slightly away from Ali and toward Liston; it was with the above quote that Liston introduced a fascinating concept onto this issue of sexuality and complexity. As Liston stumbled through "Well, that's, that's, that's what I'm afraid of," he forced us to consider the following dilemmas and implications: What was Liston afraid of? Was he afraid of Ali being "as pretty as a girl?" What was his fear? Was he merely sounding off his discomfort of having to dress up and put on the role in the "Joe Louis Tradition" of the "humble" black champion out of the ring? Or, was he issuing a sleight-ofhand quip (quite remarkable for him) in an attempt to appease a profound insecurity in his nature (sexual identity)?

It is my contention that instances such as these between Ali and Liston demonstrated that the historic fight between the two combatants had been decided before the actual physical encounter ever took place. It was at off-ring 
stagings as this dinner and press conference (the weigh-in is another clear example), that demonstrate a major element in the African-American street culture. They were"signifying on" one another. It was a verbal and psychological contest, good ol' inner city, Black American style. To the usual format of cutting your opponent down with insults, Ali added another twist: he threw the idea of effeminacy into the game. Within the African-American street culture, homosexuality is not looked on too highly. In fact, by playing the "fag," or actually being one, the individual puts himself in great deal of danger. And to be called one, as Liston did Ali, Ali was being "signified on" rather harshly by Liston. But Ali was really in control. He took Liston's best "siggin": "Come over here and sit on my knee, little boy, and I'll give you your orange juice"; and "If you go more than eight seconds, you can have the fight; you couldn't lick a popsicle" (Contrell, 73). Ali then displayed his mastery of this uniquely Black mode of discourse in the following passage:

You big ugly bear, you big ugly bear. I ain't gonna fight you on no September thirtieth, I'm gonna fight you right now. Right here. You too ugly to run loose, you big ugly bear. You so ugly, when you cry, the tears run down the back of your head. You so ugly, you have to sneak up on the mirror so it won't run off the wall. (Wolfe, 146)

In the streets of Black communities, such as in segregated Louisville, Kentucky, Ali's birthplace, black youths "signified on" one another. It was a verbal art form of insult that showed who was in control. The essential key of the contest: no blows connected; no physical contact at all. If you struck your adversary you lost and your reputation as signifier was set. It was all verbal and psychological.

What was accomplished with Ali's ranting and raving at the bigger, 
badder Liston was clear: he emotionally upset the champion which effectively forced him out of his essential fight-plan. In boxing, when a fighter fights out of anger, he fights at a disadvantage. He no longer concentrates or focuses on the basic boxing maneuvers. In his over-anxiousness to "kill" his opponent, he "loads up," instead of leading with jabs or combinations. Instead of closing off the ring and trapping his opponent in the corner, the angry fighter is compelled to chasing his opponent in hopes of landing one power punch. This, in effect, was what the Liston-Clay encounter exposed. Ali, the faster, more elusive and focused fighter easily evaded the wrath of the angry Liston. The fighter who sticks to his game plan usually comes out the winner. Liston was "out-signified" before he entered the ring, and he was unable to regain his composure once the fight began. His chasing of Ali, his constant missing of punches, and Ali's effective counterpunching throughout the seven rounds of boxing is clear evidence of this.

Liston, a crude and stark version of a man's man, could not relate to the multi-dimensional Ali, in or out of the ring. He certainly could not compete with Ali in the verbal wars. Liston saw Ali as a threat to his sexual identity because in his eyes Ali was playing the part of the "crazy nigger" and "the fag" too well.

Significantly, Liston's indefatigable image of menace and cold selfreliance had been breached. The feeble yet profound muttering, "Well, that's, that's, that's what l'm afraid of," is evidence. He was so befuddled and confused by Ali's flagrant fearlessness that he failed (or did not have the "signifying" skills) to retaliate verbally or physically. There are no expected and antagonistic comebacks such as "Man, I'm gonna kill you" or "Clay, man, oh, man I can't wait until I get you in that ring." In fact, there was nothing to indicate 
that he was secure or confident in his own masculinity.

What is it that Ali did to promote such fear in Liston? Simply, Ali said: "Sonny, I am not afraid of you." He not only said it, but he acted it, he flaunted it, he announced it to the world. He was so confident and so tough that he had no trouble or any qualm playing the fool or acting the "fag." Hence, his fundamental strength was his fearlessness of opening his mouth and saying exactly what he wished. He boasted that he was not afraid of him. Taking this further, Ali was not afraid to show Liston and the world that he was not afraid of the feminine or of the homosexual in man even though it was looked on very negatively to Black America. As Mailer noted, "the accusation of homosexuality arouses a major passion in many men; they spend their lives resisting it with a biological force" ("Ten Thousand," 243). Although branded a "fag" by Liston, Ali showed enormous power and freedom in his sexual identity. And since, Liston was mentally ill-equipped to interpret and handle such a complex nature as Ali's, Liston had lost the mental edge that was so vital to his basic game plan; he was out-bullied and out-intimidated by Ali playing the "fag."

In Ali's performance, intelligence signified quickness of hand, feet, mouth and mind. Essentially, what Ali was postulating was: I'm not afraid. If you want to win you must not be afraid to overcome your fears and insecurities. You must adopt this "sensitivity" to the feminine in performance and then sling it at these dim-witted, one dimensional male brutes who have no clue on how to suppress or interpret, let alone "kill," challengers who know who they are, who are secure in their nature. You can not win until you overcome your fears.

Liston, unable to cope with a man so secure and so confident in himself, resigned himself to the belief that Ali was the tougher man. And this was the 
mind-set of Liston at the weigh-in and for the fight itself.

Moreover, Ali introduced the ideal of "beauty" into this seedy and ultimately violent world of "egregious machismo." Gutierrez accurately perceived a major sign of power in Ali's "fighting art" when he noted:

The egregious machismo of these traditional attitudes contrasts vividly with an aspect in Ali's sensibility as a boxer and a mentality that is seldom noticed. If a "feminine" (or just humane and genderless) perception of boxing would stress its brutal or primitive aspect, it would in Ali's case characterize a portion of the psyche of his fighting art" ("The Champ of the World," 25).

Surely, this pretty or feminine idiom by Ali was an effective gimmick that generated much fanfare by the paying public. Not only was he talking too much, but he was bragging far too much about how pretty he actually believed he was. Many a patron popped ten dollars out to see his face smashed and his mouth shut, once and for all.

\section{George Foreman and N'golo.}

This psycho-sexual notion of attractiveness clashing with ugliness, masculinity with effeminacy, in the professional boxing arena was effectively drawn out by Gutierrez in his article "The Champ of the World and the Champ of the Word: Norman Mailer's The Fightt." He described the physicalized encounter between Foreman and Ali as a clash of the "traditional attitudes" of boxing and the "fighting art and boxing wit" of Ali. It is beneficial to note, Foreman's image was synonymous to that of Liston's. Much like Liston, "Foreman's strength, brawn, power and unrelenting brutality in the ring are 
frequent. Silence seems his medium (15). And like Liston's "thug" image, Foreman, too, was a "killer." Recall how Mailer described Foreman's viciousness against Ken Norton: "In Caracas that night, directly before his (Mailer's) eyes, he had seen a killer. Foreman had been vicious like few men ever seen in the ring" (The Fight, 43). For both warriors, Liston and Foreman, silence was a dominant motif in their public behavior, as Gutierrez pointed out, "in silence reside abysses of possibly insatiable hunger for violence" (15).

According to Mailer, "n'golo," refers to a person's lifeforce or libido. In The Fight, his account of the Ali-Foreman prizefight, popularly known as the "Rumble in the Jungle," Mailer believed Ali's n'golo had not truly been tested since he stared into the eyes of Liston ten years before. In light of this, Gutierrez made a compelling description of Ali's stare down with Foreman just before their battle. He exclaimed that:

Ali, during the instructions, had to be warned by the referee 5 or 6 times to be quiet. It was obvious that he was abrading Foreman psychologically. But another n'golo [italics his] is vivid for Ali here, an old ghost: he said that as Foreman glared back at him, he suddenly saw Sonny Liston ten years ago in the ring with himself, and was reminded of the claim by critics that he could never have beaten a young Liston. Now a young Liston was before him. (18)

What Foreman possessed that made his conflict with Ali so significant and profound was that same aura and image Liston had: invincibility and invulnerability. More accurately, these were the respective auras of these two omnipotent ring warriors prior to their encounters with Ali. Foreman had been a signifier of mass destruction and menace in the ring. As he said in an interview:

Of course, I've knocked out Joe Frazier, and beat him convincingly. of course, then I knocked out Ken Norton. I was able to eliminate guys pretty easily who had really given Muhammad Ali a whipping. So, people were telling me: "George, be careful. Don't 
kill Muhammad. He's old. Take it easy. (Champions Forever)

Although Ali had lost to Frazier once, and to Norton once, these fights had gone the distance and were very competitive. Both Frazier and Norton were not seen as bad guys or menacing opponents; they were dedicated fighters who gave Ali great opposition. Unlike Frazier and Norton, Foreman became known as a destructive force, cleaning up an entire division and doing it with a magnitude and aggressiveness not seen since Liston in 1961. (Interestingly, a fantasy fight shared by many boxing aficionados pits a 1973 Foreman and a 1962 Liston.) In respect to the years given, both had not yet fought and lost to Ali. As with Liston, Foreman, too, inevitably became emasculated by the unexpected and subtly feminine tactics of Ali.

First, Ali voiced him out, then, in the ring, he psyched him out. In a taped interview just days before the "rumble," Ali responded to the vast gathering of media representatives by proclaiming, with a building of intensity and volume, the following:

I've been working four months for this fight. My weight is today is 214 pounds, that's fighting weight. Already, I'm way ahead of schedule; my timing, my accuracy, my reach will be an inch and half longer. The man is slower, the man is flat-footed, the man don't stand a chance. The stage has been set; this man is supposed to annihilate me ten years from Sonny Liston; I was supposed to have gotten it that time. I think it be fitting that I go out of boxing just like I came in: shocking the world by beating a big, bad ugly monster that nobody could beat. (Champions Forever)

When it came time for the fight, Ali's complex sexual nature came into play once again. With Liston, Ali talked the talk of the "fag" before the fight. However, with Foreman it was different. Ali was not as young as he was against Liston. Then, he could depend on his swiftness of hand and feet, as well as an 
ever-opened mouth. He could not do this with Foreman. So, instead he consciously brought into the plan what would become known as the rope-adope. Ali explained that, "seven rounds of this (sticking and moving) and l'd be finished. So I realized that and I stopped. And then hit him very easily while I laid on the ropes. This became known as the rope-a-dope" (Champions). Foreman later confessed, "I hit him with a good shot, you know what he toid me: 'Is that all you got?"' He continued, "I remember hitting him so hard in his chest...not only did it hurt him, it took his... it dehumanized him. He looked at me so as if to say: I'm not going to take that you" (Champions).

Ali was triumphant in the ring because he took on the sexuallymetaphoric role of "receiver" to Foreman's menacing force. As Gutierrez noted, Ali had, throughout most of the fight, leaned back on the loose ropes---"like a woman!"---with Foreman, personifying the role of the "male," trying to batter and annihilate him (21). Ali forced Foreman's "absolute rage" to wither away. In an interview, Foreman commented on Ali's "n'golo":

I went to finish him off in two rounds. I said: I'm going, I don't care about five or six rounds---I'm going to knock him out in two rounds. In the third round, he was still there. I said: Well, who cares; I'm not going to pace myself, I'm going to knock him out! Finally, after five or six rounds I was burnt out. This experienced, great athlete withstood all of this pain, because I hit him with some of the hardest shots ever delivered on a man. They would knock him back and out---but he would literally stand there and wake up again. (Champions)

Ali had overcome Foreman's huge male force by devising "the most female and passive technique of all pugilistic artistries," he used the ropes "as a housewife, with a toothpick, feels a cake to see if it is ready to be eaten" (Gutierrez, 22). By ensconcing himself on the ropes, Ali offered himself as prey 
or concubine to predator Foreman. Ali would hold, clinch Foreman, bring his head to his and spoke into his ear some word or two. As Plimpton observed:

It's not easy to speak through a boxer's mouthpiece but Ali began to do a lot of it, more as the rounds progressed, as if it would quicken the matter of Foreman's destruction---"Is that the best you can do? You can't punch! Show me something! That's a sissy punch!"---until Ali finally came around to what must have been a devasting thing for Foreman to hear: Give it back to me! It's mine." (325)

In a strong sense, what Ali was postulating with his "feminine guile" was the same strategy he forced upon Liston: I will rag and insult and then invite the big, ugly bear to come to me, and then make him "shoot his load" and miss, at which time I will counterpunch. Ali knew he could play with "potential destruction" and be successful. He had enough confidence to realize that a sufficient amount of insulting, belittling, and mocking of the silent aggressor would eventually provoke a response. He, as he had done to Liston, had effectively forced Foreman to put "pandemonium into his mind" (339).

Appropriately, his words to Foreman during the customary ring instructions were quite in line with Ali's mastered psycho-sexual nature: "You been hearing about how bad I am since you were a little kid with mess in your pants!" (18). Foreman, as it was seen, could not cope with such an intelligent and experienced persona, so, like Liston had, Foreman resigned himself to the fact, that even though he fought "like a woman," Ali was the tougher man because he created and vocalized a firewall and a sophisticated strategy with the "feminine" nature. Foreman had shot his load and missed his opportunity, as Ali predicted. And Ali counterpunched the missed "load," as his strategy postulates. The fight between Foreman and Ali, popularly known as "the 
Rumble in the Jungle," ended with Ali winning by knockout at the end of the eighth round. 15

Whether Ali made the conscious decision to assume the feminine role or not is a compelling question. He certainly was Liston's master as signifying. Perhaps, knowing or sensing the type of personality Liston possessed (that being a violent and easily rattled one), Ali realized stringing, like a carrot, the tenuous issue of homosexuality in the face of Liston would no doubt get a reaction. To the opposing foe, this strategy of sexual complexity must be a confusing weapon to wrestle, especially if you are "manly" fighters like Liston and Foreman.

Through this complex public image, and through what Pacheco referred to as his "act of a pure passive-aggressive personality," Ali, as Mailer indicated, became "boxing's first psychologist." ${ }^{16}$ By associating and adopting the sexually complex aspect of the feminine into his performance persona, Ali was successfully able to neutralize, debilitate, emasculate, and finally defeat the two most formidable adversaries of his era.

Furthermore, Ali's tactics worked for most of his opponents. He did not lose a fight until 1971, after a three year hiatus from the ring, and still he nearly defeated his more youthful opponent, Joe Frazier. From 1960 to 1967, Ali was unstoppable. He had fought all the reigning contenders from Moore and Cooper to Liston and Patterson. In each case, the key was his mouth. It provided a mechanism for control.

Ali's merging and mixing of different roles, such as boxer and icon, male and female, continues even to this day to enhance a structural quagmire of 
complexity. It became clearer and clearer as one watched and identified certain distinctive modes of "being," masculine or feminine in nature, that Ali was not only a performer performing for an audience and himself, but also a survivalist, a master of adaptability, finding and using at his disposal those peculiar and captivating elements that are not consistent with those normally thought to be part of a particular performance code. In his iconoclasm, Muhammad Ali created, defined and performed his own unique language to the world. 
Chapter 6

Conclusion

\section{Summary}

The study has examined and identified the distinct relations between voice as a device of power and success in physical competition. Specifically, it was through the examination of the performance persona of Muhammad Ali that this investigation proposed its theoretical questioning. The results of this research reveal several interesting implications and could lead to other possible directions of study. Essentially, Ali exposed the fact that it did not take a physically superior or stronger man to defeat an "invincible" opponent. It only took a smarter one, and that intelligence demonstrated that voice can successfully be used as a device of power in competition.

In this study, there were several specific theoretical questions addressed concerning the relation among voice, power, and success in performance. Those questions posed were the following: (1) How significant was Ali's voice in performance? (2) To what extent did the power of Ali's voice affect the success in changing the social identity of the professional boxer? (3) What is the relation between success and voice as a device of power in athletic performances?

Critical analysis of the data gathered concludes that Ali's implementation of voice as an element of performance proved that a boxer did have an identity other than the preconceived notion that society held, and that a boxer was intelligent enough to treat boxing as a science, a theatrical forum, and a sport. A significant dichotomy is evident when Ali's voice is juxtaposed to the "manly silences" of Liston and Foreman. In each case, Ali defeated the bigger and 
physically stronger opponent.

In each case the use of voice proved effective in confusing and detaining the psychological constitution of each big man. Analysis also revealed that both Liston and Foreman were further deterred from their specific fight strategy by the rapidity of Ali's movement and punching frequency. By sticking and moving, giving different angles, and talking to his opponents, Ali was effectively able to "flustrate" them, or as Plimpton appropriately implied, drove "pandemonium" into their psyches.

To be certain, these results are speculative. But data from film and literature reveal evidence that tends to support these speculations. To be sure, this present study by no means attempts to conclude that Ali's voice and only his voice was responsible for his great achievements in the ring. No significant correlation exists whereby this statement could be validated as truth. However, this study concludes that Ali's voice as a device of power did have some positive effect on the outcome of his success against bigger, more "menacing" foes.

Implications

There are several interesting implications derived from this research that are potential "hot spots" for investigation. One of these is the essential role acting or theatre plays in the make-up of Ali's persona. It is fascinating to realize that Ali never had an acting or elocution lesson, but still was able to display such a virtuosity of role- and game-playing techniques. Although his grammar was bad, the quality was potent, and enabled him to capture his audience. This leads to an important conclusion. With the ability to 
communicate, as Ali showed, he was able to impersonate different characters. Ali's persona conveyed that an act was being performed; within this act, he played many roles, "the boxer," "the madman," "the crazy nigger," "the fag," "the egotist," "the poet," "the prophet," etc. This implies a very strong link to the African-American oral tradition. Like the the old African story-teller, the "griot," Ali tells and weaves stories that document the black character and attitude. The idea is of telling a story, sharing a link to a people. Historically, Blacks have always been forced to play various roles in order to survive. Ali's "play acting" is a direct link to that African-American tradition he must have experienced growing up in a segregated part of the country. ${ }^{17}$

Indeed, Ali used the ring as a forum for acting, as can be seen in the documentary, Aka: Cassius Clay. In this film, Ali speaks to the camera, demonstrating his theatrical skills. And profoundly, it is upon this "actual" stage that Ali performs his role as boxer.

Curiously however, when Ali transformed this perfected act into a mainstream film, The Greatest (1975), or a television series, Freedom Road (1978), it did not work. He could not sell his packaged product on the screen. It seemed too pretentious and artificial. Yet, in his field of performance, in the ring and in front of a microphone, he was untouchable. So, like theatre to film, Ali was better live than taped.

This type of investigation is useful to theatre research because it calls into question the significance of believability and stageability. Can a performer improvise and direct himself effectively, in such a volatile performance arena, and still persuade an audience that what it is seeing is an act? Further, a protracted study on the many theatrical qualities that make a dramatic act 
successful: such as intensity, intrigue, surprise, detail, flow, depth of character, economy, and immediacy, all would lend themselves to a systematic investigation of Ali's performance persona.

Moreover, there has yet to be an exploration on the relation between athletic performer and improvisation. Ali's public demeanor was certainly based on an improvisational and stream-of-consciousness process. This kind of technique takes confidence and practice. Further research should probably concentrate on the preparation of Ali prior to his entrance for interviews, press conferences, weigh-in ceremonies, and the actual fights themselves. This would indicate whether Ali had some special activity or aesthetic mode in which he placed himself.

Furthermore, his ability to improvise also exposed an uncanny spontaneity when the cameras and microphones were operating. He would jump from subject to subject, sometimes not finishing a thought. As in the press conference announcing his upcoming fight with Liston, he ranted from one subject to another, "I'm as pretty as a girl"..."You wanna go now?"..."Joe Louis was flat-footed." Certainly, loud and fast were aspects of his technique. Ali had made uninterested heads turn. This is a clear distinction from other boxers who had tried to make a dent on the social identity of the boxer, for example, Moore and Patterson.

The implication here is that a performer, to be heard and recognized, can not merely speak well or write adequately, but must be a shouter, a rabblerouser, which Ali was. His big mouth is the distinction. To rattle the norm, one must force a large percentage of the public to identify and acknowledge that he is doing such. 
Also, the research has uncovered that the boxer is unaccustomed to being talked at while in performance. Ali breached a traditional convention when he told another fighter that he hits like "a sissy." Surely, there had been others who had talked within the squared circle, but no one exploited and promoted this feature as Ali had. This distinction can be linked to Gorgeous George's wrestling act, and how he told the crowd and his opponent that he "was going to annihilate this bum." What can be concluded here is Ali's successful merging of boxing and the spectacle/circus atmosphere of wrestling. But more than that, this application of name-calling implies a very psychological stratagem. As noted above, boxers do not, once they engage in a fight, expect to be burdened by language. It distracts them, and it makes the process of focusing on their own fight strategy that much more difficult.

Historically, as Gorn indicates, the boxer comes from under-educated and under-privileged social classes. This may in fact be why popular culture has held such negative perceptions of the fighter. He never has successfully removed or identified himself from the pigeon hole he was in. This aspect of the boxer as an athlete first, then a performer, validates another distinction between Ali and the norm. He presented himself as an entertainer first, then an athlete.

\section{Recommendations}

There are several ideal prerequisites that would be beneficial to any future research into this field of inquiry: an adequate knowledge of boxing history, a comprehensive knowledge of black history and culture, and a thorough understanding of contemporary theatre and drama, and the broad spectrum of improvisation and motivation. 
Although this study provided a basic evaluation of the Ali phenomenon, it has left many other areas of interest unscathed.

(1) One element of this investigation that could certainly be further developed is the media's relation to Ali, and the exploration into who actually controlled whom. Did Ali manipulate the media machine, or did the media allow Ali's act to exist? For instance, later in his career, was the "Bob \& Raylike" routine that he had with Cosell a large factor in his popularity?

(2) Another direction of research concerns the relation between performer and spectator. How much does a performance depend on the audience's acceptance and belief in it? In other words, would the result have been the same if Ali had not been considered a clown or crazy, but instead, liked by everyone, including the boxing authorities? Did his act solely depend on the fans and his opponents being fooled by his role-playing?

In light of this, Chapter Five, "Voice as an Element of Performance Code," hints at possible theoretical hypotheses still needing to be identified, such as: Did Ali fight only dim-witted opponents? Was Ali only successful because he opposed foes who were tough but stupid, and therefore capable of being manipulated? Most importantly, what if Ali had entered the ring against another Ali? Could Ali have successfully defeated another boxer who was able to talk and fight as well as he? Could Ali have disposed of another boxer who was his intellectual superior? Clearly, these notions invite potential research in regards to the rationale of the spectator and performer.

(3) Perhaps, the most important area of research still needing to be examined is the African and African-American oral traditions and their corresponding influence on black performers like Muhammad Ali. There has 
been little correlation from previous writers, mostly white sports journalists, between the African "griot" and Ali. To put it more succinctly, Ali, "the story teller," has not yet been probed, even by African-Americans. The oral tradition and its subsequent effect on black performers, specifically Muhammad Ali, has yet to be identified. Books, folktales, and poems from the black perspective in recent years have, of course, identified and investigated this dominant "black" tradition. However, the link to Ali, as America's foremost signifier and outspoken oral performer (Black or White), has yet to be seriously examined.

As Gates explains in his Preface, "The image of the black tradition has suffered from the lack of sophisticated scholarly attention to it." Concerning further inquiry into the phenomenon of Muhammad Ali, several directions may be taken.

(a) Relating the vocal performances of Ali to the representation of "signifying" in Afro-American literature as a ritual speech act. In the scholarly works, The Signifying Monkey, and Talkin and Testifyin, both Gates and Smitherman, respectively, introduce a systematic approach to examine the black dialect, vernacular, and semantics. Analyzing the characteristics of Ali's voice in regard to the four black modes of discourse, call-response, signification, tonal semantics, and narrative sequencing, would seem a very logical course of action. Ali's performer code would thus be scrutinized specifically from a black (scholarly) perspective, which has been the major problem of the past and this present study. It has been in the context of a white perspective. The context that needs to be examined much more extensively by other researchers is Ali, the black trickster of African and African-American oral tradition. 
(b) Further research should delve extensively into the childhood influences of Cassius Clay in segregated Louisville, Kentucky, which ! left practically untouched, and how this Southern black background played into his subsequent success in boxing. In my research, only Jack Olsen's Black is Best: The Riddle of Cassius Clay mentions specific incidents of Clay's youth. But these are few. John Contrell's Man of Destiny describes some episodes of the teenage Clay. These are in regard to Clay, the amateur boxer. What needs to be ascertained are sources on Ali's growing years. What were his parents like? What did they talk about? How did he and his brother Rudy relate? What was his persona as a boy like? How did he learn how to survive? Did his mouth get him into much trouble? And if it did, how did he turn this negative into a profitable positive?

(4) Lastly, on the subject of professional boxing, an avenue of research that has yet to be investigated is Ali's influence on the boxers of the 1980's and 1990 's. It seems the perception of popular culture has resumed its opinion of boxing as a barbaric and inane "sport," thanks to fighters like Mike Tyson and Marvelous Marvin Hagler. The axiom is still being tossed around: my fighter will do his talking in the ring. Ali's extreme estrangement from the norm of the boxer has left an indelible and unapproachable mark. Though many have tried to emulate or stabilize an Ali-like presentation, no one has maintained the image. Former heavyweight champion Riddick Bowed tried miserably to "don" the role of poet-boxer. It failed. It gave the impression he was mimicking Ali instead of presenting a unique image of performance. Even Sugar Ray Leonard attempted to fill the void left by Ali in 1980's. He came close but he was not a rabble-rouser or an outspoken social force. His image relied on his 
in-ring performance as a crowd pleaser. He was exciting, a true warrior, a "pretty as a girl" character, but his off-ring performance was near non-existent. He spoke like Patterson, quietly and non-confrontationally. Why has there not been more estrangements from the norm? Why have there not been more Alis? It seems boxing, like life, works in cycles. Mike Tyson, with his lispy, almost effeminate voice has dispensed with the Ali mold, and instead, revised the Sonny Liston image. His voice actually scares people away because of its unattractiveness and unpleastantness. It just does not have a pleasant and resounding quality that Ali's exhibited.

Perhaps Tyson did not dispense with the Ali mode. Ali, himself, broke the mold. Harry Carpenter asked Ali recently if he missed boxing. His response, more than accurate, was, "No, it misses me." 
NOTES

- 


\section{NOTES}

1 See Sammon's Chapter 6, "The Unholy Trinity: TV, Monopoly and Crime," for a detailed discussion on the capitalistic endeavors the boxing establishment pursued and achieved, under the control of Norris and the Mob. See, also, John McCallum's "Legendary Promoters," pp. 165-179, from The World Heavyweight Championship: A History (Ontario, 1974), for a brief account of the rise of the early promoters and box-office men; such men as Rickard ("Get the finest people and give'em the best!"), Jacobs ("absolute czar of boxing from 1937 to '47"), and Kearns ("Dempsey's canny mouthpiece").

2 See Roberts, Papa Jack, pp.180-84, for an account of Johnson's forced escape and exile from America; also see Lipsyte, "The Crown Prince of Heavyweight Boxing," from Sportsworld, pp. 175-89, for a description of Ali's forced "exile," not from America, but from professional boxing. In a strong sense, Ali's exile from boxing (1967-70) because of his refusal to be inducted into the armed forces, was far worse than the exile forced upon Johnson; at least Johnson could still pursue his livelihood, whereas Ali was not allowed to leave the country (his passport was seized), he could not practice or participate in any boxing endeavor that resulted in any monetary gain.

3 Johnson was heavyweight champion from 1908-17; Robinson was welterweight champion from 1946-51 and middleweight champion from 195160 (winning and losing the title five times); and Moore was light heavyweight champion from 1952-62. Source for these dates is Bert Sugar's The One Hundred Greatest Boxers of All-Time, pp.6-9; 48-9; 68-9.

${ }^{4}$ See Sammon's descriptive and impressively researched chapter on Robinson's as well as other prominent black athletes' civil rights efforts in "Civil Rights to Rebellion to Reaction: The Era of Muhammad Ali."

5 I think it significant to note that Patterson, though he was hard-pressed, shy and introverted as a champion, did bring, as Morrison expounds upon, a tragic beauty and dignity to the sport. "He is innately a gentle man who seeks the simple life. Outside the ring, he is a withdrawn, bashful youth who is at all times courteous and considerate and who carries himself with grace and dignity" (77-8). Perhaps in another era the result would have been different for the nation at this time was on a verge of radical change for which he was not meant to be its representative "spokesman." I think it accurate to say, as a boxer he was good, but as a performer and entertainer, not so.

${ }^{6}$ From a personal interview with Julius Menendez, on 24 November 
1992. He is a former physical educator at San Jose State, and was also the boxing coach there from 1952 to 1960 . It was in 1960 that Mr. Menendez coached the U.S. Olympic Boxing Team, which had among its members an 18 year old named Cassius Marcellas Clay. "Julie" recalled that Ali "had an attitude that you'd like to have in every athlete. With him it was not a question of whether he'd win or lose. It was always a question of how soon he'd win! He never thought about losing. Losing was just not part of him."

7 In an interview from The Championship. Milt Bailey, one of Liston's seconds in the corner during the fight, has stated that Liston said, as he sat on his stool at the end of the sixth round: "I can't lift my left arm." The fight was then stopped and the commission doctors concurred afterwards, that more than likely, a tear in the shoulder muscle did occur.

${ }^{8}$ See Mailer's "Ten Thousand Words a Minute," for an excellent account of the Liston-Patterson encounter.

${ }^{9}$ Cited in Contrell's Man of Destiny (153).

${ }^{10}$ From a discussion with Karl Toepfer.

11 Ibid.

12 See especially the boxing films Ali: Skills, Brains, and Guts, Sports Illustrated's Boxing's Best: Muhammad Ali, and Aka: Cassius Clay, for clear depictions of Ali's mode of performance when prophesying on future bouts.

${ }^{13}$ Mike Tyson, before his incarceration, exemplified this gladiatorial mode to its fullest. His entrance onto the ring was preceded by a trot down the aisle with no fanfare (such as an accompanying entourage or blaring music). He was all business, and his "image" was fierce as he made his way to the ring. He wore no robe, no socks, and no tasseled, knee-hi shoes. He was clad only in black trunks and black shoes, nothing else save the glistening sweat on his body and the most intimidating blankness on his face. I refer the reader to Ring magazine's December 1988 issue, as well as February 1990, July 1991 and November 1991, for a compilation of revealing photographs and articles on Tyson's "purist" image.

14 See Early's "The Grace of Slaughter," for an extensive and well researched discussion on the boxer as deconstructed metaphor. In this article, Early continues a dialog between Oates's On Boxing and Barthes's "The World 
of Wrestling." Early, as Oates does for boxing and Barthes does for wrestling, tries to come to terms with this most tragic of "unnatural acts." He raises a profound question, then he sets about to answer it: "What is it in sport generally that appeals but that universal morbidity of the instant tragedy of youth used up?" Adding interest are the references to Ali as crucial "sign" of boxing's complexity and ambiguousness.

15 See Messenger's chapter on "passivity" in the ring, pp. 96-103. He notes Mailer's extensive preoccupation with the "murderous, tormented masculinity" and the "reclaiming of sexual identity in competition" (96). He explains that:

Mailer had some doubts about Ali's manhood and courage (before Ali-Frazier I). He cast the the two fighters in his familiar GriffithParet, Patterson-Liston split with Ali as the endangered, softer, almost feminine fighter and Frazier as the powerful menacing force....Mailer repeatedly describes Ali as almost chastely effeminate as he regretted that Ali had not had a "real" second fight with Liston that would have baptized him as slugger, "more of a man crude to crude with Liston" (The Fight, 33). (97, ellipsis mine)

16 Pacheco contends that Ali's performance (referred to as "Ali the Act") was basically:

An act of a pure passive-aggressive personality. Passiveaggressive types do not initiate action; instead they react to action. They manipulate. They make things happen by reacting to things people do to them (usually after these people have been manipulated into doing this), and so control their destinies in what appears to be a non-aggressive manner. (1992, 55-6)

${ }^{17}$ From a discussion with Ethel Pitts Walker. 


\section{REFERENCES}




\section{REFERENCES}

\section{BOOKS}

Ali, Muhammad, and Richard Durham. The Greatest: My Own Story. New York: Random House, 1975.

Bogle, Donald. Toms, Coons, Mulattoes, Mammies, and Bucks: An Interpretative History of Blacks in American Films. New York: Viking Press, 1973.

Bouissac, Paul. Circus and Culture: A Semiotic Approach. Indiana: Indiana UP, 1976.

Carpenter, Harry. Boxing: An Illustrated Boxing History. New York: Crescent Books, 1973.

Chalk, Ocaria. Pioneers of Black Sport: The Early Days of the Professional Athlete in Baseball, Basketball, Boxing and Football. New York: Dodd \& Mead, 1975.

Contrell, John. Muhammad Ali. Who Once was Cassius Clay (formally, Man of Destiny). New York: Funk \& Wagnall, 1968.

DePasquale, Peter. The Boxer's Workout: Fitness for the Civilized Man. New York: Doubleday, 1988.

Gardiner, E. Norman. Athletics of the Ancient World. Oxford: Clarendon Press, 1971.

--- Greek Athletic Sports and Festivals. New York: MacMillan, 1970.

Gates, Henry Louis, Jr. The Signifying Monkey: A Theory of African-American Literary Criticism. New York: Oxford UP, 1988.

Gilbey, John F. Western Boxing and World Wrestling: Story and Practice. Berkeley: North Atlantic Books, 1986.

Gilmore, Al-Tony. Bad Nigger!:The National Impact of Jack Johnson. New York: Kennikut Press, 1975.

Gorn, Elliot J. The Manly Art: Bare-Knuckle Prizefighting in America. Ithaca: Cornell UP, 1986. 
Harland, Richard. Superstructuralism: The Philosophy of Structuralism and Post-Structuralism. New York: Routledge, 1988.

Hauser, Thomas. Ali: His Life and Times. New York: Simon \& Schuster, 1991.

--. Black Lights: Inside Professional Boxing. New York: McGraw-Hill, 1985.

Korn, Henry James. Muhammad Ali: Retrospective. New York: Assembly Press, 1976.

Liebling, A. J. The Sweet Science. New York: Viking Press, 1956.

Lester, Julius. Black Folktales. New York: Grove Weidenfeld, 1969.

Mailer, Norman. The Fight. New York: Little \& Brown, 1975.

McCallum, John D. The World Heavyweight Boxing Championship: A History. Ontario: Chilton, 1974.

Mcllvanney, Hugh. Mclivanney on Boxing: An Anthology. New York: Beaufort Books, 1983.

Menendez, Julius. Interview. San Jose State University, San Jose, California, Nov. 24, 1992.

Oates, Joyce Carol. On Boxing. Garden City: Dolphin \& Doubleday, 1987.

Oates, Joyce Carol, and Daniel Halpern, eds. Reading the Fights. New York: Henry Holt, 1988.

Olsen, Jack. Black is Best: The Riddle of Cassius Clay. New York: Dell, 1967.

Pacheco, Ferdie. Muhammad Ali: A View from the Corner. New York: Birch Lane Press, 1992.

Plimpton, George. Shadow Box. New York: Putnam \& Sons, 1977.

Poe, Carolyn Alberta. "An Historical Analysis of Black Stereotypes in Hollywood Films During 1925 to 1935." Unpublished thesis. San Jose State University, San Jose, California, May 1975.

Robinson, Sugar Ray, with David Anderson. Sugar Ray. New York: Viking Press, 1969. 
Roberts, Randy. Papa Jack: Jack Johnson and the Era of White Hopes. New York: Macmillan, 1983.

Sammons, Jeffrey. Beyond the Ring: The Role of Boxing in American Society. Urbana: $U$ of Illinois Press, 1987.

Saussure, Ferdinand De. Course in General Linquistics. London: Peter Owen, 1959.

Silverman, Kaja. The Subject of Semiotics. New York: Oxford UP, 1983.

Smitherman, Geneva. Talkin and Testifyin: The Lanquage of Black America. Boston: Houghton-Mifflin, 1977.

Sugar, Bert Randolph. The One Hundred Greatest Boxers of All-Time. New York: Bonanza Books, 1984.

Sullivan, George. The Cassius Clay Story. New York: Fleet Pub., 1964.

Toepfer, Dr. Karl. Class Lectures. San Jose State University, San Jose, California, April-May, 1991.

Walker, Dr. Ethel Pitts. Class Lectures. San Jose State University, San Jose, California, May, 1993.

Webster-Merriam. Webster's New Collegiate Dictionary. Springfield: G. \& C. Merriam, 1973.

Webster's New Twentieth Century Dictionary of the English Language. Jean L. Mckechnie, ed. New York: World Pub., 1973.

Wilson, Peter J. Oscar: An Inquiry into the Nature of Sanity. New York: Random House, 1974.

\section{ARTICLES AND PERIODICALS}

Anderson, Jervis. "Black Heavies." American Scholar 47 (1978): 387-95.

Astor, G. "Sonny Liston: King of the Beasts." Look 28 (Feb. 25, 1964): 67-77.

Barnes, R. L. "Heavyweight with a Past: Sonny Liston." Saturday Evening Post 230 (Aug. 13, 1960): 28+. 
Bathes, Roland. "The World of Wrestling." Mythologies. New York: Hill \& Wang, 1957.

Berube, Maurice. "Defeat of the Great Black Hope." Commonweal (Mar. 26, 1971): 54.

Breslin, J. "Be a Champ, Act a Champ." Saturday Evening Post 257 (Sept. 22, 1962): 62-3.

Cleaver, Eldridge. "Lazarus, Come Forth." Soul on Ice. New York: McGrawHill, 1968.

Corig. Rec. May 4, 1976: 12372-74.

Dinning, M. "The Search for the Great White Hopes: Heavyweight Boxing in Canada (1908-15)---Arthur Pelkey: His Rise and Demise." Proceedings, The Third Canadian Symposium on the History of Sport and Physical Education, Halifax, Nova Scotia (Aug. 18-21): 1-25.

Dundee, Angelo. "Lord of the Ring." Penthouse 13.8 (Apr. 1982): $72+$.

Early, Gerald. "The Black Intellectual and the Sport of Prizefighting." Kenyon Review 10 (Summer 1988): 102-17.

--.. "The Grace of Slaughter: An Essay-Review of Joyce Carol Oates's On Boxing." lowa Review 18.3 (Fall 1988): 173-86.

-.-. "I Only Like it Better When the Pain Comes: More Notes Towards a Cultural Definition of Prizefighting." Ring (Mar. 1982): 18-29.

--.. "Three Notes Toward a Cultural Definition of Prizefighting." Hudson Review 34.1 (Spring 1981): 20-38.

Evans, Art. "Joe Louis as a Key Functionary: White Reaction Toward a Black Champion." Journal of Black Studies 16.1 (Sept. 1985): 95-111.

Gutieirez, Donald. "The Champ of the World and the Champ of the Word: Norman Mailer's The Fight." Arete 5.1 (1987): 1-24.

Jones, LeRoi. "The Dempsey-Liston Fight." Home: Social Issues. New York: Wm. Morrow, 1966.

Lipsyte, Robert. "The Heavyweight Crown Prince of the World." Sportsworld. 
New York: The New York Times, 1975.

Mailer, Norman. "King of the Hill." Existential Errands. New York: Little \& Brown, 1975.

--.. "Ten Thousand Words a Minute." Esquire 59.2 (Feb. 1963): 109-20.

Massquei, Al. "Muhammad Ali: An Intimate New Look at a Legend." Ebony 45 (Nov. 1989): 174-80.

McDermott, John R. "Liston Turned on the Evil Eye...Clay Didn't Notice." Life 56 (Mar. 6, 1964): 34-7.

--.. "A Man Child Taken in by the Muslims." Life 56 (Mar. 6, 1964): 38-8.

Messenger, Christian K. "Norman Mailer: Boxing and the Art of His Narrative." Modern Fiction Studies 33.1 (Spring 1987): 85-104.

Morrison, Allan. "Floyd Patterson: Boxing's Most Misunderstood Champion." Ebony 14 (Apr. 1959): 78-81.

---. "Sonny Liston: Boxing's Angry Man." Ebony 17 (Aug. 1962): 46-55.

Nack, William. "O Unlucky Man." Sports Illustrated 74 (Feb. 4, 1991): 66-80.

National Review Apr. 4, 1994: 4.

"Prizefighting with Mouth and Magic." Time Mar. 6, 1964: 66-9.

"Punching Brag." Newsweek Mar. 18, 1963: 93-4.

Patterson, Floyd. "In Defense of Cassius Clay." Esquire (Aug. 1966): 55-8.

Bing. New York, NY.

Stanley, Frank. "The Biggest Fight Build-up in History." Saturday Evening Post (June 15, 1946): 21.

Yeager, Bill. "Behind the Scenes with the Great Fighters." Popular Culture 76.6 (Dec. 1936): $22+$.

Zito, Stephen. "The Black Film Experience." The American Film Heritage. Tom Shales, ed. Washington, D. C.: Acropolis Books, 1972. 


\section{FILMS AND INTERVIEWS}

Aka: Cassius Clay. Videocassette. Dir. Jim Jacobs. Big Fights, Inc., 1970.

Ali: Skills, Brains and Guts. Videocassette. Dir. Jim Jacobs. Big Fights, Inc., 1978.

Bailey, Milt. Interview. The Championship: Liston-Clay. Videocassette. Dir. J. D. Hansen. NBC Sports, Feb. 25, 1989.

Brennan, Teddy. Interview. The Stylists: The Heavyweights. Videocassette. Dir. Jim Jacobs. HBO Sports, 1990.

Carpenter, Harry. Introduction. Sports Illustrated Boxing's Best: Tyson and the Heavyweights. By Peter Reason and Graham Wellman. BBC Big Fights Inc.-HBO Studios, 1987.

Champions Forever. Videocassette. Dir. Dimitri Logothetis. Ion Pictures, 1989.

Combat Sport: Boxing Yesterday and Today. Videocassette. Dir. William Rose. Community Film Group, 1987.

Dundee, Angelo. Interview. The Championship: Liston- Clay. Videocassette. Dir. J. D. Hansen. NBC Sports, Feb. 25, 1989.

---. Interview. Sports Illustrated's Boxing's Best: Muhammad Ali. Videocassette. Dir. Marc Payton. HBO Studios, 1981.

Foreman, George. Interview. Champions Forever. Videocassette. Dir. Dimitri Logothetis. Ion Pictures, 1989.

Frazier, Joe. Interview. Champions Forever. Videocassette. Dir. Dimitri Logothetis. Ion Pictures, 1989.

Goodman, Murry. Interview. The Championship: Liston-Clay. Videocassette. Dir. J.D. Hansen. NBC Sports, Feb. 25, 1989.

Geatest Fights Ever Series: The Rumble in the Jungle. Videocassette. Dir. J. Hansen. NBC Sports Showcase, Apr. 14, 1990.

Greatest Fights Ever Series: The Thrilla' in Manilla. Videocassette. Dir. J. D. Hansen. NBC Sports Showcase, May 12, 1990. 
Pacheco, Ferdie. Interview. The Championship: Liston-Clay. Videocassette. Dir. J. D. Hansen. NBC Sports, Feb. 25, 1989.

---. Interview. The Rumble in the Jungle: Foreman-Ali. Videocassette. Dir. J. D. Hansen. NBC Sports Showcase, Apr. 14, 1990.

Sports Illustrated's Boxing's Best: Grudge Fights. Videocassette. Dir. n. HBO Studios, 1986.

Sports Illustrated's Boxing's Best: Muhammad Ali. Videocassette. Dir. Miarc Payton. HBO Studios, 1981.

The Stylists: Heavyweights. Videocassette. Dir. J. Jacobs. HBO Sports, 1990. 
APPENDIX

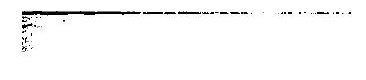




\section{APPENDIX}

The following is a list of the recorded professional boxing matches of Muhammad Ali during the years 1960 to 1981, most of which were viewed in an attempt to gather sufficient background information on his style and quality of performance.

Total Bouts: 61 Victories: $56 \quad$ Defeats: 5

Year Date Opponent $\underline{\text { Site }}$

1960

Oct. 29 Tunney Hunsaker Louisville $\quad$ W 6

Dec.27 Herb Biler Miami Beach $\quad$ TKO 4

1961

$\begin{array}{lllll}\text { Jan. 17 } & \text { Tony Esperti } & \text { Miami Beach } & \text { TKO } 3 \\ \text { Feb. } 7 & \text { Jim Robinson } & \text { Miami Beach } & \text { TKO } & 1 \\ \text { Feb. 21 } & \text { Donnie Fleeman } & \text { Miami Beach } & \text { TKO } 7 \\ \text { April 19 } & \text { Lamar Clark } & \text { Louisville } & \text { KO } & 3 \\ \text { June 26 } & \text { Duke Sabedong } & \text { Las Vegas } & \text { W } & 10 \\ \text { July 22 } & \text { Alonzo Johnson } & \text { Louisville } & \text { W } & 10 \\ \text { Oct. } 7 & \text { Alex Miteff } & \text { Louisville } & \text { TKO } & 6 \\ \text { Nov. } 29 & \text { Willi Bearnanoff } & \text { Louisville } & \text { TKO } 7\end{array}$

1962

$\begin{array}{lllll}\text { Feb. 10 } & \text { Sonny Banks } & \text { New York } & \text { TKO } & 4 \\ \text { Feb. 28 } & \text { Don Warner } & \text { Miami Beach } & \text { TKO } & 4 \\ \text { Apr. 23 } & \text { George Logan } & \text { Los Angeles } & \text { TKO } & 4 \\ \text { May 19 } & \text { Billy Daniels } & \text { New York } & \text { KO } & 5 \\ \text { July 20 } & \text { Alejandro Lavoranta } & \text { Los Angeles } & \text { TKO } & 4 \\ \text { Nov. } 15 & \text { Archie Moore } & \text { Los Angeles } & \text { TKO } & 4\end{array}$

1963

$\begin{array}{lllll}\text { Jan. 24 } & \text { Charlie Powell } & \text { Pittsburgh } & \text { KO } & 3 \\ \text { Mar. 13 } & \text { Doug Jones } & \text { New York } & \text { W } & 10\end{array}$


$\begin{array}{lll}\text { June } 18 \text { Henry Cooper } & \text { London } & 5\end{array}$

1964

$\begin{array}{llll}\text { Feb. } 25 & \text { Sonny Liston } & \text { Miami Beach } & \text { TKO } 7\end{array}$

1965

May 25 Sonny Liston

Nov. 22 Floyd Patterson

Lewiston, Me. KO 1

Las Vegas $\quad$ TKO 12

1966

$\begin{array}{lllll}\text { Mar. 29 } & \text { George Chuvalo } & \text { Toronto } & \text { W } & 15 \\ \text { May 21 } & \text { Henry Cooper } & \text { London } & \text { TKO } 6 \\ \text { Aug. 6 } & \text { Brian London } & \text { London } & \text { KO } 3 \\ \text { Sept. 10 } & \text { Karl Mildenberger } & \text { Frankfurt } & \text { TKO } 12 \\ \text { Nov. 14 } & \text { Cleveland Williams } & \text { Houston } & \text { TKO } 3\end{array}$

1967

$\begin{array}{lllll}\text { Feb. } 6 & \text { Ernest Terrel } & \text { Houston } & \text { W } & 15 \\ \text { Mar. } 22 & \text { Zora Folley } & \text { New York } & \text { KO } & 7\end{array}$

1968-1969 (Inactive)

1970

Oct. 26 Jerry Quarry

Dec. 7 Oscar Bonavena

1971

Mar. 8 Joe Frazier

July 26 Jimmy Ellis

Nov. 7 Buster Mathis

Dec. 26 Jurgen Blin

1972

Apr. 1 Mac Foster

May 1 George Chuvalo

June 27

July 19

Sept. 20
Jerry Quarry

Alvin (Blue) Lewis

Floyd Patterson
Atlanta

New York

TKO 3

TKO 15

$\begin{array}{lll}\text { New York } & \text { L } & 15 \\ \text { Houston } & \text { TKO } & 12 \\ \text { Houston } & \text { W } & 12 \\ \text { Zurich, Switz. } & \text { KO } & 7\end{array}$

Tokyo W 15

Vancouver, B. C. W 12

Las Vegas $\quad$ TKO 7

Dublin TKO 11

New York TKO 7 
Nov. 21 Bob Foster

Stateline, Nev. KO 8

1973

Feb. 14 Joe Bugner

Mar. 31 Ken Norton

Sept. 10 Ken Norton

Oct. 20 Rudi Lubbers

$\begin{array}{lll}\text { Las Vegas } & \text { W } & 12 \\ \text { San Diego } & \text { L } & 12 \\ \text { Los Angeles } & \text { W } & 12 \\ \text { Jakarta } & \text { W } & 12\end{array}$

1974

Jan. 28 Joe Frazier

Oct. 30 George Foreman

New York $\quad$ W 12

Kinshasa, Zaire $\quad \mathrm{KO} \quad 8$

1975

$\begin{array}{lllll}\text { Mar. 24 } & \text { Chuck Wepner } & \text { Cleveland } & \text { TKO } & 15 \\ \text { May 16 } & \text { Ron Lyle } & \text { Las Vegas } & \text { TKO } & 11 \\ \text { July } 1 & \text { Joe Bugner } & \text { Kuala Lumpur } & \text { W } & 15 \\ \text { Oct. } 1 & \text { Joe Frazier } & \text { Quezon City } & \text { TKO } & 14\end{array}$

1976

Feb. 20 Jean Pierre Coopman

San Juan, P.R. KO 5

April 30 Jimmy Young

May 24 Richard Dunn

Landover, Md. W 15

Sept. 28 Ken Norton

Munich

TKO 5

New York

W 15

1977

$\begin{array}{lllll}\text { May } 16 & \text { Alfredo Evangelista } & \text { Landover } & \text { W } & 15 \\ \text { Sept. } 29 & \text { Ernie Shavers } & \text { New York } & \text { W } & 15\end{array}$

1978

Feb. 15 Leon Spinks

Las Vegas

New Orleans

L $\quad 15$

Sept. 15 Leon Spinks

W 15

1979 (Inactive)

1980

Oct. 2 Larry Holmes

Las Vegas

TKO by 11

1981

$\begin{array}{llll}\text { Dec. } 11 \text { Trevor Berbick Nassau } & \text { L } & 10\end{array}$ 